Illinois State University

ISU ReD: Research and eData

Theses and Dissertations

$2-20-2017$

\title{
Death and Destruction: Insight into the Rhino Poaching Epidemic in South Africa
}

Richard Wayne Charlton

Illinois State University, dixie6913@gmail.com

Follow this and additional works at: https://ir.library.illinoisstate.edu/etd

Part of the Criminology Commons, Criminology and Criminal Justice Commons, and the Natural Resources and Conservation Commons

\section{Recommended Citation}

Charlton, Richard Wayne, "Death and Destruction: Insight into the Rhino Poaching Epidemic in South Africa" (2017). Theses and Dissertations. 661.

https://ir.library.illinoisstate.edu/etd/661

This Thesis is brought to you for free and open access by ISU ReD: Research and eData. It has been accepted for inclusion in Theses and Dissertations by an authorized administrator of ISU ReD: Research and eData. For more information, please contact ISUReD@ilstu.edu. 


\title{
DEATH AND DESTRUCTION: INSIGHT INTO THE RHINO POACHING EPIDEMIC IN SOUTH AFRICA
}

\author{
Richard Wayne Charlton
}

\section{Pages}

The poaching of wildlife has been a concern to many involved in the protection of wildlife. Poaching is found throughout the world and has been around for thousands of years. In the past century, poaching has reached new heights and the concern of an extinction of a species has brought the topic of poaching to new light. Whilst poaching has been seen as a biological or conservation topic in the past, criminologists around the world have now started to delve into the topic. The poaching of wildlife and more so in recent years, rhino poaching, has been a concern in South Africa. South Africa has seen an increase in rhino poaching in the past 8 years, where over 4,000 rhinos have been slaughtered. This research explores the current rhino-poaching epidemic in South Africa and looks at the problem from a criminological point of view, where possible solutions can be recommend using criminological theories for the prevention of rhino poaching.

KEYWORDS: Rhino poaching, South Africa, Anti-poaching units, Wildlife criminology, Situational crime prevention, Problem oriented policing, Routine activities theory, Rational choice theory, Market reduction approach, Community oriented policing. 
DEATH AND DESTRUCTION: INSIGHT INTO THE RHINO POACHING EPIDEMIC IN SOUTH AFRICA

\section{RICHARD WAYNE CHARLTON}

A Thesis Submitted in Partial Fulfillment of the Requirements for the Degree of

\section{MASTER OF SCIENCE}

Department of Criminal Justice Sciences

\section{ILLINOIS STATE UNIVERSITY}


(C) 2017 Richard Wayne Charlton 
DEATH AND DESTRUCTION: INSIGHT INTO THE RHINO POACHING EPIDEMIC IN SOUTH AFRICA

\author{
RICHARD WAYNE CHARLTON
}

COMMITTEE MEMBERS:

Jacqueline Schneider, Co-Chair

Dawn Beichner, Co-Chair

Cara Rabe-Hemp 


\section{ACKNOWLEDGMENTS}

I would like to dedicate the research to all the field rangers and game rangers around the world, who put their lives on the line for the protection of our wildlife, on a daily basis. To all the research participants, thank you all so much for agreeing to partake in this vital research. I believe that this research will assist in future strategies to reduce poaching. I would like to acknowledge all of my professors throughout my academic career for always believing in me and pushing me to achieve my best. I would personally like to thank the members of my thesis committee, Jacqueline Schneider, Dawn Beichner and Cara Rabe-Hemp. I have never worked with such committed, patient and motivational people in my life. I can honestly say that without your guidance and assistance I would not be where I am today. I would like to give a special thanks to my family and friends all around the world for their guidance and support. You have always believed in me and pushed to achieve the utmost best and for this, I would like to thank

you all. To my cousin Wade Frost, thank you for accompanying me on my journey of the research I conducted in South Africa. The thousands of kilometers we travelled, the late nights and "dodgy" places we had to sleep at would not have been the same without you. To my sister, Kerry Shone, and brother-in-law, Charlie Shone, thank you so much for your guidance throughout my life and during my research. Last, but not least, I would like to give a special thanks to my mother, Sharon Charlton, and father, William (Bill) Charlton. My loving, adoring parents have given their all to ensure I attain my goals and have the finest education. The hundreds of thousands of Rands you have spent on my education has not gone unnoticed and this thesis is dedicated to you.

R. W. C. 


\section{CONTENTS}

\section{Page}

ACKNOWLEDGMENTS

CONTENTS

ii

TABLES

FIGURES

vii

CHAPTER I: INTRODUCTION 1

$\begin{array}{ll}\text { Poaching? } & 3\end{array}$

Legal Parameters of Poaching $\quad 4$

IUCN - International Union for Conservation of Nature 5

CITES - Convention on International Trade in Endangered Species of Wild Fauna and Flora $\quad 5$

$\begin{array}{ll}\text { South African Laws } & 7\end{array}$

$\begin{array}{ll}\text { The Rhinoceros Species } & 10\end{array}$

$\begin{array}{ll}\text { Rhino Poaching in South Africa } & 14\end{array}$

Statement of the Problem 16

$\begin{array}{ll}\text { Military Involvement in Poaching } & 17\end{array}$

Change in Rhino Population through the 1900s to 2000s 19

The Increase in Rhino Poaching 21

$\begin{array}{ll}\text { Purpose of the Study } & 22\end{array}$

$\begin{array}{ll}\text { Description of the Study } & 23\end{array}$

$\begin{array}{ll}\text { Contribution to Conservation Criminology } & 23\end{array}$

$\begin{array}{ll}\text { Research Objectives and Questions } & 23\end{array}$ 
Research Paper

CHAPTER II: LITERATURE REVIEW 26

$\begin{array}{ll}\text { Parrot Poaching } & 26\end{array}$

$\begin{array}{ll}\text { Tiger Poaching } & 33\end{array}$

$\begin{array}{ll}\text { Elephant Poaching } & 37\end{array}$

$\begin{array}{lr}\text { Illegal Fishing } & 40\end{array}$

$\begin{array}{ll}\text { Rhino Poaching } & 42\end{array}$

$\begin{array}{ll}\text { Conclusion } & 55\end{array}$

CHAPTER III: THEORETICAL FOUNDATION 56

$\begin{array}{ll}\text { SCP Case Studies } & 56\end{array}$

$\begin{array}{ll}\text { Target Hardening } & 57\end{array}$

$\begin{array}{ll}\text { Access Control } & 58\end{array}$

$\begin{array}{lr}\text { Deflecting Offenders } & 59\end{array}$

$\begin{array}{ll}\text { Entry/Exit Screening } & 60\end{array}$

$\begin{array}{ll}\text { Formal Surveillance } & 61\end{array}$

The Problems of Enforcement 63

$\begin{array}{ll}\text { Preventing Wildlife Crime } & 67\end{array}$

$\begin{array}{ll}\text { Alternative Approaches } & 70\end{array}$

$\begin{array}{ll}\text { Situational Crime Prevention (SCP) } & 71\end{array}$

$\begin{array}{ll}\text { The Four Components of SCP } & 74\end{array}$

$\begin{array}{ll}\text { The Action Research Methodology } & 75\end{array}$

Twenty-Five Techniques of Situational Prevention 76

Body of Evaluated Practice Including Displacement 77 
Rational Choice Theory $\quad 82$

$\begin{array}{ll}\text { Routine Activities Theory } & 84\end{array}$

Motivated Offender $\quad 86$

$\begin{array}{ll}\text { Suitable Targets } & 87\end{array}$

Lack of Capable Guardians $\quad 88$

Problem Oriented Policing (POP) $\quad 89$

The SARA Model 91

Market Reduction Approach (MRA) $\quad 92$

$\begin{array}{ll}\text { Conclusion } & 97\end{array}$

CHAPTER IV: METHODOLOGY 99

$\begin{array}{ll}\text { Setting } & 100\end{array}$

Selection of Participants $\quad 101$

Challenges in the Selection of Participants 105

$\begin{array}{ll}\text { IRB Approval } & 106\end{array}$

Data Collection Procedures 106

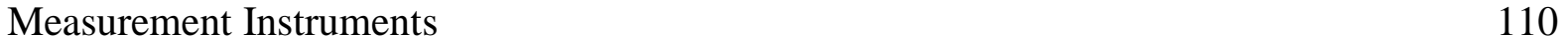

Difficulties in Conducting Research 113

$\begin{array}{ll}\text { Data Analysis } & 115\end{array}$

Reason for Choosing Methodology 116

$\begin{array}{ll}\text { CHAPTER V: FINDINGS } & 117\end{array}$

What is the Extent of the Rhino Poaching Problem in South Africa? 117

$\begin{array}{ll}\text { Rhino Poaching Statistics } & 117\end{array}$

$\begin{array}{ll}\text { Cycle of Rhino Poaching } & 123\end{array}$ 
Who Is Committing the Poaching?

How are Rhino Poached?

How much is Rhino Horn Worth?

Trafficking of Rhino Horn

Use of Rhino Horn

Link between Rhino Poaching and Other Forms of Crime

What is Being Done to Prevent Rhino Poaching in South Africa?

Awareness

APU Activities

What Needs to Be Done to Prevent Rhino Poaching in South Africa

Recommendations

Community Oriented Policing

Situational Crime Prevention

Routine Activities Theory

Conclusion 


\section{TABLES}

Table

Page

1. Rhinoceros Species and Classifications

2. Twenty-five Techniques of Situational Prevention

3. Twenty-five Techniques of Situational Crime

Prevention - Endangered Species

4. Elements of the SARA model

5. Focus of Attention for the Market Reduction Approach

6. Poaching Statistics Received from Data Collection from 2000 to 2016 (11 September)

7. Rhino Poaching Statistics from 2010 to 11 September 2016

8. Proposed Twenty-five Techniques of Situational Crime

$$
\text { Prevention - Rhino Poaching in South Africa }
$$




\section{FIGURES}

Figure

Page

1. Chart of Levels of Organized Crime Involved in the Rhino Horn Trade

2. Routine Activities Theory Showing When the Three

Parties Come Together, Crime is More Likely to Occur

3. The Market Reduction Approach Interagency Model

4. Incidents of Rhino Poaching in South Africa from

January 2010 to 11 September 2016

5. Average Number of Rhino Poaching Losses/Day in

South Africa from January 2010 to 11 September 2016

6. Seasonal Patterns of Rhino Poaching Incidents in

South Africa 2010 - June 2012 


\section{CHAPTER I: INTRODUCTION}

The field of criminology has historically shown little interest in the topic of environmental crimes, especially wildlife crimes. Environmental crimes and noncompliance to international laws, and regulations create future risks to humans and the natural world. The risk that humans face is the demolishing of the natural environment, which can alter the way the ecosystem functions. With the fear of this risk, came the emergence of environmental or green criminology, and more recently, conservation criminology. Conservation criminology is the study of environmental crimes and risks that occur in the fields of criminology, criminal justice, conservation and natural resource management, and risk and decision science to offer broader theoretical perspectives on environmental problems and to expand the types of interventions used to address them (Gibbs, Gore, McGarrell, \& Rivers III, 2010). The goal of conservation criminology is to use, conduct related research, teaching and engagement with local communities, and organizations in order to help reduce environmental crimes and threats at the local, national and international levels (Gibbs, et al., 2010). Conservation criminology is based on three disciplines - criminal justice and criminology, risk and decision analysis, and natural resource conservation and management (Gibbs, et al., 2010, p. 134). Criminology can be used to study human behavior as well criminal justice interventions designed to shape that behavior (Gibbs, et al., 2010, p. 134). Criminology is relevant to conservation criminology because it is able to provide possible strategies for measuring criminal behavior, as well identify possible interventions that can be used to prevent environmental crimes. Risk and decision sciences offer scientific risk assessment tools to understand risk perception (Gibbs, et al., 2010, p. 135). Risk and decision making is linked to conservation criminology because it able to use the methods in the field of criminology to establish the risks involved in certain actions. This will include any 
risks that could possibly harm an environment or species. Natural resource disciplines can offer knowledge and systematic tools and methods to measure, manage and conserve natural resource ecosystems and the people that interact with them (Gibbs, et al., 2010). Natural resource disciplines are related to conservation criminology because they can help identify species population dynamics, habitat requirements, species range and interaction with their environments and human attitudes and behavior about wildlife management (Decker, Brown, \& Siemer, 2001). Wildlife crime can consist of many forms, from the more familiar offences such as poaching, overfishing or killing a protected species, to some of the less familiar crimes like trading or trafficking in endangered species and products derived from them. According to Interpol (2014), wildlife crime is any action or the illegal exploitation of the world's flora fauna in contravention of national and international laws. Examples of wildlife crimes include poaching for trade or personal possession, illegally killing for bush meat and killing animals due to human animal conflict (Pires \& Moreto, 2011, p. 104). Another example and the focus of this study is the poaching of African rhinoceros (rhinos) for their horns.

Wildlife crime is something that has been happening for many decades and the more it goes unacknowledged the worse the problem gets. Wildlife crimes can affect the natural environment in which humans and flora and fauna live. Each organism has an ecological niche that if disturbed would directly affect the sustainability of the ecosystem. Thus if nothing is done to prevent wildlife crimes in the near future, many species are at risk of becoming extinct, thus affecting the ecological system. The focus of this research is rhino poaching of the southern white rhino (Ceratotherium simum simum), poaching of the south-western black rhino (Diceros bicornis bicornis), and poaching of the south-central black rhino (Diceros bicornis minor) in South Africa. Therefore in order to understand how this topic can be studied in a criminological 
framework, the definition of poaching needs to be clearly identified as well as what laws there are to prevent rhino poaching, and the illegal trade that is associated with it. Wildlife crime in South Africa, specifically poaching, goes beyond the threat to the survival of a species. Poaching can negatively affect the tourist industry in South Africa, which relies heavily on revenue generated from public and private game reserves (Herbig, 2011, p. 3). A prosperous conservation area with diverse wildlife population attracts tourists whose money supports the reserves and creates jobs for local residents in, and nearby, the area (Herbig, 2011, p. 3). The increase of poaching means that tourists have a higher possibility of viewing animal carcasses and an increased potential for violent encounters between the poachers and the tourists, which ultimately can lead to less tourism in an area and thus less job opportunities for locals (Herbig, 2011, p. 3).

\section{Poaching?}

Poaching is the illegal killing or hunting of wildlife in an area in violation of local, national or international law (Lin, 2011). Activities that are considered poaching include killing: an animal out of season; without a license; with a prohibited weapon and / or by using poison, traps, snares, dogs or darts (Goitom, 2013). Poaching has also been defined as the unlawful taking of wildlife from a landlord's property (Siegel, 2007); the taking of a game animal out of season or through illegal means (Clifford, 1998) and as a game law violation (Beattie, 1976).

Poaching in South Africa is committed for three main reasons. The first and most general reason is to obtain meat, which is commonly known as bush meat (TRAFFIC, 2002). In South Africa, bush meat hunting is undertaken at both the individual level for personal use, and at the commercial level where poachers sell the meat to local villages (Jackson, 2008; Knecht, 2006; McMullan \& Perrier, 2002). The second reason for poaching is to obtain plants and live animals, 
mainly birds and reptiles for collectors of exotic and rare pets, as well as for sport hunters who illegally pursue trophy game in national parks (Herbig, 2011; Davis, 2005). The final and most publicized aspect of poaching is to supply specific animal parts, such as ivory tusks, rhino horn and pelts for sale as decorations or traditional medicines (Warchol, Zupan, \& Clack, 2003). Poaching of rhinos for their horns will be the focus in the paper, and the purpose of the paper is to explore the nature and extent of rhino poaching in South Africa, with the aim of identifying intervention techniques that can be used to diminish the poaching statistics in South Africa. It is important to understand what poaching is and how it is related to this research, however, it is important to understand the legal aspects of poaching in both South Africa and internationally. This next section of the paper discusses the various laws and conventions that deal with the poaching and the illegal trade in wildlife.

\section{Legal Parameters of Poaching}

According to Schneider and Charlton (2014, p. 3), "the role that criminology can play in combating wildlife crime remains largely theoretical." Criminologists have only recently begun to research crimes associated with endangered species. There have, however, been various laws and conventions that have been used to make the poaching, killing or trading of certain species illegal.

There are a number of international treaties that have produced national, regional and local laws that are violated every time an endangered species is killed, or removed from its natural habitat for monetary gain or personal use (Schneider \& Charlton, 2014, p. 15). These international treaties and laws act as tools for guiding the development of legislation and enforcement within individual member states (Schneider \& Charlton, 2014, P. 15). Some of the tools which are used include, the Convention on International Trade in Endangered Species 
(CITES), Convention on the Conservation of Migratory Species of Wild Animals (CMS), the International Convention for the Conservation of Atlantic Tunas (ICCAT), and the UN Convention of the Law of the Sea (UNCLOS) (Schneider, 2008). Member states of these treaties or conventions are thus obligated to implement their own laws that mirror the codes of CITES and other international agreements (Schneider, 2008). For the purpose of this research CITES is the main convention to be discussed, and will be related to the various laws and legislation that are found in South Africa.

\section{IUCN - International Union for Conservation of Nature}

In order to understand CITES and how the convention works, one first needs to understand the methods that the convention uses to place species into different appendices. The International Union for Conservation of Nature is (IUCN) is what CITES uses to place the species into different appendices. The IUCN in conjunction with the Species Survival Commission create the IUCN Red List of Threatened Species. This Red List classifies species into one of several categories based on the level of threat. These categories of the Red List include least concern (LC); near threatened (NT); vulnerable (VU); endangered (EN); critically endangered (CE); extinct in the wild (EW) and extinct (EX) (Rodrigues, Pilgram, Lamoreux, Hoffmann, \& Brooks, 2006, p. 72).

\section{CITES - Convention on International Trade in Endangered Species of Wild Fauna} and Flora

CITES is an international treaty that regulates the trade of species that have varying levels of risk for extinction. The basic idea of the convention is that if trade in the most endangered fauna and flora is regulated and strictly monitored, the probability of extinction is reduced (Schneider \& Charlton, 2014, p. 16). The status of a species is determined through 
scientific analysis by examining the populations, threats, ranges and viability. The status of the species is done through the IUCN. Once the level of threat of a species has been established, it will then be placed into one of three CITES appendices. Appendix 1 includes the species that are at most risk of extinction and thus strictly restricts the trade of that species. Commercial trade of a species in Appendix 1 is completely prohibited, while trade for other reasons must demonstrate that no further harm to the species status will occur due the trade (Crawford, 1995; Lee, 1996). Appendix 2 includes species that have a high level of risk that if trade is not regulated strictly, the species level of threat will increase. Trade in flora and fauna and their by-products can be traded between countries if the trade will not further jeopardize the species (Crawford, 1995; Lee, 1996). Appendix 3 is reserved for species that are at risk at the country level, where trade is restricted within that country and among its regional neighbors (Crawford, 1995; Lee, 1996). Only the southern white rhino in South Africa, and Swaziland are recognized in Appendix 2, all other species of rhinos, and populations found in other countries are recognized in Appendix 1 (CITES, 2016).

Signatory parties of CITES must agree to formulate domestic laws that mirror the tenets of CITES. While joining CITES is voluntary, if a country does join CITES, they are responsible for self-monitoring and submitting reports to CITES, which is the Secretariat of the United Nations (UN). According to Schneider and Charlton (2014, p. 17), it is still unclear what sanctions are applied to member-states failing to adhere to it. This research is focused in South Africa, thus it is important to identify what legislation the South African government has implemented to mirror the basis of CITES. 


\section{South African Laws}

Rhino poaching did not start to increase in South Africa until 2003, however, other illicit ways of obtaining rhino horn started before this. The first method identified to obtain rhino horn illegally, was that of pseudo-trophy-hunting, which started on a small scale but then escalated dramatically, peaking in 2010 and 2011 when 116 applications for rhino trophy hunting came from Vietnamese nationals in both years (Taylor, Brebner, Coetzee,Davies-Mostert, Lindsey, Shaw, 't Sas-Rolfes, 2014, p. 8). A pseudo-trophy-hunt is when an applicant applies to hunt a rhino for trophy purposes, but then contravenes the terms and conditions of the application and uses the horn for illegal or medicinal purposes. With an increase in trophy hunting applications, and an increase in pseudo-hunting, the South African government, in 2007, implemented the Threatened or Protected Species (TOPS) regulations under the National Environmental Management: Biodiversity Act, 2004 (Act No. 10 of 2004) (NEMBA) (Taylor, et al., 2014, p. 8). These regulations placed stricter controls on trophy hunting but did not target pseudo-hunting. To prevent pseudo-hunting, norms and standards were introduced in 2009 (Schedule 2: Management of the hunting of white rhino; Government Gazette No. 32426, Notice No. 756, 20 July 2009); however, by 2011 these measures were not very effective because pseudo-hunting continued to increase (Taylor, et al., 2014, p. 8). These norms and standards were amended in 2012 (Schedule 3: Management of the hunting of rhinoceros; Government Gazette No. 35248, Notice No. 304, 10 April 2012), with the result that the total number of applications for hunting white rhinos in 2012 dropped to 66 and only included eight applications from Vietnamese nationals.

The NEMBA prohibits anyone from carrying out a restricted activity involving any threatened or protected species without a permit. The species that are listed as threatened will be 
established by the Minister of Environmental Affairs and Tourism of South Africa, and will be classified as critically endangered, endangered and vulnerable (Goitom, 2013). The restricted activities with regard to the listed species include:

i. Hunting, catching, capturing or killing any living specimen of a listed threatened or protected species by any means or methods whatsoever;

ii. Importing into the Republic, or introducing from the sea, any specimen of a listed threatened or protected species;

iii. Exporting from the republic any specimen of a listed threatened or protected species;

iv. Having possession or exercising physical control over any specimen of a listed threatened or protected species;

v. Growing, breeding or in any other way spreading any specimen of a listed threatened or protected species;

vi. Translocating any specimen of a listed threatened or protected species

vii. Selling or trading in, buying, receiving, giving, donating or accepting as a gift, or in any way acquiring or disposing of any specimen of a listed or protected species; or

viii. Any other prescribed activity that involves a specimen of a listed threatened or protected species (Goitom, 2013).

Any person who violates these prohibitions, including violating the terms and conditions in a permit will be classified as committing an offense. The NEMBA regulations forbid certain activities involving listed large predators, white rhinoceros and black rhinoceros (Goitom, 2013). NEMBA bans hunting: in a controlled environment, with the use of any tranquilizer, narcotic, or 
other immobilizing agent; in an area near a holiday facility for such animals; with the use of a gin trap; or where the hunter does not first obtain a written affidavit from the owner of the land where the animal is located (Goitom, 2013). The NEMBA regulations also impose a ban on the use of certain hunting methods by prohibiting the issuance of a permit to hunt a threated or protected species using poison, traps, snares, dogs, darts, or an automatic weapon (Goitom, 2013). These regulations also prohibit luring of animals for hunting by using bait, sounds, smell or any other method. Any person found to be in violation of these regulations can be arrested and tried for an offence. A person convicted of an offence under the NEMBA is subject to fines $(100,000$ South African Rand (ZAR) or about US\$10,000) and/or up to five years imprisonment (Goitom, 2013). If the conviction is for an offense regarding a listed threatened or protected species, the fine could reach up to three times the value of the animal (Goitom, 2013).

The second illicit method of obtaining rhino horn is by traders buying horn directly from private owners (Taylor, et al., 2014, p. 9). International trade in rhino horn has been prohibited under CITES regulations since 1977, however, it remained legal for South African citizens to sell and exchange rhino horn within the country as long as permits were acquired. In the early 2000s, this legal trade began to be exploited for illegal purposes and the horns were being sold to foreign nationals, mostly Asians, particularly Vietnamese (Taylor, et al., 2014, p. 9). The horns were then smuggled out of the country for illegal sale in Asia. With this, the South African government placed a national moratorium on the sale of individual rhino horn and any byproducts within South Africa to ensure that no legally obtained horns appear in the illegal trade. This moratorium was published in February 2009 (Government Gazette No.31899, Notice No. 148, 13 February 2009), and was thought to reduce the illegal trade of rhino horn. However, it has since been seen that rhino poaching increased throughout the country, indicating that the 
illegal trade is still strong. According to Taylor, et al., (2014, p. 9), "around the same time as the implementation of TOPS of regulations under NEMBA (2007), the norms and standards (2009) and the national trade ban on trade in rhino horn (2009), poaching of rhinos in South Africa escalated".

More recently the National Environmental Management Laws Amendment Act, 2013 (NEMLA) was implemented. The NEMLA Act allows for the domestic or subsistence use of indigenous biological resources. Legal mechanisms have been put into place to regulate the markets and the industry (hunting, and farming). These legal mechanisms ensure that listed species are properly regulated, regardless of whether the species is of high conservation value or not (Modise, 2013). In addition, the NEMLA act addresses the challenges with the permit system regarding hunting of listed threatened or protected species. The permit system has previously been abused by permit applicants to obtain rhino horn. The government does acknowledge that the NEMLA Act will not be able to stop rhino poaching, but it will assist to address the activities associated with poaching (Modise, 2013). To assist in this, the Act requires professional hunters and hunting outfitters to register with the national database. If such individuals facilitate in the killing of a rhino or exporting of the horn, their registration will be revoked (Modise, 2013). The individual will then not be able to obtain a permit or operate as professional hunter or hunting outfitter in any province. The NEMLA Act proposes that an individual who does not necessarily kill a rhino illegally, but is involved in the activity or allows it to be carried out is also guilty of an offence (Modise, 2013).

\section{The Rhinoceros Species}

There are five living species of rhinoceros (rhino) worldwide, with two species occurring in Africa and three in Asia. Table 1 details the rhinoceros species, ranges, estimated populations, 
and threats. The rhinoceros species that are found in African are the white rhinoceros (Ceratotherium simum ssp.) subspecies and the black rhinoceros (Diceros bicornis ssp.) subspecies (Taylor, et al., 2014, p. 12). The white rhino has two subspecies, the southern white rhino (Ceratotherium simum simum) and the northern white rhino (Ceratotherium simum cottoni) (Emslie, 2012a). The black rhino has four subspecies, the south-western black rhino (Diceros bicornis bicornis), the western black rhino (Diceros bicornis longipes) which is now extinct (Emslie, 2013), the eastern black rhino (Diceros bicornis michaeli) and the south-central black rhino (Diceros bicornis minor) (Emslie, 2012b). ${ }^{1}$ South Africa is home to both subspecies, the southern white rhino, the south-central black rhino and the south-western black rhino (Taylor, et al., 2014, p. 12). There is also a single population of the eastern black rhino on private land in South Africa, but this is outside its natural range and is kept in isolation from the other two subspecies (Taylor, et al., 2014, p. 12).

\footnotetext{
${ }^{1}$ This research will examine south-central, and south-western black rhino. Therefore, unless otherwise specified, the term black rhino will be used to discuss both of these species. The southern white rhino discussed in this research will simply be referred to as white rhino.
} 


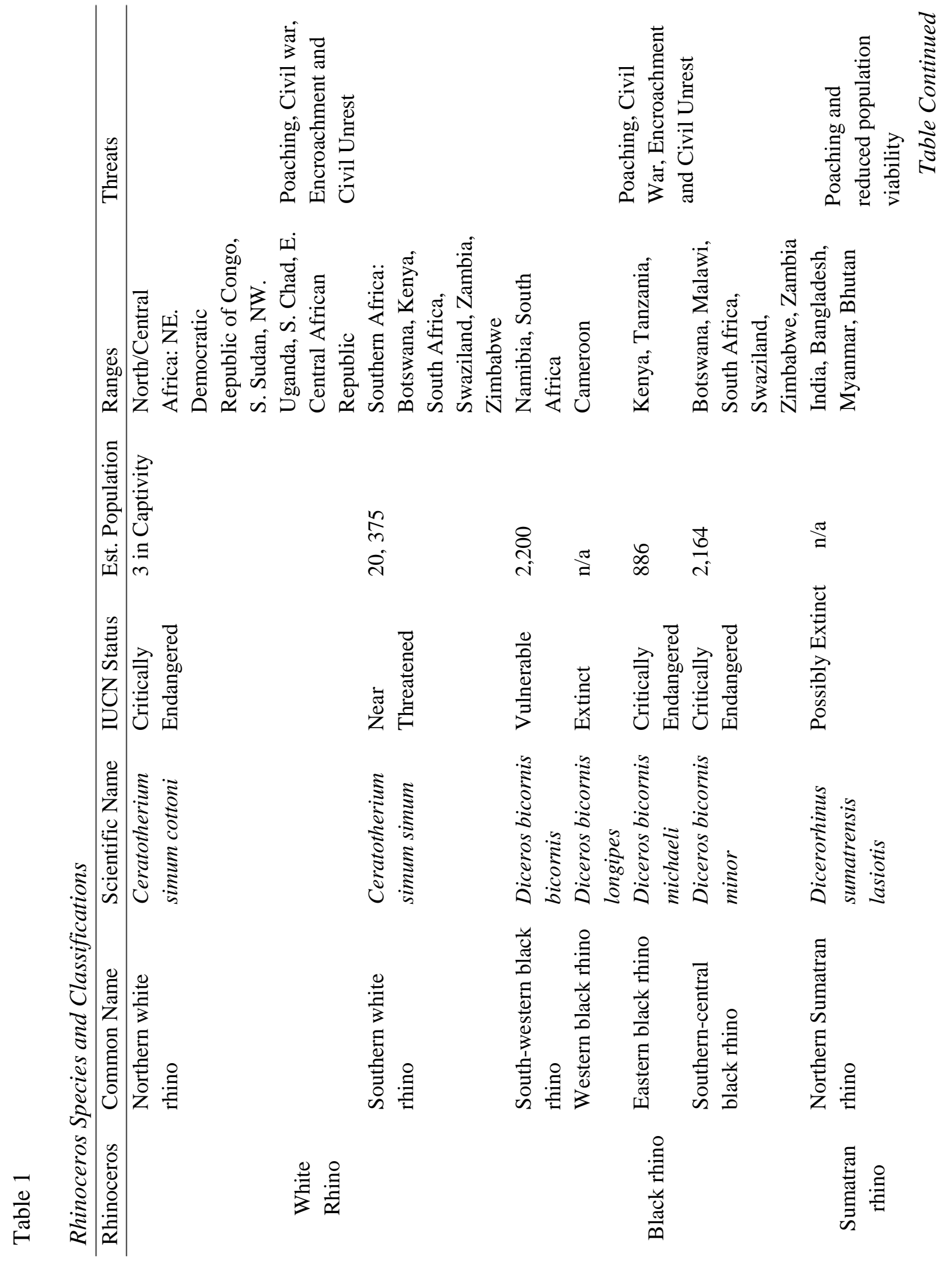




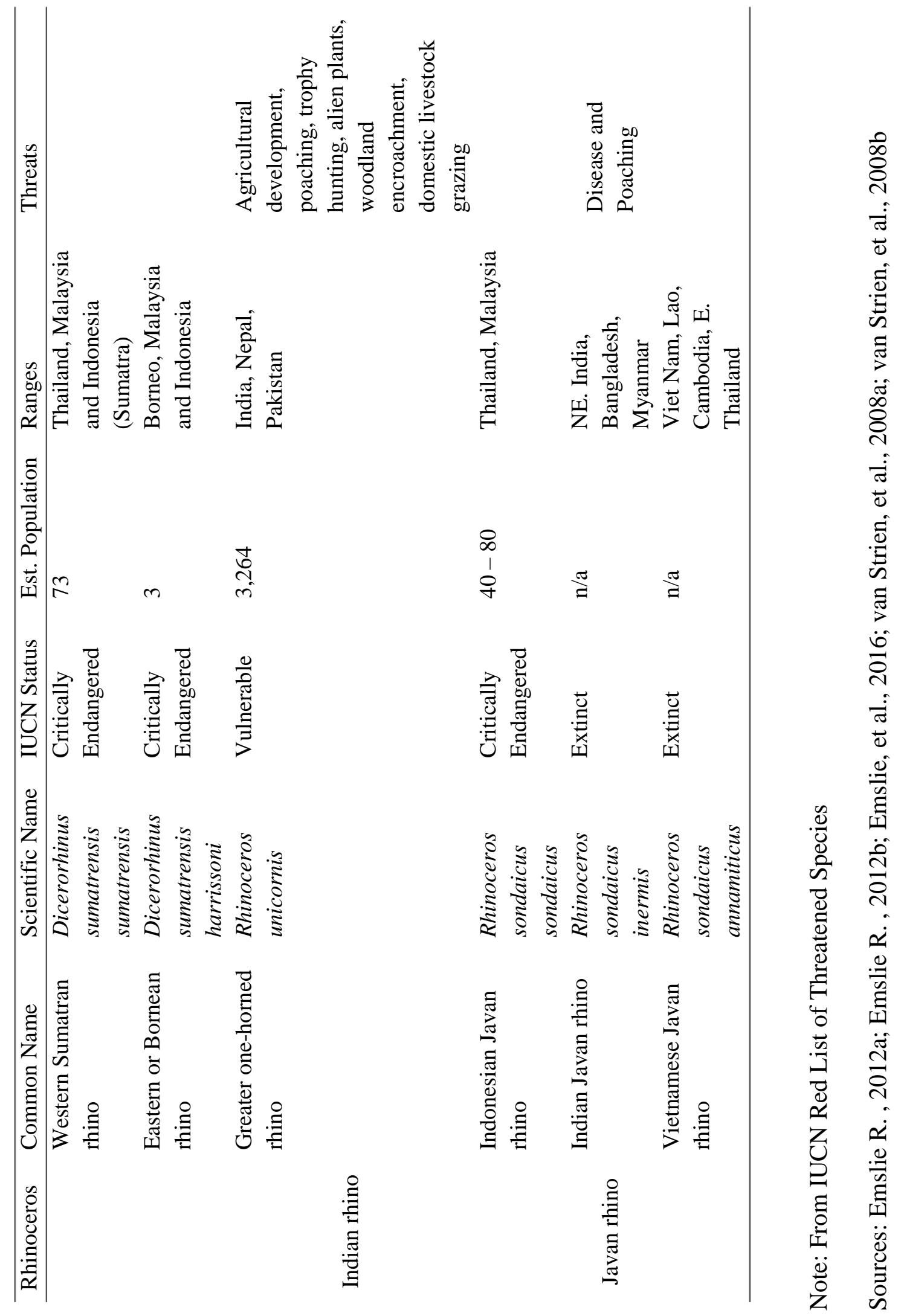




\section{Rhino Poaching in South Africa}

Since the early 1900s, the African rhino population has been targets for trophy hunters around the world and for traditional medicinal purposes in Asia. Africa's rhinos have faced two catastrophic crises over the past 50 years. The first crisis saw a large population of rhinos decimated through, what some would say, ruthless waves of poaching to support traditional medicine in Asia (Milliken \& Shaw, 2012, p. 18). Many areas with black rhino saw populations completely disappear or be reduced to only a handful (Milliken \& Shaw, 2012, p. 18). It is estimated that from 100,000 black rhino in Africa in 1960, only around 2,400 were left in 1995 (Emslie, Milledge, Brooks, van Strien, \& Dublin, 2007, p. 8). The hardest hit of the rhino population was that of the western subspecies of black rhino, which was declared extinct in 2011 (Emslie, 2013; Knight, 2013). Likewise, the southern white rhino was considered extinct in the late $19^{\text {th }}$ century, until a small population of around 30 to 50 rhinos were discovered in the Umfozozi-Hluhluwe region in Kwa-Zulu Natal, South Africa. Thanks to years of conservation efforts these numbers slowly rose to about 2,000 in the 1960s and after a century of conservation this number has increased to approximately 20,150 white rhinos in 2010 (Emslie, 2012a). In recent years, however, the number of rhinos has been affected due to an increase in poaching of rhinos for their horns. It is estimated that for approximately 16 years, between 1990 and 2005,

South Africa lost an average of 14 rhinos a year to poaching (Milliken \& Shaw, 2012, p. 11). ${ }^{2}$ In 2008, this number rose to 83 , and in 2009 it rose to 122 and this number has continued to increase to 1004 rhinos poached in South Africa in 2013, 1215 in 2014, and a slight decrease to 1175 in 2015 (Department of Environmental Affairs, 2014; Modise, 2016).

\footnotetext{
${ }^{2}$ As of 11 September 2016, the estimated number of rhino killed by poaching is 702 for 2016 .
} 
It is estimated that the price of rhino horn is $\$ 65,000$ to $\$ 85,000$ per kilogram of rhino horn on the black market (Biggs, Courchamp, Martin, \& Possingham, 2013, p. 1038). This amount is worth more than the value of gold, platinum and even cocaine. According to Milliken and Shaw (2012, p. 11) even with the increase of rhino poaching in recent years, the rhino population continued to increase because the amount of births still exceeded the deaths. In 2014, however, this has changed and there is now a declining population of rhinos in South Africa. If taken into account the value of rhino horn, one is able to find that the process of obtaining the horn is a multifaceted approach and is a multi-million dollar illegal trade. There is evidence that the illegal trading in rhino horn has links to other highly profitable natural resource product trades, including abalone, ivory, lion bones, crocodile organs and live game (Milliken \& Shaw, 2012, p. 76). According to Hübschle (2010) rhino crime syndicates operate multi-nationally and are known to be involved in other high-risk criminal activities such as drug and diamond smuggling, vehicle theft, armed robberies and ATM (cash point machine) bombings.

South African game reserves have come under attack by poachers in the past six years, where poachers have killed well over 3,000 rhinos for their horns since 2010. Poaching has always been a problem in South Africa, however, in recent years South Africa is seeing a new breed of poaching, where the poachers are more sophisticated, better trained and have better technology. The new style of poaching has compelled many game reserves to implement drastic changes to combat rhino poaching. Many game reserves now have specialized units or security forces that are known anti-poaching units (APU), are there to prevent rhino poaching, and act as a proactive unit and not a reactive unit. These units have implemented various styles of antipoaching enforcement that have been taken from law enforcement and the military. The APU members are highly trained by ex-military and law enforcement members and are trained in 
counter-insurgency, tactical response and the use of informant networks. In essence, the fight against rhino poachers has turned from the fight for the survival of the rhinos, to a war against the poachers. Investigations have found that rhino poachers are often highly trained and often have some type of military or law enforcement background, so they are aware of how to "hide" their tracks in a "war" zone and are able to get away after committing their crime. It seems only fitting then, that specialized units are deployed to protect the rhinos of South Africa. These methods of anti-poaching notwithstanding, rhinos are still being poached on a daily basis and very little research has been conducted to date.

Crime reduction has been made a top priority for many countries and cities worldwide. For years, criminal justice practitioners have explored ways to prevent or reduce crime, with the focus on murder, rape, armed robberies and other crimes against humans. It is quite rare; however, that criminal justice approaches, policing theories, and crime reduction models have been employed to combat environmental crimes. This research thus aims to bridge the gap and explore the problem of rhino poaching in a criminal justice view by implementing a market reduction model and problem oriented policing (POP) approach to the rhino-poaching epidemic.

\section{Statement of the Problem}

South Africa has a unique history of rhino conservation and through these efforts census counts have substantially recovered. South Africa is home to approximately 35 percent of all black rhinos, and 93 percent of the white rhino. These animals have been protected and managed through state-run and privately owned properties. In fact, this method of conservation is a frequently cited success story and is often used for similar projects worldwide (Cousins, Sadler, \& Evans, 2008; Milliken \& Shaw, 2012). However, even with the successful conservation of rhinos, rhino poaching has increased dramatically since 2009. In order to understand the problem 
of rhino poaching, one firsts needs to understand a historical view of poaching and rhino numbers in South Africa.

\section{Military Involvement in Poaching}

South Africa was involved in three wars between 1960 and 1994 in Namibia, Angola and Mozambique. The South African Defence Force (SADF), then under the leadership of P.W. Botha in the 1970s and later under General Magnus Malan in the 1980s, openly supported the National Union for Total Independence of Angola (UNITA). UNITA was a rebel union run by Jonas Savimbi in South Western Angola from the mid-1970s to the late 1980s (Van Vuuren, 2006, p. 50). The SADF also openly supported the Mozambican National Resistance (RENAMO) rebels in Mozambique. The SADF took direct military intervention, in the form of attacks, in Angola against civilians, the Angolan military as well as South West Africa People Organization (SWAPO), and the African National Congress (ANC) freedom fighters (Van Vuuren, 2006, p. 50). It also believed that the SADF often assisted Jonas Savimbi by supplying him with an annual budget, weapons and military support in his battle against the Angolan government (Reeve \& Ellis, 1995). According to Reeve and Ellis (1995, p. 227), the wars in which South Africa was involved, had a major impact on Africa's elephant population and on the ivory trade. Since the 1980 s, evidence has emerged that large scale poaching of elephants, and to a lesser degree rhinos, was organized by the SADF (Rademeyer, 2012, p. 53). It has emerged that SADF had encouraged their allies, RENAMO, UNITA and the Rhodesian Selous Scouts to obtain and trade ivory, as a means to pay for the South African aid in weapons and other services (Ellis, 1994, p. 57; Rademeyer, 2012, p. 53; Reeve \& Ellis, 1995, p. 227).

The first publicity given to these events was in 1988 when a U.S environmentalist testified before the US House of Representatives that senior members of the SADF, government 
members and South African Military Intelligence were involved in a massive ivory smuggling operation in Africa (Ellis, 1994, p. 57; Montesh, 2012, p. 3). According to Ellis (1994, p. 57) the involvement of SADF, UNITA, RENAMO and the Rhodesian Selous Scouts had been involved in the slaughter of as many as 100,000 elephants in about 12 years. The ivory tusks and rhino horns were being smuggled through a pipeline that was created by the SADF through South Africa, Burundi and Democratic Republic of Congo (then Zaire) for resale abroad. The statement by the US environmentalist led to the establishment of the "Roos Inquiry" by the SADF in 1988. This inquiry's findings suggested that there was no evidence to prove that the defense force was responsible for the killings of elephants or rhinos. However, small quantities of ivory captured by UNITA from poachers were transported by the defense force on behalf of UNITA (Mail and Guardian, 1995; Montesh, 2012, p.3). In 1994, when former President Nelson Mandela came into power he appointed one of the most highly decorated judges, Mark Kumleben to investigate into the alleged smuggling of ivory and rhino horn by the SADF (Rademeyer, 2012, p. 60). This commission had found that there was substantial proof that the SADF was involved in the ivory and rhino trade through a front company, Frama Inter-Trading, which was later privatized (Rademeyer, 2012, p. 61). The commission found that the SADF had provided covert vehicles to transport the ivory and horn from the Angolan border to a veterinary services quarantine station at Rundu in Namibia (Montesh, 2012, p. 3). The contraband was then stored until a SADF employee collected it and sold it on behalf of UNITA. Finally, the commission found that the SADF was involved in the illegal trading of rhino horn and ivory until about 1986 (Montesh, 2012, p. 3).

These highlight the involvement of the SADF in trafficking and poaching of not only rhinos, but also elephants. The importance lays in the fact that individuals and syndicates engage 
in poaching activities, but so did the Apartheid SADF. The following section explores the rhino population in South Africa over the past century.

\section{Change in Rhino Population through the 1900s to 2000s}

It is estimated that at the beginning of the 20th century, there were approximately 500,000 rhinos across Africa and Asia (Weber, 2016, p. 243). Due to a high amount of poaching and trophy hunting, these numbers declined to about 70,000 in the 1970s and as of late 2010, there are roughly only 29,000 rhinos left in the wild (Deppe, 2013). In Africa, in the early 19th century, there were roughly over 100,000 rhinos throughout the continent, but by the end of the century, the rhino was at the brink of extinction (World Wildlife Fund, 2014). Large scale poaching saw a dramatic decrease in the white rhino population to about 20 to 50 white rhino left in the wild in the Hluhluwe-iMfolozi game reserve in 1895 (Milliken \& Shaw, 2012, p. 9). Likewise, large scale poaching of the, now critically endangered black rhino, saw a dramatic decline in population by an estimated 97.6 percent to about 2,400 in 1995 (Emslie, Milledge, Brooks, van Strien, \& Dublin, 2007, p. 8). Despite these bleak figures and the continuing threat of poaching, the rhino population has been on the increase in past years. As of the end of 2010, there were roughly 20,150 white rhinos in the wild (Emslie, 2012a). Like the white rhino, the black rhino has seen a steady increase in population and has almost doubled since 1995 to about 4,880 by the end of 2010 (Emslie, 2012b). As of 2010, South Africa's white rhino population is estimated to be 18,800 , which is roughly 95 percent of Africa's total white rhino population (Milliken \& Shaw, 2012, p. 9). South Africa, as of 2010, also holds about 1,915 or 40 percent of total black rhino alive today (Milliken \& Shaw, 2012, p. 9).

South Africa has the most successful record for the protection of rhinos (Cousins, Sadler, \& Evans, 2008; Milliken \& Shaw, 2012, p. 8). According to Milliken and Shaw (2012, p. 8) 
South Africa, in 2011, protected about 83 percent of Africa's rhinos and nearly three-quarters of all wild rhinos worldwide. The country is one of the most biologically diverse nations globally and has long promoted conservation through sustainable use of natural resources (Milliken \& Shaw, 2012, p. 8). This value for biodiversity and conservation has been found in South Africa's constitution, where the country calls for: "a prosperous, environmentally-conscious nation, whose people are in harmonious coexistence with the natural environment, and which derives lasting benefits from the conservation and sustainable use of its rich biological diversity" (Department of Environmental Affairs and Tourism, 1997). South Africa has used a strategy of using private landowners and government land to conserve and increase the rhino population over the past century. In fact, wildlife-based land use among private owners and game ranches in South Africa today make up an area almost three times that of all national and provincial protected areas in South Africa (Milliken \& Shaw, 2012, p. 8). Although these private and government-owned areas are what have helped increase rhino populations in the past, it is mainly because of the conservation efforts by the Hluhluwe-iMfolozi game reserve and the Natal Parks Board that the rhino population has increased. After the success of the Hluhluwe-iMfolozi game reserve, the Natal Parks Board's “Operation Rhino," pioneered a wildlife translocation and management strategies. It is because of this operation, that there is a large private sector of rhino owners in South Africa (Milliken \& Shaw, 2012, p. 9). Approximately 25 percent of all white rhinos in South Africa are privately owned, and it estimated that private rhino owners own approximately 22 percent of South Africa's black rhino population (Milliken \& Shaw, 2012, p. 9).

Wildlife in South Africa, rhinos in particular, have benefited from South Africa's natural resource policies and the use of private and government owned conservation efforts. However, 
South Africa's conservation efforts, of more than a century, are currently under threat. The unprecedented increase in rhino poaching, since 2009, has brought fear that if poaching does not come to a stop or decline significantly, the rhino deaths will outnumber the births and the population will begin to decrease dramatically (Daily Mail, 2014).

\section{The Increase in Rhino Poaching}

Rhino poaching has been a historical constant, however, over the past several years rhino poaching has dramatically increased. Between the years of 1990 and 2005, rhino poaching losses in South Africa averaged 14 animals each year (Milliken \& Shaw, 2012, p. 11). This figure suddenly increased to 83 rhinos in 2008 and by 2009 the number had increased to 122 (Milliken \& Shaw, 2012, p. 11). In 2010, rhino poaching incidents continued to increase and saw 333 rhinos slaughtered (Department of Environmental Affairs, 2014). Since 2010, rhino poaching has been on the increase at a drastic rate and in 2011, 448 rhinos were poached; in 2012, 668 rhinos were poached and in 2013 total climbed to a new annual record of 1004 rhinos poached (Department of Environmental Affairs, 2014). This amount continued to increase and in 2014, 1215 rhino were poached, in 2015, there was slight decrease to 1175 , and as of 11 September 2016, 165 rhinos have been poached in South Africa (Department of Environmental Affairs, 2015; Modise, 2016). The total amount of rhino lost to poaching from the year 2000 to the time of writing is well over 4,000. These numbers are of great concern to the well-being and survival of the rhino in South Africa. If the poaching numbers continue to rise, as they have in recent years, it is only a matter of time until rhinos become extinct. Due to the continued decline in rhino populations because of human illegal activities, the time is ripe to develop intervention strategies to combat rhino poaching in South Africa. 


\section{Purpose of the Study}

The purpose of this research is to explore the rhino-poaching problem with the aim to create crime prevention techniques that can be used to prevent rhino poaching in South Africa. In order to combat any illegal market, one needs to evaluate the supply and demand network. Much of the focus into the illegal wildlife trade has been in an international scale and has looked at international policies and laws that prevent the illegal trade in wildlife. However, little research is available as to what is being done at the local level where poaching takes place. In order to understand the illegal wildlife trade, it is important to untangle the criminal networks that are involved, and one of the areas that is often neglected is that of the actual poacher (Ayling, 2012). According to Felbab-Brown (2011, p. 13), "policies to curb the illegal trade in wildlife and ensure its conservation and biodiversity preservation need to address the diverse and actorspecific drivers of illegal wildlife trade." In other words, it is difficult to combat a problem or to design effective policies without having a good knowledge of all parts of the network that contribute to the illegal trade in wildlife. Ayling (2012, p. 1), mentions that academic literature on this topic has focused on the "advantages and disadvantages of possible solutions ranging from stricter enforcement mechanisms and greater efforts to enforce (Webb, 2000; Wellsmith, 2011; Zimmerman, 2003) to the application of SCP techniques (Graycar and Felson, 2010; Schneider, 2008; Pires and Moreto, 2011) and community based solutions" (Felbab-Brown, 2011). A recent and comprehensive report published by TRAFFIC (The Wildlife Trade Monitoring Network) looked at trafficking of South African rhino horn to Vietnam. Milliken and Shaw (2012) give detail to the networks involved in the rhino horn trade and is another piece of valuable information to the problem. Finally, the investigative journalist Julian Rademeyer 
looked into the trade in rhino horn in a holistic view and looked at problem from source to end market use (Rademeyer, 2012).

If rhino poaching is broken down and one thinks of it like a puzzle or building blocks, one quickly realizes that it is impossible to complete a puzzle or build a structure without all the pieces. In order to prevent the illegal trade in rhino horn, all aspects of and parties involved in the illegal trade must be scrutinized. This research focuses on the beginning part of the network, the actual poachers who are killing the animals.

\section{Description of the Study}

This study is an exploratory, qualitative study that used a purposive sampling technique to obtain its participants. Because of the exploratory nature of this study, the data obtained were from various parties involved in the protection of rhinos in South Africa. Qualitative interviews were conducted with 12 participants in South Africa during December 2013 and January 2014.

\section{Contribution to Conservation Criminology}

This research explores the extent of the rhino-poaching problem in South Africa and utilizes criminological frameworks, specifically Situational Crime Prevention (SCP), as a technique to prevent rhino poaching in South Africa.

\section{Research Objectives and Questions}

South Africa has a history of rhino poaching and has been successful in bringing the rhino population back from near extinction. However, in recent years, rhino poaching has reached new levels and is done so in a more organized manner. It is not too long before rhino deaths start outnumbering rhino births and the rhino population will begin to decrease. Therefore, the objectives of this research is to explore the rhino poaching problem in South 
Africa with the aim of applying SCP techniques to combat and reduce the rhino poaching numbers. Due to the exploratory nature of this research, the research questions of this paper are:

- What is the extent of the rhino-poaching problem in South Africa?

This question aims to explore the problem in its entirety by evaluating the numbers of rhinos being killed; how they are killed; how much rhino horn is worth; and how rhino horn is trafficked to other parts of the world.

- What is currently being done to prevent rhino poaching in South Africa?

This question seeks to identify what methods and techniques are currently being used in South Africa by law enforcement, APUs and non-governmental organization (NGOs) to combat the rhino-poaching problem.

- What can be done in the future to prevent rhino poaching in South Africa?

This question aims to identify various techniques and methods that can be used to prevent rhino poaching from happening. This question will be answered by evaluating what the extent of the problem is, what is currently being done and what the research identifies as possible techniques to prevent the problem in the future.

In order to understand how the topic can be researched in criminal justice, the theories and prevention techniques of criminal justice becoming utterly important in the research. The following chapter (Chapter 2) will begin by exploring wildlife crime in general, by giving example of previous research. Chapter 2 will then explore previous research on the topic of rhino poaching in South Africa. 


\section{Research Paper}

The outline of the research paper is as follows.

Chapter Two - Literature Review

This chapter provides an exploration into the literature that has been found on wildlife crime in general and rhino poaching in South Africa.

\section{Chapter Three - Theoretical Foundation}

This chapter discusses the various techniques that have been used to combat crime. The literature will focus on SCP and will discuss the background to SCP by identifying the theories that are related to it. Finally, this chapter will discuss the various techniques that are associated with SCP.

\section{Chapter Four - Research Methodology}

This chapter provides an explanation of the research techniques and procedures that were used in the research.

\section{Chapter Five - Research Findings}

This chapter provides the findings that were discovered in the research.

\section{Chapter Six - Recommendations and conclusion}

A discussion of the findings will be related to the various theories and schools of thought that were discussed in chapter three of this paper.

\section{References and Appendices}

This section of the paper will include the references and appendices that were used during the study. 


\section{CHAPTER II: LITERATURE REVIEW}

Wildlife crime has become of great concern to criminologists in the past decade.

Research has been conducted on various wildlife crimes by criminologists as a means to identify the problem. Some of the research topics in wildlife crime include the illegal trade in parrots, the poaching and killing of tigers for their pelts, poaching and killing of elephants for their ivory, illegal fishing operations and the killing and poaching of rhinos for their horns. The first section of this chapter will provide a literature review of some of the previous research that has been conducted on the various wildlife crimes that are found.

\section{Parrot Poaching}

The first wildlife crime topic that will be discussed in this literature review is the poaching of parrots. In the 1970s and 1980s, many species of Central and South American parrots became close to extinction due to large exportation of the species overseas (Juniper \& Parr, 1998). It is estimated that around 50,000 to 150,000 parrots were taken from the wild and sent to the United States alone (Cantu, Saldana, Grosselet, \& Gamez, 2007). The high amount of parrot poaching made many Central and South American countries become parties to the CITES agreement of prohibiting unauthorized international trading of parrots and passed domestic laws prohibiting the taking of parrots (Pires \& Clarke, 2011). The CITES agreement reduced the international trade in wild parrots, however, it has since been found that a substantial amount of parrots are still being poached for domestic markets (Pires \& Clarke, 2011). One report found that an estimated 65,000 to 78,500 parrots continue to be poached each year in Mexico, where 86-96 per cent are sold within the country (Cantu, Saldana, Grosselet, \& Gamez, 2007). Another study investigated an illegal pet market in Santa Cruz, Bolivia, that openly sells parrots. This study found that 7,277 birds among 30 parrot species were offered for sale during a one-year 
period and the research suggested that similar numbers could be found in other markets in Santa Cruz (Herrera \& Hennessey, 2007). It is suggested that the reason that the domestic trade still exists, despite the legal prohibitions, is due to the low cost of the parrots that are caught in the wild and due to the fact that parrots are common pets in Central and South America (Pires \& Clarke, 2011). Research has suggested that much of the parrot poaching in Mexico is done by local opportunistic criminals, who take advantage of a relatively easy way to supplement their incomes (Pires \& Clarke, 2011).

In a study by Pires and Clarke (2011), the authors researched the reach or catchment area of parrots for the Los Pozos market in Bolivia, by applying biological forging theory. In addition, the authors set out to examine whether or not parrot poaching is mainly opportunistic. The sample studied for this study was the 47 parrot species in Bolivia, 27 of which had been found in the Los Pozos market (Pires \& Clarke, 2011, p. 317). For this study, the author's first hypothesis was that the outer boundary of the catchment area for parrots in the Los Pozos market is approximately 100 miles around Santa Cruz (Pires \& Clarke, 2011, p. 318). The second hypothesis was the parrot species whose ranges are within 50 miles of Santa Cruz would appear more commonly in the market than those whose ranges are between 50 and 100 miles. The final hypothesis was "for the 27 Bolivian parrot species found in the Los Pozos market, the larger the proportion of their ranges within 100 miles of Santa Cruz, the larger will be their numbers appearing in the market (Pires \& Clarke, 2011, p. 318).”

This study found that relatively few parrot species accounted for most of the birds in the market and that these species were locally abundant and easily accessible to opportunistic poachers (Pires \& Clarke, 2011, p. 328). The rare and more expensive parrot species, sought after by "professional" poachers, looking to maximize profits, were found in much smaller 
numbers (Pires \& Clarke, 2011, p. 328). The study found that 25 of the 27 species found in the Los Pozos market are within 103 miles of Santa Cruz, where the other 20 species of parrots found in Bolivia, are not found within a 100-mile radius of Santa Cruz, they were not found in the market (Pires \& Clarke, 2011, p. 320). In total 19 of the 27 parrot species found in the market, are found within 50 miles of Santa Cruz, which suggests that the poachers are opportunistic in nature. The findings also suggested that the larger and more beautiful parrots were more likely to be found in the market, compared to the less desirable species (Pires \& Clarke, 2011, p. 328).

The study by Pires and Clarke (2011) also suggested techniques that can be used to prevent the poaching of parrots. In this the authors suggest that the usual remedies for poaching, such as increased penalties, more enforcement, and more protected areas are likely to be of limited effectiveness when the poaching is done by opportunistic poachers (Pires \& Clarke, 2011, p. 329). The authors suggest that situational prevention, ecotourism and managed off-take are all approaches that can help increase the parrot numbers; however, these methods require hard work, careful planning, determination and bountiful resources, which most poor countries do not have (Pires \& Clarke, 2011, p. 329). For this study, the authors suggest cracking down on the illegal markets, such as Los Pozos, and the traders that supply the markets to reduce parrot poaching. Disrupting the markets instead of cracking down on thousands of opportunistic poachers may be the easier and more viable option in Bolivia (Pires \& Clarke, 2011, p. 330). In another article on parrot poaching, the authors looked at nest poaching of Neotropical parrots. There are a number of factors that can cause the declining of parrot populations, the two main factors are habitat loss and the capture of parrots for the pet trade (Collar \& Juniper, 1992; Juniper \& Parr, 1998). It is estimated that habitat loss affects 73 of the 93 endangered parrot 
species and that trapping for the pet trade affects 39 species (Juniper \& Parr, 1998). The article on nest poaching of Neotropical parrots set out to calculate the rates of mortality due to nest poaching in 23 studies of Neotropical parrots, which included 4,024 nesting attempts in 21 species and 14 countries (Wright, et al., 2001). In each study, investigators monitored nests during the breeding season and collected data on nesting success (Wright, et al., 2001, p. 712). The nests were then classifies as either "successful fledge" (some chicks fledged), "failed naturally" (all chicks taken by predators or died of natural causes), "poached" (all chicks taken from nest by humans), "suspected poached" (poaching suspected, but not confirmed), or "other" (sources of mortality other than the designated categories) (Wright, et al., 2001, p. 712). The "other" category only accounted for one percent of all nests studied (Wright, et al., 2001). Most of the populations studied were protected from poaching in some way, ranging from legal prohibitions against capture and trade to active patrolling of nest areas by armed guards (Wright, et al., 2001, p. 714). The effectiveness of these methods varied and investigators classified each site into one of two categories: (1) unprotected, with no active enforcement of legal protections or preventing poaching, and (2) protected to some degree of active protection for nests or nest sites (Wright, et al., 2001, p. 714).

This research found that nest poaching is a widespread and significant cause of nest mortality in Neotropical parrots and that the species experiencing nest poaching, mortality due to poaching was greater than mortality due to natural causes (Wright, et al., 2001, p. 717). These results suggest that nest poaching for the pet trade is a major conservation threat for many parrot species (Wright, et al., 2001, p. 717). In addition, the results found that the poaching rate across all studies was 30 percent of all nest observed. Thirteen studies reported poaching rates of 20 percent and four reported rates of 70 percent, where only six studies documented no nest 
poaching (Wright, et al., 2001, p. 717). Of the six studies with no nest poaching, four were found in the Caribbean region, which had lower rates of poaching than the mainland Neotropics (Wright, et al., 2001). The other two studies were conducted on the two species with the lowest economic value (Wright, et al., 2001). The research also found that poaching in protected sites was much less than poaching in unprotected sites, which suggests that active protection efforts can be effective in reducing nest poaching (Wright, et al., 2001). Poaching of parrots from the wild is an economic activity driven by the market demand for parrots as pets, the large profits from the pet industry and rural poverty in many of the countries with wild-parrot populations (Wright, et al., 2001, p. 718). The research found that the price of a parrot is set by the demand for a particular species and influenced by a species rarity, beauty, mimicry ability, personality and size (Wright, et al., 2001, p. 718). The data for this research found that poaching rates were significantly lower for species valued under $\$ 500$ and the more expensive species created greater incentives for poaching (Wright, et al., 2001, p. 718).

Pires and Clarke (2012) conducted the third study on parrot poaching, which identified that poaching significantly contributes to the endangerment of protected wildlife. This study takes a concept that says that thieves are after "hot products" which are concealable, removable, available, valuable, enjoyable and disposable (CRAVED) (Pires \& Clarke, 2012). The CRAVED concept is often used to explain theft preferences and some common forms of theft, including shoplifting, residential burglary, and auto theft (Pires \& Clarke, 2012, p. 3). However, in this study the authors take this concept and relate it to non-traditional forms of criminological research. This particular study aims to examine whether CRAVED, a general model of theft choices drawn from the routine activities and rational choice theory, can help to explain the parrot poaching rates among 22 species of Mexican parrots (Pires \& Clarke, 2012, p. 3). The 
research compares estimates of the numbers poached of the 22 species of Mexican parrots with measures of CRAVED components (Pires \& Clarke, 2012, p. 1). The research will not only help explain which species are most stolen and why, but the results will provide insight into the nature of the parrot trade (Pires \& Clarke, 2012, p. 4). The research will identify if the nature of the parrot trade is organized or whether it is more opportunistic as suggested by other literature on poaching of other endangered species (Pires \& Clarke, 2012, p. 4). The researchers state that if most parrots are taken from the wild by opportunistic poachers, then the birds taken should be the more widely available species in terms of abundance and accessibility and easier to capture (Pires \& Clarke, 2012, p. 7). The least taken species would then be the rarer, more valuable birds that require more professional expertise, organization and resources to capture (Pires \& Clarke, 2012, p. 7). Finally, the research has two main objectives: “(1) to investigate the broader applicability of CRAVED and implicitly to draw attention to the need for further work on the nature of suitable targets, and (2) to make a contribution to conservation criminology by providing information to assist thinking about the prevention of parrot poaching (Pires \& Clarke, 2012, p. 4)."

The research by Pires and Clarke (2012) found that there was a significant relationship between the elements of CRAVED and poaching of the 22 species of Mexican parrots (Pires \& Clarke, 2012, p. 13). No suitable measure could be developed for "concealable" in the CRAVED elements (Pires \& Clarke, 2012, p. 8). For "available", the authors measured the parrots in both aspects of availability, which were abundance and accessibility (Pires \& Clarke, 2012, p. 9). "Removable" was measured by the nesting type, which dictates the methods used by the parrot poachers (Pires \& Clarke, 2012, p. 10). "Valuable" and "disposable" were difficult to operationalize because the relationship between value and disposability is not straightforward 
(Pires \& Clarke, 2012, p. 11). The reason for this is because rare parrots attract higher prices and fewer buyers and thus the rare and more expensive parrots only account for about six percent of all parrots poached on an annual basis (Cantu, Saldana, Grosselet, \& Gamez, 2007). The research found that the species that are widely available and whose nestlings are easily removable were captured in larger numbers and that those that were more valuable, disposable, and enjoyable were captured in smaller numbers (Pires \& Clarke, 2012, p. 13). The main reason for this is that these species, although highly desirable, were heavily poached in the 1980 s and are now rare in the wild (Pires \& Clarke, 2012, p. 13). The research found similar results as previous research and the findings suggest that most poaching in Mexico is committed by opportunistic villagers, looking to supplement meager incomes, rather than by "professional" poachers looking to obtain large profits (Pires \& Clarke, 2012, p. 13).

The authors in this study suggest that the normal remedies for poaching, such as increased penalties, more enforcement, and more protected areas, will be of limited effectiveness (Pires \& Clarke, 2012, p. 16). The authors suggest that SCP techniques might offer a more promising approach (Pires \& Clarke, 2012, p. 16). One should focus on the six species of parrots that account for 88 percent of the birds poached in Mexico; this will yield the greatest benefits (Pires \& Clarke, 2012, p. 16). Nest poaching was found to be the most prevalent method and because parrots breed at the same time every year, one can focus on protecting the nests of these species in the breeding season (Pires \& Clarke, 2012, p. 16). Another method could be to focus on the areas where most species are concentrated. This can be done by including physical barriers to protect the nests, such as nets, CCTV surveillance and the installation of nest boxes too high for poachers to reach (Pires \& Clarke, 2012, p. 16). The authors suggest that no matter 
what approach is used, it is utterly important to include the local villagers in reducing the problem, as they are the one who are mostly responsible for it.

\section{Tiger Poaching}

Tigers (Panthera Tigris), like other endangered species, have been poached for decades and their numbers in the wild are of concern. The illegal trade in tiger products, including skins, bones, meat and tonics is a primary threat to tigers, which has led to the decline in numbers and the disappearance from areas that are suitable habitat (Chundawat, et al., 2011). Asia, which has a large population of tigers, is a densely populated and rapidly developing region that brings huge pressure on the large wild areas required for viable tiger populations (Chundawat, et al., 2011). The conversion of forestland to agriculture land, commercial logging and human settlement are the main drivers of habitat loss for the tigers (Chundawat, et al., 2011). Tigers require a healthy large prey base, but because of human development, the species they prey on are reducing and thus tigers are attacking livestock (Chundawat, et al., 2011). The attacks on livestock's and people have led to an intolerance of tigers by neighboring communities and present a challenge for the conservation of tigers (Chundawat, et al., 2011). It is estimated that there are approximately 3,948 tigers in the 13 tiger range countries, with another 2,154 in 42 protected source sites (Chundawat, et al., 2011).

A study by Plowden and Bowles (1997) on the Sumatran tiger (Panthera Tigris sumatrae) aimed to evaluate the extent and nature of the illegal hunting of tigers and the commercialization of tiger products both within and from Sumatra (Plowden \& Bowles, 1997, p. 59). The Sumatran tiger is the only one of three original species of tigers that survives in Indonesia today and their wild population is estimated to be approximately 441-679 (Linkie, Wibisono, Martyr, \& Sunarto, 2008; Plowden \& Bowles, 1997). The research found that major 
threats to the future of the tiger include trophy hunting, the use of poison to kill problem animals by farmers, and the use of bones for the Traditional Chinese Medicine (TCM) market, where they are used as cures for rheumatism and other ailments (Plowden \& Bowles, 1997, p. 59). The research for this study was conducted by covert investigation into the availability of tiger products in northern Sumatra, particularly around the city of Medan. The research was conducted by visiting various shops in the area to enquire about obtaining tiger products. The shops for this study consisted of four stores selling western-style medicines, five shops selling traditional Indonesian medicines (jamu), nine TCM shops, seven souvenir shops, and ten gold shops (Plowden \& Bowles, 1997, p. 61). Another 53 gold stores and one street market were visited in 11 towns around Ganung Leuser National Park in Aceh province (Plowden \& Bowles, 1997, p. $61)$.

The results found that out of the 88 sites visited, only 10 (11 percent), offered verified tiger products for sale, where five of the shops had bones for sale and only one had a pelt for sale (Plowden \& Bowles, 1997, p. 61). It was also discovered that none of the western pharmacies or shops selling jamu offered any tiger product for sale (Plowden \& Bowles, 1997, p. 61). Only one Chinese pharmacy had tiger products on the premises and the owner of the shop claimed that tiger bone was available at other TCM stores in Medan (Plowden \& Bowles, 1997, p. 61). The research also found that only one souvenir shop and one gold shop in Medan of 17 visited, contained tiger parts. Although the number of tiger parts found in gold shops was low, it became evident through the research, that gold shops were an important part of the tiger trade (Plowden \& Bowles, 1997, p. 61). The researcher also found that four gold shops in towns around Medan were willing to sell tiger bones. In addition, skeletons of nine tigers were observed: one at a TCM shop in Medan and eight in gold shops in Blankejeren and Tankengon (Plowden \& 
Bowles, 1997, p. 61). Tiger teeth and claws were also recorded for sale in seven gold shops and the only non-gold store that had tiger teeth or claws for sale was a souvenir shop in Medan (Plowden \& Bowles, 1997, p. 62). The research found that there was no evidence that there is organized poaching for tigers for trophy mounts or for the international trade in bones used in oriental medicine (Plowden \& Bowles, 1997, p. 64). It was apparent, however, that many tigers are killed opportunistically or deliberately by farmers are being fed into a commercial domestic market for tiger bones, skins, teeth, and claws (Plowden \& Bowles, 1997, p. 64). The authors conclude by stating that the majority of the tigers poached are done so on the edge of protected, where there is a potential for conflict between domesticated animals and tigers, therefore, the majority of the poaching is done so by local farmers who are the main suppliers of the markets in Medan (Plowden \& Bowles, 1997, p. 64).

The second review on tiger poaching is a report that was conducted by TRAFFIC on the trade of the Sumatran tiger (Shepherd \& Magnus, 2004). The Sumatran tiger is listed as critically endangered on the IUCN Red List of Threatened Species (Linkie, Wibisono, Martyr, \& Sunarto, 2008). This report organized a comprehensive survey of tiger poaching and trade in Sumatra, in an attempt to document the full extent of the problem and to provide the necessary information to management and enforcement authorities to act upon (Shepherd \& Magnus, 2004, p. vi). For this research, surveys were carried out in all eight of Sumatra in 2002, in a total of 24 towns and cities, recording 484 observations from shops and dealer sources (Shepherd \& Magnus, 2004). It was found that only seven towns in the survey did not have tiger parts for sale and in the other 17 towns a total of 117 shops and dealers were found to have tiger parts for sale (Shepherd \& Magnus, 2004, p. 67). In addition, 453 retail shops were surveyed and 86 were recorded to have tiger parts for sale, mainly canines and claws (Shepherd \& Magnus, 2004, p. 67). The research 
also found that most of the trade in skins and bones were carried out in a covert manner by a variety of dealers, where thirty-one dealer contacts were made with information on the sale of tiger parts (Shepherd \& Magnus, 2004). Contrary to what was found in the previous article by Plowden and Bowles (1997), this report found that most Sumatran tigers were found to be killed by professional or semi-professional hunters operating individually or in small groups (Shepherd \& Magnus, 2004, p. 67). It is estimated that each team kills on average two tigers annually (Shepherd \& Magnus, 2004, p. 67). In addition, the tigers were found to be killed mainly by the use of inexpensive and simple-to-make-wire cable leg-hold snares (Shepherd \& Magnus, 2004). The human-tiger conflict in Sumatra has long been a serious problem, compared to other parts of the world. Many people have been killed or wounded by tigers and the tigers frequently prey on livestock. As a result, villagers take the law into their own hands and seek to have problematic tigers killed (Shepherd \& Magnus, 2004). The numbers of tigers lost due to the human-tiger conflict are significant; however, most tigers in Sumatra are killed deliberately for commercial gain (Shepherd \& Magnus, 2004). The report found that tiger bones and other tiger parts are smuggled out of Sumatra and are sold to Korea, Taiwan, Singapore, Japan, Malaysia, and China (Shepherd \& Magnus, 2004). Finally, the report found that despite apparent progress in limiting markets for tiger bones used in Traditional Asian Medicines (TAM), there is little evidence to suggest that there is a decline in tiger poaching (Shepherd \& Magnus, 2004).

The report suggests that 78 percent or 51 Sumatran tigers are poached every year for the value of their parts in the Sumatran markets. For this reason, the report consisted of a variety of recommendations (see Shepherd \& Magnus, 2004); however, the primary recommendation for this report is that "Indonesian authorities must improve enforcement of their laws banning trade in tiger parts and products" (Shepherd \& Magnus, 2004, p. 70). Eliminating the market for tiger 
parts will in turn, reduce tiger poaching. The report suggests that this may not necessarily save the Sumatran tiger because loss of habitat through illegal logging and high levels of human-tiger conflict will continue to threaten the Sumatran tiger (Shepherd \& Magnus, 2004).

\section{Elephant Poaching}

The African elephant (Loxodonta africana) saw a decline in population from 1.3 million to 600,000 between 1979 and 1987 , and has largely been attributed to indiscriminate poaching for ivory (Douglas-Hamilton, 1987). The drastic decline in elephant populations prompted the CITES to move the African elephant from Appendix II to Appendix I, effectively banning the trade in ivory (Burton, 1999). The ivory ban was contested by several southern African countries that had thriving elephant populations, and thus saw ivory sales as a means to fund wildlife conservation and protect habitat (Maingi, Mukeka, Kyale, \& Muasya, 2012, p. 234). The ban in ivory trade was intended to increase the African elephant population, which had decreased from severe poaching in the decade before (Lemieux \& Clarke, 2009, p. 451). With the ban in place, the continents overall population of elephants increased, however, it was found that in some of the 37 countries in Africa with elephants continued to lose a large amount of elephants (Lemieux \& Clarke, 2009, p. 451). This pattern is largely explained by the presence of unregulated domestic ivory markets in and near countries with declines in elephant populations (Lemieux \& Clarke, 2009, p. 451).

Lemieux and Clarke (2009), set out to examine the effectiveness of the CITES ban on the international trade of ivory. The ban on trade regulates the trade internationally, however, it does not stipulate anything about trade within a countries borders. The countries are responsible for the presence or absence of unregulated markets in its borders (Lemieux \& Clarke, 2009, p. 454). To evaluate whether the ban on trade had an effect on the elephant population in Africa, the 
authors set out to evaluate the population numbers of elephants pre-and-post trade ban. Before the ban on ivory trade poaching was occurring throughout Africa, however, the elephant population of every country was not declining (Lemieux \& Clarke, 2009). In fact, the data for this study ranged from nearly 300,000 elephants lost in the Democratic Republic of the Congo (DRC) and a gain of 62,000 elephants in Gabon (Lemieux \& Clarke, 2009, p. 458). It was found that fifteen countries saw no change in their local populations and that only 20 African countries recorded a decline in their elephant population in the decade before the ban was implemented (Lemieux \& Clarke, 2009, p. 458). In total, it is estimated that Africa lost nearly 1 million elephants between 1979 and 1989 (Lemieux \& Clarke, 2009, p. 458).

After the ban in the ivory trade (1989-2007), the data varies between a loss of just over 60,000 elephants in the DRC and a gain of nearly 125,000 elephants in Botswana (Lemieux \& Clarke, 2009, p. 459). According to Lemieux and Clarke (2009), the ban actually increased the overall number of elephants in Africa by approximately 140,000 between 1989 and 2007. The research found that not only did the ban increase elephant numbers in certain countries, but in countries where poaching was high, it slowed down the poaching numbers and reduced the number of elephant losses (Lemieux \& Clarke, 2009, p. 459). The findings of this research are consistent with previous research, which states that the ban was successful in reversing the decline of the elephant population in Africa. Another important finding is that the changes in the elephant populations of the 37 African countries show considerable variation, where before the ban 13 countries saw an increase in their elephant population and the other countries lost nearly one million elephants (Lemieux \& Clarke, 2009, p. 463). After the ban, the same pattern was found where some countries gained elephant populations and others still continued to see declining populations (Lemieux \& Clarke, 2009, p. 463). According to the authors, this shows 
that the ban on ivory trade is unable to protect all of Africa's elephants from the ivory trade, despite its universal application (Lemieux \& Clarke, 2009, p. 463). Two important findings in this research was that "countries with unregulated markets were more likely to lose elephants during the post-ban period" and "75 percent of total elephant losses came from five countries, all of which bordered three or more unregulated countries with access to multiple unregulated markets (Lemieux \& Clarke, 2009, p. 463).” The last finding of this research was that countries that had a civil war or were highly corrupt saw a decrease in local elephant populations (Lemieux \& Clarke, 2009, p. 463).

In another study on elephant poaching in Africa, the authors aimed to describe the temporal and spatial patterns of elephant poaching in south-eastern Kenya between 1990 and 2009 (Maingi, Mukeka, Kyale, \& Muasya, 2012). In this article, the authors aimed to examine the relationships between observed patterns of poaching, and human and biophysical variables (Maingi, Mukeka, Kyale, \& Muasya, 2012). The study aimed to answer the following questions: firstly, how has elephant poaching varied seasonally and annually; secondly, what are the spatial patterns of elephant poaching in the Tsavo Conservation Area (TCA); and finally, what are the relationships between observed patterns of poaching and human and biophysical variables (Maingi, Mukeka, Kyale, \& Muasya, 2012, p. 234)? The methods for this research included using elephant poaching data and various GIS-data layers that represent human and environmental variables to describe the spatial and temporal patterns of elephant poaching (Maingi, Mukeka, Kyale, \& Muasya, 2012, p. 234).

The key findings of this research was that elephant poaching was somewhat clustered, with the majority of the poaching occurring during the dry season (Maingi, Mukeka, Kyale, \& Muasya, 2012, p. 240). Approximately 53.6 percent of all elephant poaching occurred in the dry 
season, compared to 38.2 percent in the wet season and 8.2 percent in the short-dry season (Maingi, Mukeka, Kyale, \& Muasya, 2012, p. 240). The hotspots of the poaching were identified in areas with higher road density, waterholes, rivers and streams (Maingi, Mukeka, Kyale, \& Muasya, 2012, p. 240). The results of this research found that 53.7 percent of elephants poached were found in the Tsavo East National Park and 44.8 percent of elephants poached were found in the Tsavo National Park (Maingi, Mukeka, Kyale, \& Muasya, 2012, p. 240). Finally, it was also found that the key predictors for elephant poaching in these areas were the density of elephants, conditions of vegetation, proximity to ranger bases and outposts, and densities of roads and rivers (Maingi, Mukeka, Kyale, \& Muasya, 2012, p. 240). The predictors in this explained 61.578 percent of the elephant poaching in the locations chosen (Maingi, Mukeka, Kyale, \& Muasya, 2012, p. 234). In addition, the locations of the hotspots suggest that human-elephant conflicts in the area may contribute to the poaching of the animals. The results from this study can be used by Kenyan Wildlife Service (KWS) to implement measures that ensure local community support for conservation (Maingi, Mukeka, Kyale, \& Muasya, 2012).

\section{Illegal Fishing}

Illegal, unreported and unregulated (IUU) fishing is one of the most damaging example of wildlife crime due to its reach and the extent of the market (Pires \& Moreto, 2011, p. 114). Doulman (2000) cautions that IUU fishing is found in all capture fisheries, irrespective of their location, species targeted, fishing gear used or intensity if exploitation. IUU fishing not only destabilizes the sustainable management of global fisheries, but it affects the millions of lives of the fisherman who live in impoverished rural coastal villages who rely on marine wildlife for sustenance, employment and income (Doulman, 2000; Baird, 2006). Research has found that formal enforcement and surveillance of IUU fishing is very difficult to conduct, due to the large 
areas which IUU fishing can occur (two-thirds of the Earth's surface is covered by water) (Pires \& Moreto, 2011, p. 114). In addition, the differences in resource capabilities between countries (either developed or underdeveloped countries) can alter their ability to monitor the areas which IUU fishing is done (Pires \& Moreto, 2011, p. 114). This means that alternative methods ought to be looked at for viable options for the sustainable management of fisheries, especially in the areas that include rural communities (Pires \& Moreto, 2011, p. 114). The main reason for this is that it is estimated that approximately 95 percent of the 30 million fishers in the world live in developing countries, thus an alternative approach to dealing with IUU fishing is required (Pires \& Moreto, 2011, p. 114).

The Food and Agriculture Organization of the United Nations (FAO) has in the past used a sustainable livelihoods approach, by implementing several projects in rural communities in West Africa (Pires \& Moreto, 2011, p. 114). These sustainable livelihoods attempts go beyond the traditional definitions of poverty and the means to address them. Instead, it focuses on three main aspects. Firstly, explicit focus on the abilities of the impoverished to take advantage of economic opportunities; secondly, recognize that poverty is not just financial but also includes other factors such as illiteracy and lack of social services; and finally, it must include the impoverished communities in the development of policies and programs (Krantz, 2001). One example of such project is the project implemented in Aido Beach in Benin, where the local fisherman were involved in the creation and implementation of the project which aims to catch more mature fish and not smaller or juvenile fish (FAO, 2003). This project does not only provide sustainability for the fish, but also provides a financial incentive by generating higher value fish yields for the rural fisherman (Pires \& Moreto, 2011, p. 114). 


\section{Rhino Poaching}

The focus of this paper is not on wildlife crime in general; rather it focuses on rhino poaching in South Africa. There are currently only two recent reports that have looked into the rhino-poaching problem in South Africa. The first is a report by the Wildlife Trade Monitoring Network (TRAFFIC) and the second is a report that was conducted by the Department of Environmental Affairs (DEA) South Africa.

The report by TRAFFIC is probably the most comprehensive report on the rhino poaching problem and illegal trade in rhino horn to date. The report gives information on the events and dynamics that drive an escalating trade in rhino horns from South Africa to Viet Nam (Milliken \& Shaw, 2012, p. 8). This report does acknowledge that there are other role players in the rhino horn trade in Africa and Asia, however, the report focuses on the basic supply and demand chain, where South Africa is the supply and Viet Nam is the demand (Milliken \& Shaw, 2012). The report aims to make a valuable contribution to the understanding of the main factors in both source country and end-use market that underlie the rhino crisis (Milliken \& Shaw, 2012, p. 8). In turn, this knowledge that the report offers should lead to strategies, actions and interventions that can help prevent further losses of Africa's iconic rhino species (Milliken \& Shaw, 2012, p. 8). According to Milliken and Shaw (2012, p. 8), in 2011 South Africa conserved about 83 percent of Africa's rhinos and nearly three-quarters of all wild rhinos worldwide. South Africa is one of the most biologically diverse nations around the world and has long promoted biodiversity conservation through the sustainable use of natural resources (Milliken \& Shaw, 2012, p. 8). South Africa is proud of the conservation efforts and sustainable use of natural resources that it enshrines these principles in its constitution, calling for: "a prosperous, environmentally-conscious nation, whose people are in harmonious coexistence with the natural 
environment and which derives lasting benefits from the conservation and sustainable use of its rich biological diversity (Milliken \& Shaw, 2012, p. 8).”

For the section on South Africa in this report, the authors gathered various data and historical information through a series of meetings and personal interviews with key individuals in national and provincial environmental wildlife agencies in Bloemfontein, Cape Town, Johannesburg, Nelspruit, Polokwane, Pretoria and Skukuza (Milliken \& Shaw, 2012, p. 20). The report also used a comprehensive literature search that obtained published reports and internet articles on rhino conservation and rhino poaching in South Africa (Milliken \& Shaw, 2012, p. 20). The DEA, South African National Parks (SANParks) and provincial wildlife agencies provided the data and statistics on the status of the Black and White rhinos in South Africa, as well as poaching and anti-poaching operations and details of the illicit trade and crime syndicates (Milliken \& Shaw, 2012, p. 20).

The report found that there has been a sharp increase in rhino poaching since 2007 in South Africa. The report also mentioned that rhino poaching is found throughout the year (Milliken \& Shaw, 2012). The report also found that the hardest hit areas of rhinos poached in South Africa are the Kruger National Park, the Limpopo Province, Kwa-Zulu Natal Province, North West Province and Mpumalanga Province (Milliken \& Shaw, 2012, p. 72). During the report, it became evident that the techniques used to kill rhinos have changed. The authors suggest that these new techniques are indicative of the new type of people who are behind the killing of rhinos and suggests involvement of organized crime syndicates (Milliken \& Shaw, 2012, p. 74). These results are in contrast to what other research has shown regarding organized crime involvement in wildlife crime. It was found that previously poachers in Africa were often recruited from local communities living in close proximity to protected areas, however, today it 
is found that poachers often have specialized skills, obtained from being involved in the military, police or as a game scout, all of which would have specialized training to develop tracking and shooting (Milliken \& Shaw, 2012, p. 74). It has been found that such individuals have joined the ranks of those profiting from the illegal killing of wildlife in South Africa. It was found that the methods of killing the rhinos usually involved shooting them with guns, usually AK47 assault rifles and more recently the use of skilled marksmen to kill rhinos instantly with heavy-caliber weapons, such as the .375 and .458 rifles (Milliken \& Shaw, 2012, p. 75). Another method that was found is the use of crossbows to kill rhinos, due to the silent nature of the weapon; this too requires highly developed professional skills and equipment, which are rarely available to the common poacher (Milliken \& Shaw, 2012, p. 75). It was found that groups of up to 16 individuals have been into the Kruger National Park to conduct rhino poaching and move in para-military formations to provide better protection against security patrols (Milliken \& Shaw, 2012, p. 79). It is thought that the increased size of the groups means that there is an evolution of division of labor within the gangs, where the additional members now act as protection for the skilled poachers who actually shoot the rhino (Milliken \& Shaw, 2012, p. 79). As the poaching gangs kill more rhino, they obtain more cash and therefore have access to better equipment to conduct their activities.

This report, through the help of the National Wildlife Crime Reaction Unit (NWCRU) in South Africa, has identified five levels at which rhino horn trade syndicates operate within and outside South Africa (see Figure 1.). The illicit trade in rhino horn occurs along a chain that begins at a local level in South African area, to an end-use buyer in an international level, usually Viet Nam (Milliken \& Shaw, 2012, p. 78). Middlemen buyers, exporters and couriers all play roles along the trade chain, dealing with the horns obtained from all sources, including trophy 
hunts, stock thefts and poached animals (Milliken \& Shaw, 2012, p. 78). The nature of the report by Millikan and Shaw (2012) is very detailed and lengthy, for this reason only the main findings of the paper were discussed. In short, the report found that poaching is a major problem in South Africa and if nothing is done to stop it, the rhino population in South Africa will be decreased dramatically (Milliken \& Shaw, 2012). The report also found that the individuals involved in the poaching have moved away from opportunistic poachers and have become organized syndicates (Milliken \& Shaw, 2012).

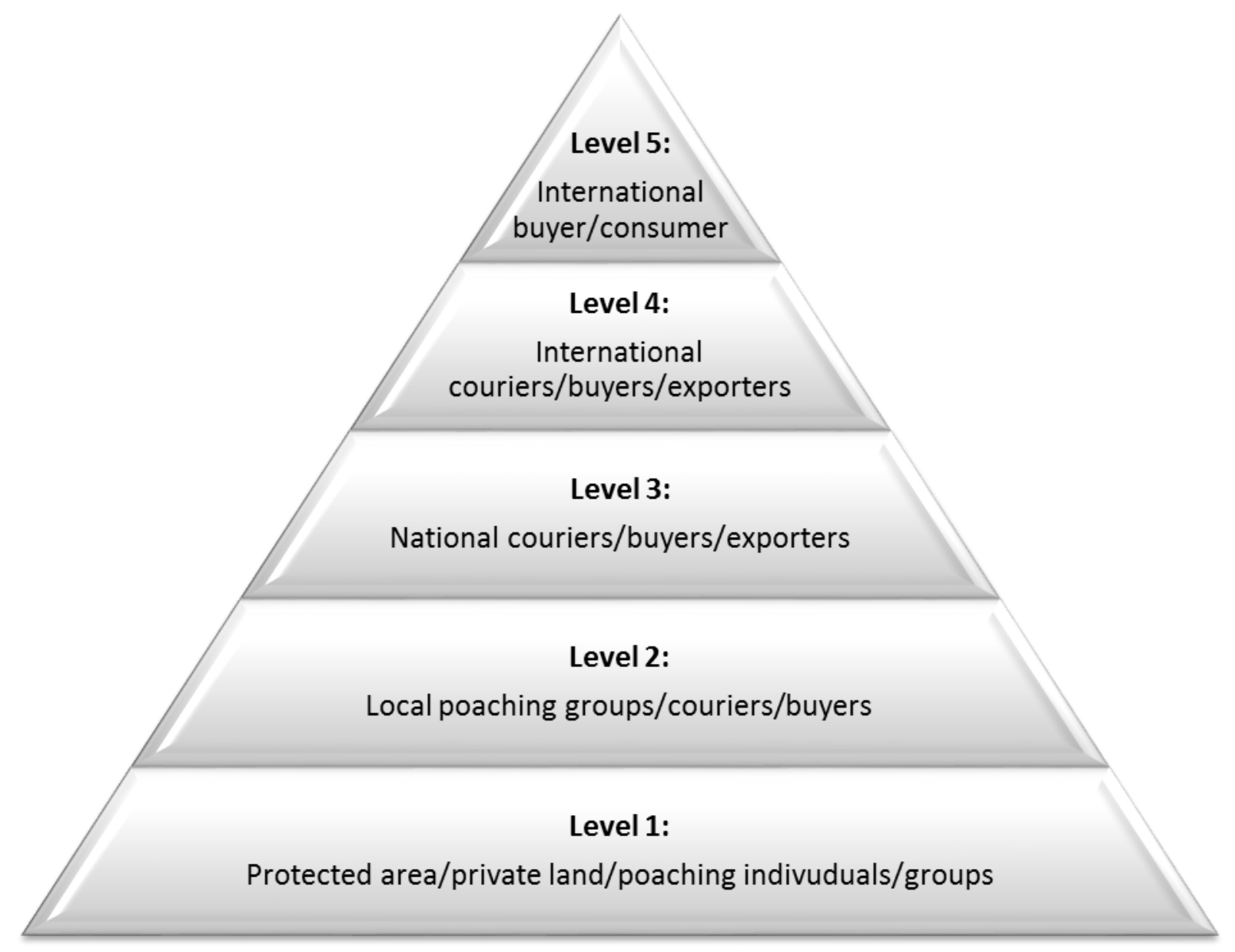

Figure 1. Chart of Levels of Organized Crime Involved in the Rhino Horn Trade. From (Milliken \& Shaw, 2012, p. 78). 
The report also identified recommendations that the South African government should implement in order to reduce the poaching of rhinos. The nest mix of corrupt wildlife professionals, corrupt government officials and hardened Asian criminal syndicates has converged to create a major problem for rhino poaching. In order to combat this, the report suggests the following recommendations:

- Make addressing rhino crime a non-negotiable, high-profile national priority;

- Address capacity and resource constraints affecting conservation authorities at national, provincial and site levels;

- Design and implement a secure, national, electronic permit system for all activities related to threatened species that links to other databases on live rhino and horn stockpiles;

- Continue to support the implementation of mandatory registration, marking and DNA sampling of legally owned rhino or horn stocks;

- Develop and enact bilateral treaties to promote collaborative law enforcement action;

- Ensure that appropriate penalties, which serve as a deterrent are given to those convicted of rhino crimes;

- Deny those with charges for rhino crimes access to continued legal access to permits;

- Improve capacity for investigations, intelligence gathering and analysis, and communication collaboration between law enforcers at local, provincial, national and international level; 
- Tighten law enforcement at all ports of entry and exit from South Africa, to detect the illegal movement of rhino horn;

- Ensure effective monitoring and regulation of sport hunting of rhinos;

- Develop better regulation of professionals within the wildlife industry;

- Continue to designate rhino crime cases to specific prosecutors in each province; and take an objective and strategic approach to assess the long-term outcomes of any future interventions in relation to global rhino conservation objectives and trade (Milliken \& Shaw, 2012, p. 13).

The last section of this report was insight into the situation in the end-use market in Viet Nam. Viet Nam is a Southeast Asian country with about 87 million people and the world's 13th largest country (Milliken \& Shaw, 2012, p. 14). It is believed to be the sole reason for the increase in rhino poaching and the drive force behind the illegal trade in rhino horn today (Milliken \& Shaw, 2012, p. 14).

For this section of the research, the research was primarily conducted via a comprehensive literature review on recent seizures, media reports of the trade, information from the internet, and an analysis of trade records in the United National Environment Program's World Conservation Monitoring Centre (UNEP-WCMC) CITES wildlife trade database (Milliken \& Shaw, 2012, p. 21). Since 2009, TRAFFIC staff have held discussions with Vietnamese medical practitioners and academics working in biological and social sciences to collect any information on the perceptions of consumers and the characteristics of the domestic rhino horn trade (Milliken \& Shaw, 2012, p. 21).

The research on Viet Nam found that Viet Nam was a rhino range state, that had Asia's only surviving population of the Critically Endangered Javan rhinoceros (Rhinoceros sondaicus 
annamiticus) (Milliken \& Shaw, 2012, p. 112). It was found that by 2010, however, the last rhino had been poached for its horn. For this reason, the Viet Nam rhino horn trade has shifted towards new sources in Africa and therefore there is an increase in rhino poaching, especially in South Africa (Milliken \& Shaw, 2012, p. 14). The research found that the demand comes from the usage of rhino horn in Viet Nam and is linked to TCM (Milliken \& Shaw, 2012, p. 14). Both Western and traditional medicines are promoted by the government, however, traditional medicines remains significant with at least 48 hospitals and institutes, over 240 departments in central and provincial hospitals, and more than 9,000 health centers licensed to practice traditional medicine (Milliken \& Shaw, 2012, p. 15). The research found that rhino horn usage in Viet Nam is linked to reducing temperature, especially internal heat in the blood and eradicating the body and blood of toxins (Milliken \& Shaw, 2012, p. 15). Rhino horn is assumed to treat ailments ranging from high fever, delirium and severe headaches to measles, convulsion, epilepsy and strokes (Milliken \& Shaw, 2012, p. 15). There has been at least five, between 2002 and 2007; comprehensive Vietnamese-language traditional medicine reports published which feature sections on rhino horn as medicine (Milliken \& Shaw, 2012, p. 15). More recently, rhino horn is now promoted as a treatment for life-threatening diseases such as cancer. Cancer causes around 82,000 deaths per year in Viet Nam and thus many turn to the belief that rhino horn can cure cancer (Milliken \& Shaw, 2012, p. 15). This being said, there is no clinical evidence of rhino horn having pharmacological value as treatment for cancer in the peer-reviewed medical literature anywhere in the world (Milliken \& Shaw, 2012, p. 15).

There are four other known important rhino horn user groups in Viet Nam. According to Milliken and Shaw (2012, p. 15), the most obsessive of rhino users in Viet Nam today is unrelated to illness and it is believed that rhino horn has detoxification values, especially after 
excessive alcohol intake and rich food. This belief in its detoxification values has given rise to an affluent group of habitual users, who routinely mix rhino horn powder with water or alcohol as a hangover cure or general health tonic (Milliken \& Shaw, 2012, p. 15). Secondly, it has been found that there is a strong social bonding element behind the consumption of rhino horn at elite group functions and between business elites (Milliken \& Shaw, 2012, p. 15). The use of rhino horn as an aphrodisiac is a common myth that many have heard before, however, Milliken and Shaw (2012, p. 15) note that there are documented cases of the social elite in Viet Nam now using it an aphrodisiac. In addition, it has been found that the extravagant use of something so rare and expensive becomes a means to flaunt ones wealth, status and success amongst friends and associates (Milliken \& Shaw, 2012, p. 15). These users are assumed to account for the greatest volume of rhino horn used in Viet Nam today and is obtained through informal channels, including social networks, internet distributors and links with government officials (Milliken \& Shaw, 2012, p. 15). The idea here is that rhino horn is now seen as a luxury goods item, it is in the same category as a luxury car. The third consumer group represents middle to upper income young mothers who keep rhino horn at hand for home for medicines to treat high fever that occurs in children (Milliken \& Shaw, 2012, p. 15). The fourth and final consumer group is individuals who embrace the cultural value of giving expensive gifts; this is usually found in the socio-economic or political elites (Milliken \& Shaw, 2012, p. 15). It has been found that rhino horn has been used as an acceptable currency for luxury products, such as a partial payment for a new car (Milliken \& Shaw, 2012, p. 15). Rhino horn is an illegal commodity, however, it is secretly traded in many local traditional medicine and wild meat markets in Viet Nam (Milliken \& Shaw, 2012, p. 16). Rhino horn can also be obtained through internet trading as well as through business trading and social networking sites, while other informal channels include 
personal connections in political, economic and social elites involved in the trade (Milliken \& Shaw, 2012, p. 15).

With the growing amount of evidence that Viet Nam is the world leader in consumption of rhino horn, the researchers have included the following recommendations for Viet Nam:

- Demonstrate strong political will to make rhino horn crime a national priority;

- Review and strengthen legislation and penalties regarding the illegal rhino horn trade;

- Address the problem of legally importing rhino horn trophies from South Africa that then enter the commercial trade;

- Restrict internet advertising and trading in rhino horn;

- Address the issue of "fake" rhino horns found in the markets;

- Develop and implement bilateral treaties to promote collaboration between law enforcement between South Africa and Viet Nam;

- Develop a strategy to track legal rhino horn trophies;

- Implement effective law enforcement strategies in the market place;

- Commit enough financial and human resources to fight rhino horn crime;

- Support research and monitoring;

- Promote demand reduction and activities; and

- Conduct clinical trial and peer review research on the medicinal properties of rhino horn as a step to promote alternative substances (Milliken \& Shaw, 2012, p. 17).

The second report that will be discussed in this section is a report that was done by the Department of Environmental Affairs South Africa on the viability of legalizing trade in rhino 
horn in South Africa (Taylor, Brebner, Coetzee, Davies-Mostert, Lindsey, Shaw, \& Sas-Rolfes, 2014). The report suggests that as of 2012, South Africa could sustain the rate of poaching that was seen in 2011 and 2012 (Taylor, et al., 2014). The reason behind this is that the population growth rate (approximately 6.5 percent for white rhinos and 5 percent for black rhinos) is higher than the death rate (natural, legal and illegal) (Taylor, et al., 2014, p. 7). It is, however, cautioned that if the poaching continues to escalate, a tipping point may be reached forcing the population into decline for the first time in over 50 years (Taylor, et al., 2014, p. 7). This would reverse the achievements of South African conservationists responsible for one of the greatest conservation success stories ever seen in large mammals (Taylor, et al., 2014, p. 7).

The driver behind the increased incidents of rhino poaching is the demand for rhino horn from Asia. This demand cannot be met by legal supplies because international trade in rhino horn was banned by CITES in 1977. South Africa was allowed to continue legal trade within its borders after the international ban, but when Asian nationals bought rhino horn through the legal permitting system and exported the horn illegally out of the country, South Africa placed a national moratorium on trade in rhino horn to prevent this fraudulent activity (Taylor, et al., 2014, p. 7). The implementation of the national moratorium coincided with the on-going surge in rhino poaching and suggests that the moratorium has contributed towards, or even caused, the current crisis (Taylor, et al., 2014, p. 7).

This report obtained its data from various sources in South Africa, including DEA, SANParks, Provincial Parks, Provincial permit offices, the IUCN, TRAFFIC and the CITES trade database (Taylor, et al., 2014, p. 8). Along with this, the report conducted survey questionnaires to 66 rhino experts and 54 private rhino owners. A total of 104 survey 
questionnaires were conducted because 16 private rhino owner surveys overlapped with rhino expert surveys (Taylor, et al., 2014, p. 8).

The report found that the rhino-poaching crisis is being driven by a demand for rhino horn that cannot be supplied through legal means because of the national and international bans (Taylor, et al., 2014, p. 8). The high price of rhino horn has encouraged the involvement of criminal syndicates and has provided strong incentives for poachers to risk their lives to acquire horns through poaching (Taylor, et al., 2014, p. 9). According to Taylor, et al. (2014, p. 9), Viet Nam is the main international market for rhino horns where wealthy consumers are using the horn as a detoxifying beverage, or desperate individuals using horn in an attempt to cure life threatening illnesses like cancer (Taylor, et al., 2014, p. 9). It was found that live sale prices of white rhinos dropped between ZAR35, 000 and ZAR60, 000 per animal (approximately USD $3,300-5,650$ at an exchange rate of 1 USD for 10.62 ZAR in April 2014) in 2009, the year the national moratorium in trade in rhino horn was implemented and the year after the surge in rhino poaching (Taylor, et al., 2014, p. 9). The expert opinion was that if the moratorium remained in place, live rhino prices would continue to decrease and if the international trade were legalized, the price of live rhinos would increase (Taylor, et al., 2014, p. 9).

With regards to the potential market for trading rhino horn, the report found that in 2012, the minimum value of rhino horn in South Africa is approximately ZAR83,720,000 (USD 7,876,963), given that that the minimum amount was ZAR35,000 (USD 3,300)/kg of horn (Taylor, et al., 2014, p. 10). The report found that 60 percent of rhino experts did not agree with the idea of lifting the national moratorium if international trade was not also legalized (Taylor, et al., 2014, p. 10). The reason for this being that even if trade was legalized within South Africa, the buyers of the horn could do nothing with it because the international trade ban is still in 
place. In addition, reasons given for this was that there is no end-user market in South Africa, so this would not deter the demand from Asia nor curb poaching (Taylor, et al., 2014, p. 10). The results suggest that 62 percent of rhino experts agreed with the idea of legalizing international trade. The main reasons given were:

- South Africa would control the supply for rhino horn, economic forces would take effect, horn prices would drop, and the incentive to poach would decrease;

- The international trade would generate funds to pay for anti-poaching activities;

- The current bans are not working and the legal trade cannot be worse;

- It is the only option that is financially sustainable;

- Rhino horn is a renewable resource and a legal supply can provide more horn to the end-user;

- There are other examples of threatened species that are recovering under legal trade (e.g. vicuna Vicugna vicugna);

- International trade will get rid of stockpiled horn which will reduce security risks of theft;

- Anti-poaching and protection cannot stop poaching alone;

- International trade in rhino horn would make live rhinos more valuable than dead rhinos, which will be the opposite to the current situation; and it is not feasible to pretend that the trends of the last four decades will be reversed by continuing with failed trade ban policies (Taylor, et al., 2014, p. 11).

With regards to the implication of lifting the national moratorium, and the international trade ban still in place, the report found that this might lead to laundering of illegal rhino horn into national trade and leakage of rhino horn into the illegal international market (Taylor, et al., 
2014, p. 11). It was also found that there was a fear that this would tarnish South Africa's international conservation reputation and that overall it would have no effect on reducing rhino poaching (Taylor, et al., 2014, p. 11). The implications of not lifting the national moratorium were that the incentive to poach rhinos will remain high and it may cause some private rhino owners to de-stock if protecting the animals becomes financially unsustainable (Taylor, et al., 2014, p. 11). This may also lead to the decrease in live-sale prices of rhinos and reduce the incentive to protect them and illegal activities may increase rather than decrease (Taylor, et al., 2014, p. 11).

The overall conclusions for this report found that South Africa should not lift the national moratorium at the present time (Taylor, et al., 2014, p. 12). Instead, South Africa should start to develop a secure national electronic permitting system to bring non-compliance issues under control, where the system must be linked to a rhino database that includes horn stockpile and DNA profile information (Taylor, et al., 2014, p. 12). The report suggests that private rhino owners must be incentivized to continue protecting rhinos during this poaching period. One way of doing this may be to legalize the international trade, however, in the meantime South Africa must continue to comply with CITES trade ban and if the country would like to legalize it, they must ensure a proposal for legalizing international trade before the deadline for submission for CITES COP17 (17th Conference of Parties of the Convention on the International Trade in Endangered Species of Wild Fauna and Flora) in 2016 (Taylor, et al., 2014, p. 12). In conjunction with the concluding remarks, the report recommends that the South African government conduct regular audits of horn stockpiles to discourage illegal sales and to increase capacity at ports of entry and exit to detect illegal wildlife products (Taylor, et al., 2014, p. 102). 


\section{Conclusion}

The above literature displayed a variety of wildlife crimes that are found around the world today. Through the literature, it became evident that many of the studies have looked at implementing some form of SCP technique in order to prevent poaching from occurring. It was found that recommendations for the prevention of rhino poaching looked at other methods such as the legalizing of trade, increase law enforcement capacities and a change in laws and policies in both Viet Nam and South Africa. Nothing was mentioned about using SCP techniques to reduce the rhino poaching numbers in South Africa. This gap that is found in the literature is the purpose of conducting the research for this thesis, if past research has recommended using SCP for preventing wildlife crime, surely SCP techniques ought to be looked at and tailor-made for the rhino poaching problem in South Africa. 


\section{CHAPTER III: THEORETICAL FOUNDATION}

For many years, criminologists have been looking at ways in which to prevent crime from happening, rather than reacting to crimes. SCP techniques have in the past proven successful in a variety of domains. The 1970s saw a change in criminology that acknowledged the impact that environmental factors may have on criminal activity (Cornish \& Clarke, 2003). During this shift, researchers began to identify that the environment was an active participant in the criminal event and had the capacity to prompt, permit and provoke offending (Newman, 1997). New ways were developed in order to consider this and research found that offenders had a level of rationality when selecting their victims (rational choice). In addition, research found that a new theoretical premise, routine activity, focused attention on situational variables and the criminal event (O'Neill \& McGloin, 2007). The result of this shift helped in the development of SCP. According to Clarke (1983, p. 225), SCP can be viewed as "comprising measures directed at highly specific forms of crime that involve the management design, or manipulation of the immediate environment in as systematic and permanent a way as possible so as to reduce the opportunities for crime and increase its risks as perceived by a wide range of offenders." This chapter of the paper will discuss how SCP has been used in the prevention of crime; in addition, it will go into detail on what SCP is, and how it can be used in the prevention of wildlife crime.

\section{SCP Case Studies}

There are over 200 evaluations of SCP projects that have been published, many showing large reductions in the specific forms of crime addressed with only limited displacement

(Guerette \& Bowers, 2009). For the purpose of this paper, however, only a few of the published projects will be outlined. The first few published projects are on general crimes and the final two studies are on the use of SCP in wildlife crime. 


\section{Target Hardening}

Preventive techniques come in a variety of methods and one such method is that of target hardening. In the early years of motor vehicles, there was very little interest of built-in security by the motor vehicle manufacturers (Webb, 1997). This caused a problem and a gradual increase was seen in motor vehicle thefts, therefore, it was necessary for car security, door-locking systems and devices for protecting ignition switches to be improved (Webb, 1997). It was found that car thieves were able to overcome the existing car security and this eventually led to the introduction of legislation in Europe and the United States in the 1960s and 1970s that required manufacturers to fit cars with anti-theft devices (Webb, 1997). The regulations that were implemented focused on preventing cars from being stolen and provided manufacturers with a number of options, including transmission locks and devices to prevent the engine from running. The favored option by nearly all manufacturers was the steering wheel or column lock (Webb, 1997, p. 47). All of the above options are what is known as target hardening in SCP techniques. The research by Webb (1997) aimed to identify if the steering column locks had any effect in reducing car thefts in Britain, Germany and the United States.

The research found that there was a considerable amount of evidence that the action taken by governments, introducing steering column locks, had a beneficial effect on motor vehicle theft (Webb, 1997, p. 57). The data found that in the three countries, overall motor vehicle theft rates either reduced or stabilized after anti-theft device legislation and agreements became effective and that this effect was sustained over long periods (Webb, 1997, p. 57). It was found that the vehicle theft patterns in the three countries reflect the quickness in which vehicles were protected by steering column locks. Germany had an immediate reduction in vehicle theft because of the anti-theft policy, which required all cars and motor cycles to be fitted with 
steering column locks within a short period (Webb, 1997, p. 58). The United States, however, only required new cars to be fitted with steering column locks and thus saw a longer time to see a reduction compared to Germany (Webb, 1997, p. 56). Britain was the only country that found that the anti-theft devices were less effective at reducing car theft (Webb, 1997, p. 54).

Displacement of crimes was found in all three countries, where theft from vehicles increased after the anti-theft policies (Webb, 1997, p. 53).

\section{Access Control}

During the 1960s and 1970s, a characteristic of the British medium-high-density public housing was the overhead walkway system (Poyner, 1997a, p. 60). This system saw housing blocks that were connected by a network of walkways and corridors on several levels above ground that enabled pedestrians to move along the estate without the need to return to ground level. This network of corridors and walkways saw an increase of crime in the mid-1980s and residents and visitors feared being victimized (Poyner, 1997a, p. 60). In 1982, seven walkways had been removed in the Lisson Green Estate and the authors used this to assess the effects of this technique to reduce crime.

Overall, the research found that the changes to the walkway system had some beneficial effect on crime (Poyner, 1997a, p. 70). The effects were very specific and limited to robberies and snatches that took place on the walkways where the walkways were enclosed (Poyner, 1997a, p. 70). The removal or changing of the walkway system had no effect on crimes such as burglary (Poyner, 1997a, p. 70). In addition to the reduction of robberies and snatches, residents and visitors of the building felt safer and feared less to become victimized (Poyner, 1997a). 


\section{Deflecting Offenders}

Prostitution and curb-crawling (seeking prostitution) have been associated with a variety of other crimes that tend to happen in the areas where prostitution happens (Matthews, 1997). The areas, known as "red light" areas, often cause an increase in harassment, intimidation and have been linked to an increase of motor vehicle crime, burglary and other major crimes (Matthews, 1997). Finsbury Park in North London had seen an increase of prostitution and other crimes between 1980 and 1986 (Matthews, 1997). In order to reduce crime and prostitution a multi-agency approach was developed, where the police worked closely with the local residents and the local authority to develop a response that involved new styles of intensive policing, combined with a traffic management scheme that was designed to reduce or remove curbcrawling and soliciting in the area (Matthews, 1997, p. 76). The response for this problem included a 16-strong vice squad, intensive policing and eventually a road closure scheme (Matthews, 1997).

The results for this research found that the total number of crimes reported in the area had reduced from 475 in 1984 to 275 in 1985 (Matthews, 1997, p. 79). This shows that the multiagency approach had a positive effect on reducing crimes in the area. In addition, the multiagency approach resulted in an increased sense of security for the female residents of the area; a reduction in the volume of traffic, mainly at night; an improved relationship among the police, the public and local authority; and it was found that displacement of crimes did not occur (Matthews, 1997, p. 79). Overall, the research found that the problems associated with prostitution and curb crawling can be effectively overcome through a multi-agency initiative and changes in environmental design (Matthews, 1997, p. 81). It also found that it is vitally important for any successful strategy to include the cooperation of the local residents (Matthews, 1997, p. 
81). By reducing the chances for offending to occur, the multi-agency approach was able to reduce the amount of crimes and ultimately bring cohesiveness and sense of safety into the community.

\section{Entry/Exit Screening}

Electronic article surveillance (EAS) is a term used to describe retail anti-theft protection systems for both apparel and packaged goods (DiLonardo, 1997, p. 123). This system was introduced in 1968-69 and has been in widespread use since the mid-1980s (DiLonardo, 1997). This system uses an electronically detectable element (tag) which is pinned onto a garment or affixed via adhesive to the item to be protected. Transmitters and receivers are placed at store exits in order to detect the presence of the tags as shoppers leave the stores. At the point of purchase, these tags are usually deactivated or removed so that the purchaser may leave the shop without the alarm going off (DiLonardo, 1997, p. 123). According to DiLonardo (1997, p. 123) these systems have proved to be an effective psychological and physical deterrent to shoplifting, and in recent years technological advancement has seen these products become more reliable, smaller and less expensive.

One small study on the psychological deterrence of EAS was conducted at the University of Wisconsin-Whitewater. The research attempted to quantify whether there was a significance difference in the rate of book theft before and after installation of EAS (Scherdin, 1986). The research concluded that theft levels were reduced for both books, which were protected by EAS, and audiovisual materials, which were not protected by EAS (Scherdin, 1986). In another study DiLonardo (1997), the author set out to firstly identify if EAS will reduce inventory shortage, and if so, by how much; secondly, what is the effect on shortage if EAS is removed, then reinstalled, and finally how can the effects of EAS be measured if the equipment is installed over 
a long period of time (DiLonardo, 1997)? The research found that stores without EAS suffered greater shortages of stock than stores with EAS. Stores with EAS had a decrease of around 17 percent of stock shortage compared to stores without EAS who had an increase by 30 percent over 5 years (DiLonardo, 1997, p. 127).Secondly, the research found that when EAS was installed, removed, and then reinstalled again, the departments shortage of stock dropped 47 percent during the first year after installation (DiLonardo, 1997, p. 127). Once the EAS was removed, the shortages rose up 7.7 percent (DiLonardo, 1997, p. 128). The EAS system was then reinstalled and shortages dropped to 2.9 percent (DiLonardo, 1997, p. 128). Overall, the amount that EAS was able to save a store from implementing it was approximately $\$ 378,000$ (DiLonardo, 1997, p. 128).

\section{Formal Surveillance}

In another study, Poyner (1997b) set out to identify if situational measures for crime prevention can be used in what is considered a stable setting and measure the effect on crime. This article evaluated two parking lots in England and looked at two kinds of auto crime, stealing cars and theft from cars (Poyner, 1997b). It is suggested that these two types of auto crime require different preventive measures (Poyner, 1997b, p. 158).

The first case study was a public parking garage in the town center of Dover in Kent, England. This building had suffered from vandalism and theft for a long time and security for the building was provided for by a private security company that patrolled at night and inspectors from the town authority during the day (Poyner, 1997b). These measures were found to be ineffective as vandalism, including graffiti and damage to windows, lifts, doors, and fire extinguishers continued to increase (Poyner, 1997b, p. 158). In addition, auto crime and thefts from cars was a problem and had been reported to the police (Poyner, 1997b). In order to 
improve security, a package of measures was developed in order to prevent the use of the parking garage by youth who could gain access by climbing over ground level walls. In order to prevent unwanted access to the building the low-level walls at ground level were filled with wire mesh (Poyner, 1997b, p. 158). The pedestrian entrance by the stair and lift lobby was fitted with a self-closing steel door so that it could only be used as an exit, which made the only pedestrian entrance via the main entrance/exit (Poyner, 1997b, p. 158). Another two measures were used to enhance the surveillance of the main entrance/exit, which included improving lighting at the main entrance and pedestrian exit door and an office was constructed next to the main entrance for the use of a taxi company (Poyner, 1997b, p. 158). The measures, which were implemented during the last three months of 1983, were found to have reduced vandalism and thus reduced costs to maintenance and repairs (Poyner, 1997b, p. 158). In addition, these measures saw all crime recorded go down from 96 reported crimes before the measures (1982/1983) to 49 after the measures (1984/1985) (Poyner, 1997b, p. 160). Theft from vehicles was also reduced from 42 cases before the measures (1982/1983) to 33 after the measures (1984/19845) (Poyner, 1997b, p. 160). Finally, theft of vehicles was also reduced from 38 (1982/1983) to seven (1984/1985) because of the implementation of the measures (Poyner, 1997b, p. 161).

The second case study is of security measures introduced to car parking at the University of Surrey at Guildford, England (Poyner, 1997b, p. 162). There are several large parking lots available along a perimeter roadway around the campus and some distance from the university buildings. Access to these perimeter-parking areas is via a road that has a manned security gate; however, these parking lots have suffered a considerable amount of crime (Poyner, 1997b, p. 162). It was found that auto crime was one of the main security problems facing the university and measures that were proposed was to increase the surveillance of the three main perimeter 
parking lots, in the form of lighting and by cutting back or pruning of landscape planting and tress in and around the parking lots (Poyner, 1997b, p. 162). In addition, a Close-Circuit Television (CCTV) camera would be set up on a tower overlooking the two largest parking lots (Poyner, 1997b, p. 162). The camera would be able to scan most of the parking facilities and was equipped with infrared sensing and loudspeakers through which the security guards could give warnings (Poyner, 1997b, p. 162). The landscape foliage was done in September 1985 and the CCTV installation was completed and running by March 1986 (Poyner, 1997b, p. 163).

The results for these measures found that theft from cars was reduced from 61 incidents in 1984 and 92 incidents in 1985 to only 31 incidents in 1986. Additionally, theft of vehicles was reduced from 5 in 1984 and 15 in 1985 to 12 in 1986. Finally, damage to vehicles was reduced from 82 in 1984 and 31 in 1985 to 65 in 1986 (Poyner, 1997b, p. 163). Total incidents of crime were reduced from 82 in 1984 and 138 in 1985 to 65 incidents in 1986 (Poyner, 1997b, p. 163). The results from the above studies show that although the crimes may be similar in nature, the measures that are used to reduce the criminal activity may differ, depending on the environment.

\section{The Problems of Enforcement}

Wellsmith (2011, p. 127) stated that criminology can actively contribute in the field of environmental crime reduction through approaches such as SCP. Wellsmith (2011) considers the problems with relying on an enforcement technique for controlling wildlife crime, offenses against the environment and outlines alternative forms of control. Wellsmith (2011) outlines the legislative framework that criminalized harm or exploitation of wildlife and the main enforcement techniques used in wildlife crime in England and Wales. Throughout her manuscript, the author critically assessed the problems that face the enforcement technique. These problems include under resourcing and marginalization of this area of crime and the 
response to it; the large dark figure of wildlife crime and the lack of truth known about it; the possibility of corruption amongst those responsible for enforcing the legislation, mainly in developing countries; the lack of seriousness attached to wildlife crimes and at times they are not even viewed as criminal and finally the overall lack of or limited deterrent effect, due to the lack of certainty of detection and any punishment (Wellsmith, 2011, p. 134; Armitage, 2011, p. 84). Through thorough research within the field of environmental crime, the author states that only an estimated 10 percent of known environmental crimes are prosecuted in court and that a large proportion of offenses never come to the attention of authorities (Wellsmith, 2011, p. 135). Additionally, the author explains how the severity of punishment, if caught, rarely outweighs the financial benefits that are associated with such offences (Wellsmith, 2011, p. 134). This information is of importance, as it is closely related to the rational choice theory, which has that the offender will look at the cost and benefit before committing a crime. The author highlights the cost benefit analyses by using a study by Akella and Cannon (2004) that used case studies in four countries to consider the deterrent effects of conservation legislation.

Akella and Cannon (2004) used calculations to find the probability for detection, arrest given detection, prosecution given arrest, conviction given prosecution, value of fine, and time from detection to fine, which was then multiplied by a negative interest rate (cited from Wellsmith, 2011, p. 133). In other words, Akella and Cannon (2004) were assessing the certainty, severity, and speed of deterrence to calculate an economic risk measure that could be compared to the benefits of offending (Wellsmith, 2011, p. 133). The researchers found that in all four of their cases studies, the risk of punishment was low and the economic disincentive of punishment varied from $\$ 0.09$ to $\$ 6.44$, with profits from offending ranging from $\$ 70.57$ to $\$ 91,967.36$ (Akella \& Cannon, 2004). From these results, one is able to see that with the risk of 
detection being low and the financial benefits outweighing the potential costs, the key factors upon the deterrent principles are not being met in relation to wildlife crime.

Wellsmith (2011) questions why those who have been instructed to reduce environmental crime focus on enforcement at the expense of alternative approaches. Additionally, Wellsmith (2011, p. 140) insists that weak or ineffective enforcement needs to be addressed in order to have a greater impact on the reduction of wildlife crime and the harms associated with it. Wellsmith (2011, p. 141) mentions that such responses can be categorized as either improving enforcement or alternative forms of control. Improving enforcement would include providing more resources; increase efforts to improve reporting and recording data and intelligence gathering; dealing with corruption; increasing the seriousness with which wildlife crimes are viewed; and increasing the deterrent effect of sentencing through greater conviction rates and more severe punishments (Wellsmith, 2011, p. 141). Another way of improving enforcement is using a market reduction approach (MRA) and how this can be used for tackling illicit trade in endangered species (Schneider, 2008 cited from Wellsmith, 2011, p. 126).

Criminological research has shown that even some of the most severe deterrents, including the death penalty, do not always work (Chan \& Oxley, 2004). Improving enforcement is not going to prevent wildlife crime from happening; it is only one aspect that can help prevent it from happening, therefore the next response to reducing wildlife crime is through alternative forms of control. Alternative forms of control include offering non-crime alternatives to those involved in wildlife crime and moving away from enforcement based approaches to place a greater importance on prevention, particularly the methods used in SCP (Armitage, 2011, p. 84; Wellsmith, 2011, p. 142). According to Wellsmith (2011, p.142), conservation research suggests that much of wildlife crime is committed as a response to local conditions. This is mainly the 
case in developing countries, where crime such as killing, trapping, persecuting, and poaching animals, are often committed by subsistence offenders who see the animals as a food source or as threats to crops (Bulte \& Rondeau, 2007; Engler \& Parry-Jones, 2007; McMullan \& Perrier, 2002; Rao, Maikhuri, \& Saxena, 2002; Wellsmith, 2011, p. 142). This may be true in previous studies; it is not found to be the same as in rhino poaching, where offenders are part of a larger trade network that are incentivized by the material gain resulting from their actions. Therefore, in conjunction with improved enforcement one could make legal activities be seen as more rewarding than offending (Wellsmith, 2011, p. 143). This can be done by using a provision of alternative subsistence schemes or by employing members of the local community, including poachers as rangers (Wellsmith, 2011, p. 143). The main idea here is to educate the local community about the value of the wildlife and explain how the animals are more valuable to the communities alive and protected in their natural habitats, then captured or poached. By employing members of the local communities, the local residents will feel included in the business and will understand that the animals are a revenue of income and are more valuable alive than dead.

Another aspect of alternative forms of control can be the use of public awareness campaigns, by NGOs, which highlight the negative impact of wildlife crimes. NGOs are able to collaborate with conservation and enforcement agencies and are able to supply financial support. According to Wellsmith (2011, p. 143), NGOs are in a better position than enforcement agencies to implement and motivate incentive schemes for sustainable and non-criminal activities.

As Wellsmith (2011, p. 143) highlights in her article, preventing a crime from taking place is always preferable than relying upon detection and punishment after the crime has occurred. In wildlife crime, the result of the crime may result in the extinction of a species, thus 
prevention is more crucial to reduce such risks (Wellsmith, 2011, p. 143). The final aspect that Wellsmith (2011, p. 143) mentions in her article is the use of POP and SCP. According to Wellsmith (2011, p. 143), SCP "seeks to manipulate the immediate environment in which offending opportunities are presented," this can be done by preventing the three main ingredients of crime from coming together (routine activities theory), a motivated offender, suitable target and the absence of a capable guardian (Cohen \& Felson, 1979; Felson, 1995). It can also be done by pushing the offender towards non-criminal decisions by increasing the perceived risks or effort of offending, decreasing the perceived benefits (rational choice theory) of offending, and reducing any excuses for offending (Cornish \& Clarke, 2003).

\section{Preventing Wildlife Crime}

In an article by Pires and Moreto (2011), the authors applied SCP techniques to the reduction of wildlife crime. In this article, the authors highlight how most of the time, the common response to reducing wildlife crime has been the creation of laws and international trade agreements. This approach, as noted by the authors, has failed to take into account the fact that most of the offenders are locals, motivated by financial gain and often opportunistic and not organized crime groups (Pires \& Moreto, 2011, p. 102). The locals subsist on very little income and take advantage of flora and fauna species that are in close proximity to their homes, where they conduct their routine activities and can easily sell the product to a middleman or market (Pires \& Moreto, 2011, p. 102). Illegal wildlife trade is often a secondary and sometimes a primary source of income for many impoverished communities around the world. Therefore any solutions in tackling the illegal trade in wildlife must first understand that the livelihoods of the locals depend on exploiting the species for their monetary gain, thus in order to prevent poaching, one ought to come up with viable alternatives (Pires \& Moreto, 2011, p. 102). 
Conservation biology literature has found that tougher anti-poaching laws and increasing law enforcement resources are a way forward or a solution to the illicit trade in wildlife (Pires \& Moreto, 2011, p. 106). As noted previously in this chapter, criminological research has argued that deterrence has had insignificant effects on crime reduction (Kennedy, 2009; Pratt \& Cullen, 2005). Deterrent driven practices such as police crackdowns will have no long-term effect in reducing wildlife crime, given the temporary nature and focus of the crackdown (Pires \& Moreto, 2011, p. 106). Once law enforcement has reduced their presence and goes back to their normal routines, the individuals involved in poaching and illegal wildlife trade continue their illegal activities. According to Pires and Moreto (2011, p. 106), police crackdowns are also ineffective because many of the poachers and locals see wildlife crimes as minor offenses. It is also difficult to punish more poachers, as law enforcement would risk the chances of losing the support of the local communities (Pires \& Clarke, 2012, p. 137). The support of local communities is essential to the success of conservation solution because the local communities are most involved in the poaching of the animals (Pires \& Moreto, 2011, p. 106). Pires and Moreto (2011, p. 106) also state that even if underdeveloped countries had an increase in law enforcement resources, this would do little to disrupt the illicit trade in wildlife products. This is mainly due to wildlife crime literature which reveals that law enforcement resources in underdeveloped countries are often lacking and corrupt (Cantu, Saldana, Grosselet, \& Gamez, 2007; Hauck \& Sweijd, 1999; Lee, Gorog, Dwiyahreni, Siwu, Riley, Alexander, Paoli, Ramono, 2005; Moyle, 2009; Nellemann \& Refisch, 2010; Nijman, 2009; Project Tiger, 2005; TRAFFIC, 2008; Smith \& Anderson, 2004; Wellsmith, 2010 cited from Pires and Moreto, 2011). Even if some countries had more resources to combat the illegal wildlife trade, actual guarding of the 
wildlife would be near impossible due to the amount of land that would need to be patrolled (Pires \& Moreto, 2011, p. 106).

With regards to SCP, Pires and Moreto (2011, p. 107) state that applying SCP to wildlife poaching can be very helpful in reducing the illegal wildlife trade in the near future. The authors argue that the application of SCP to wildlife crime presents a unique and viable option to its reduction (Pires \& Moreto, 2011, p. 107). Situational crime prevention can be defined as a practical approach to address specific types of crimes, with a specific focus on instigating changes to the environment or management of such an environment in order to prevent opportunities for offending (Clarke, 1999; Clarke, 2008; Clarke, 2009). Pires and Moreto (2011) argue that the opportunistic factors that lead to wildlife crime are similar to those for the more "traditional" property crime, including accessibility and abundance. The authors highlight the importance of SCP by implementing solutions and interventions that are locally targeted, where SCP creates opportunity for preventative approaches to be targeted to the issues and concerns at a community level (Pires \& Moreto, 2011, p. 107). This approach is in stark contrast to many of the current wildlife policies that tend to be focused at the international and national level. Research has shown that blanket bans on wildlife trade are not always a good policy. In Mexico, for example, making parrot poaching illegal may not reduce the illegal trade, just as banning the ivory trade did not stop Asian and a few African countries from continuing elephant poaching (Lemieux \& Clarke, 2009; Smith, Muir, Walpole, Balmford, \& Leader-Williams, 2003). In order to reduce the illegal wildlife trade, one would need to understand the opportunities that arise within each stage of the chain in context of the local environment (Pires \& Moreto, 2011, p. 109). One example is found in Lemieux and Clarke's (2009) study, which found that most African countries had an increase in elephant populations after the CITIES ban on the ivory trade 
in 1989. However, they did find that some countries had experienced a decline in elephant populations, after 1989, and this was due to the presence of an unregulated domestic ivory market in and around those specific countries (Lemieux \& Clarke, 2009, p. 451). Thus, it shows that the accessibility to numerous markets appeared to be an incentive to continue elephant poaching and therefore eliminating unregulated markets could have the biggest impact on reducing elephant poaching, in conjunction with an international ivory trade ban (Pires \& Moreto, 2011, p. 109).

It is important to note that what may work in one community or country, may not necessarily work in another. That is why it is important to understand the problem from root upwards. If one is able to understand the cultural make up and the background to a community and problem, one will be able to come up with suitable and viable solutions to a problem. This is especially true in the case of rhino poaching in South Africa. Currently, there are international and national rhino horn trade bans in South Africa. This is just one-step to the prevention of rhino poaching. The one aspect that is missing is the community aspect. In order to prevent rhino poaching, one needs to examine and understand the community from which the rhinos are poached and identify viable, legal, alternatives for the poachers. One method of doing this is by evaluating and implementing alternative approaches.

\section{Alternative Approaches}

According to Pires and Moreto (2011, p. 103) “alternative conservation solutions and wildlife management systems have been receiving more attention and have become more utilized as a small-scale approach in reducing wildlife poaching." Alternative approaches provide other options for locals to abstain from poaching, by creating economic interests in the conservation of the wildlife around them (Pires \& Moreto, 2011, p. 103). Alternative approaches are based on 
three premises: (1) it is the locals who are committing the majority of wildlife poaching and not outsiders, (2) these individuals are motivated by generating an income, (3) anti-poaching laws and tougher sentencing have had no effect on reducing poaching and the illegal wildlife trade (Pires \& Moreto, 2011, p. 103). In South Africa, two of the three premises are met in the crime of rhino poaching. First, the majority of the time it is outsiders who are the ones committing the poaching, however, it has been found that in all incidents of rhino poaching, there is always one local who acts as a spotter for the poaching group. Second, the outside poachers and local spotters are motivated by generating an income and finally a tougher stance on poaching has had little effect on reducing poaching. Using the approach of targeting locals may result in the reduction of poaching in the long run (Pires \& Moreto, 2011, p. 103). This perspective stresses that in order to prevent poaching; community-based enforcement needs to be the priority over formal social control by the government. According to Pires and Moreto (2011, p. 103), it recognizes that law enforcement can do very little to deter poachers, given that there is a lack of resources, too much land to patrol and law enforcement exhibit a general indifference to wildlife crimes.

\section{Situational Crime Prevention (SCP)}

According to Clarke (1997, p. 4), SCP can be defined as opportunity reducing measures that: 1) are directed at highly specific forms of crime, 2) involve the management, design or manipulation of the immediate environment in a systematic and permanent way, and 3) make crime more difficult and risky or less rewarding and excusable as judged by a wide range of offenders. Another way of looking at SCP is that it aims to reduce the number of crime events by focusing on limiting the opportunities of crime to occur. Some of the strategies in SCP include: target hardening, improving surveillance of areas that attract crime, deflecting potential offenders 
from settings where crimes may occur, making changes to streets or building to make them safer, using common sense to stop criminals, using neighborhood watches and working with different agencies.

As noted by Clarke (1997, p. 4), there are several aspects of the definition of SCP that need to be discussed further. First, the definition makes it clear that SCP measures ought to be tailored to specific categories of crime. Poyner and Webb (1991) stated that preventing domestic burglaries targeting electronic goods may require different measures from those needed to prevent domestic burglaries on cash and jewelry, given the different nature of the crimes and locations where the crimes occur (cited from Clarke, 1997). Cash and jewelry burglaries generally take place in the city center in older homes, with the offenders on foot. Electronic burglaries, on the other hand, are done in newer homes, in the suburbs of the city, which requires that the offender have a vehicle to transport the stolen goods (Poyner \& Webb, 1991). Considered another way, one measure that may be successful at reducing rhino poaching in Kruger National Park, may not necessarily reduce rhino poaching in the North West Province of South Africa. Although the crimes are the same, the methods for conducting the poaching are somewhat different. For example, poachers from Mozambique are able to jump the fence or walk into Kruger National Park and obtain the rhino horn on foot, whereas in the North West Province, the Mozambican poachers need a vehicle to get there and are unaware of the terrain, so would need the assistance of a local. Thus, it is important to look at the problem from the ground upwards and understand the make-up of a community and game reserve. Environmental factors are utterly important in SCP and understanding the difference in environment can help with the implementation of different measures. If one is able to dissect the problem into smaller pieces and understand each one of those pieces, only then can viable measures be implemented. 
The second important feature of the definition is that it provides that a wide range of offenders, attempting to satisfy a variety of motives and employing multiple methods may be involved in even highly specific offenses (Clarke, 1997, p. 4). In addition, SCP recognizes that all people have the same probability of committing crime, depending on the circumstances in which they find themselves, thus SCP does not differentiate between criminals and others (Clarke, 1997, p. 4). This aspect of the definition can be applied to rhino poaching, as there are wide varieties of individuals who have committed rhino poaching in the past. Some poachers are poor individuals who are trying to obtain an income, whereas others are game reserve owners or game rangers, who are looking to make extra money (Milliken \& Shaw, 2012). The methods of committing rhino poaching also vary, depending on the skills and organized manner of the individual. For example, some poachers have access to silenced weapons; others still use traditional means, such as snares and poisoned arrows or spears.

The third point from this definition is that by changing the environment, one is able to change the assessments made by potential offenders about the costs and benefits associated with the particular crimes (Clarke, 1997, p. 5). This implies that there is some rationality by the offender and there is a degree of adaptability (Clarke, 1997, p. 5). Relating this to rhino poaching does not mean to change the environment of the rhinos, instead it simply means that if changes are made regarding the protection of rhinos, this can lead to greater costs than benefits to the poachers.

The fourth important part of the definition recognizes that the decisions made by offenders are done so by evaluating the moral costs of offending (Clarke, 1997, p. 5). We may all be willing to illegally download a new song or movie off the internet, however, very few of us would be willing to murder somebody. Not all offenses are seen as equally wrong or disgraceful 
and this is especially true in different cultures around the world. The idea of poaching in a South African cultural context often brings about the idea of the "Robin Hood" effect, where the poachers are idolized by their communities as they engage in stealing from the rich and giving to the poor. To some, wildlife crime or poaching is not seen as a reprehensible crime, but to others it is disgraceful. According to Clarke (1997, p. 5) "this means that making it harder to find excuses for criminal action may sometimes be an effective opportunity-reduction technique." The final part of the definition is designed to be general in that it makes no mention of any particular crime (Clarke, 1997, p. 5). Therefore, SCP is assumed applicable to every kind of crime and not to only opportunistic or property offenses, but also to more organized and deeply motivated offenses (Clarke, 1997, p. 5).

\section{The Four Components of SCP}

From what has been mentioned, the definition of SCP represents problem-solving techniques, which can be undertaken by managers in a variety of public and private agencies (Clarke, 1997, p. 6). In order to understand how SCP can work for a specific crime or problem, one needs to be able to understand the framework in which SCP was intended. According to Clarke (1997, p. 6), the framework has four components:

1. A theoretical foundation drawing principally upon routine activity and rational choice approaches, one can also add problem oriented policing, community oriented policing and environmental criminology here,

2. A standard methodology based on the action research paradigm,

3. A set of opportunity-reducing techniques, and

4. A body of evaluated practice including studies of displacement. 
The theories of routine activity and rational choice will be discussed later in this chapter, thus only the second, third and fourth components of the framework will be discussed.

\section{The Action Research Methodology}

This part of the framework is where researchers and practitioners work together to analyze and define the problem, as well as to identify and try out possible solutions, to evaluate the results and if necessary repeat the cycle until success is achieved (Koshy, Koshy, \& Waterman, 2011, p. 2; Lewin, 1947). The idea here is that it is a collaborative effort, undertaken by individuals with a common purpose or goal (Koshy, Koshy, \& Waterman, 2011, p. 3). This comes from the understanding that in theory a solution may work to solve a problem, however, in reality that solution will not work. Thus, it is important to get practitioners and researchers together, to share their ideas and come up with viable solutions to a problem. The actions research methodology can be seen in the five stages of a situational prevention project (Gladstone, 1980).

1. Collection of data about the nature and dimensions of the specific crime problem;

2. Analysis of the situational conditions that permit or facilitate the commission of the crimes in question;

3. Systematic study of possible means of blocking opportunities for these particular crimes, including analysis of costs;

4. Implementation of the most promising, feasible and economic measures;

5. Monitoring of results and dissemination of experience. 
These five stages of a situational prevention project are very similar to what is found in POP, which will be discussed later on in this chapter. The third part of the framework is identifying a set of possible opportunity-reducing techniques.

\section{Twenty-Five Techniques of Situational Prevention}

Clarke's (1997, p. 18), highlighted sixteen opportunity-reducing techniques. Since then the original sixteen techniques of situational prevention have been expanded to twenty-five. Table 2 lists the twenty-five techniques that can be used in situational prevention. There are five mechanisms that are involved in the creation of the techniques; the first mechanism is to increase the effort. Under this mechanism there are a further five sub-categories which are target harden, control access to facilities, screen exits, deflect offenders and control tools/weapons (Schneider, 2012, p. 182). This mechanism is designed to increase the effort that the offender has to put in, in order to commit the crime by making it more difficult for the offender. The second mechanism is to increase the risk. The techniques included in the mechanism are extended guardianship, assistance with natural surveillance, reduction of anonymity, utilization of place managers and the strengthening of formal surveillance (Schneider, 2012, p. 183). This mechanism is designed to increase the risk to the offender, in order to prevent a potential offender from committing a crime. The third mechanism is to decrease the rewards. In this category, the techniques used are concealment of targets, removal of targets, identification of property, the disruption of markets and denial of benefits (Schneider, 2012, p. 183). This mechanism is designed to decrease the benefits to the offender for committing the crime, thus reducing the chances of a rational offender choosing to commit the crime. A good method in this mechanism would be to use a MRA that would help reduce the rewards gained by offenders (Schneider, 2012, p. 183). The fourth mechanism is to reduce provocations. In order to reduce provocations the following 
techniques can be used: reduction of frustrations and stress, avoidance of disputes, reduction of emotional arousal, neutralization of peer pressure, and the discouragement of imitation (Schneider, 2012, p. 184). This mechanism aims to reduce any confrontations or arguments in order to prevent possible criminal activities. The final mechanism within the matrix is to remove any excuses. In order to remove any excuses the following techniques are proposed: setting rules, posting of instructions, alerting of ones conscious, and assist in compliance and controlling drugs and alcohol (Schneider, 2012, p. 185). The goal of this mechanism is to reduce and remove any excuses that the offender may have for their reason for committing a crime.

In order to comprehend how the twenty-five techniques of situational prevention are relative to this paper, the twenty-five techniques of situation crime prevention for endangered species need to be discussed. In the prevention, techniques for endangered species the five main mechanisms do not change as these are the foundations for situation prevention. In addition, the sub categories for each mechanism do not change either. The only aspects that change are the techniques that can be used for prevention in each sub-category (See Table 3). SCP techniques were highlighted in Schneider (2012). The idea for creating tailor-made techniques is because each crime type is different and thus specific techniques are meant to be used through correct analysis on specific crimes.

\section{Body of Evaluated Practice Including Displacement}

According to Clarke (1997, p. 28), under the assumptions of traditional criminological theory, situational variables just determines the time and place of offending. Therefore, if one manipulates the situation, then offenders would simply shift their attention to some other target, time or place, change their tactics or even switch to another type of crime (Clarke, 1997, p. 28). This may be true for certain crime, but under the rational choice theory, displacement is no 
longer seen as inevitable, but rather depends upon the offenders judgments about alternative crimes (Clarke, 1997, p. 28). If the alternatives are not viable, then the offender may settle for smaller criminal rewards or for a lower rate of crime (Clarke, 1997, p. 28). In the case of prevention of rhino poaching, SCP techniques used may in fact displace crime from one game reserve to another. However, in the case of the Kruger National Park, this is not necessarily a bad thing. Kruger National Park is the currently the hardest hit area of rhino poaching in South Africa, thus if poaching is displaced, it will bring relief to a population of repeatedly victimized groups of rhinos. 


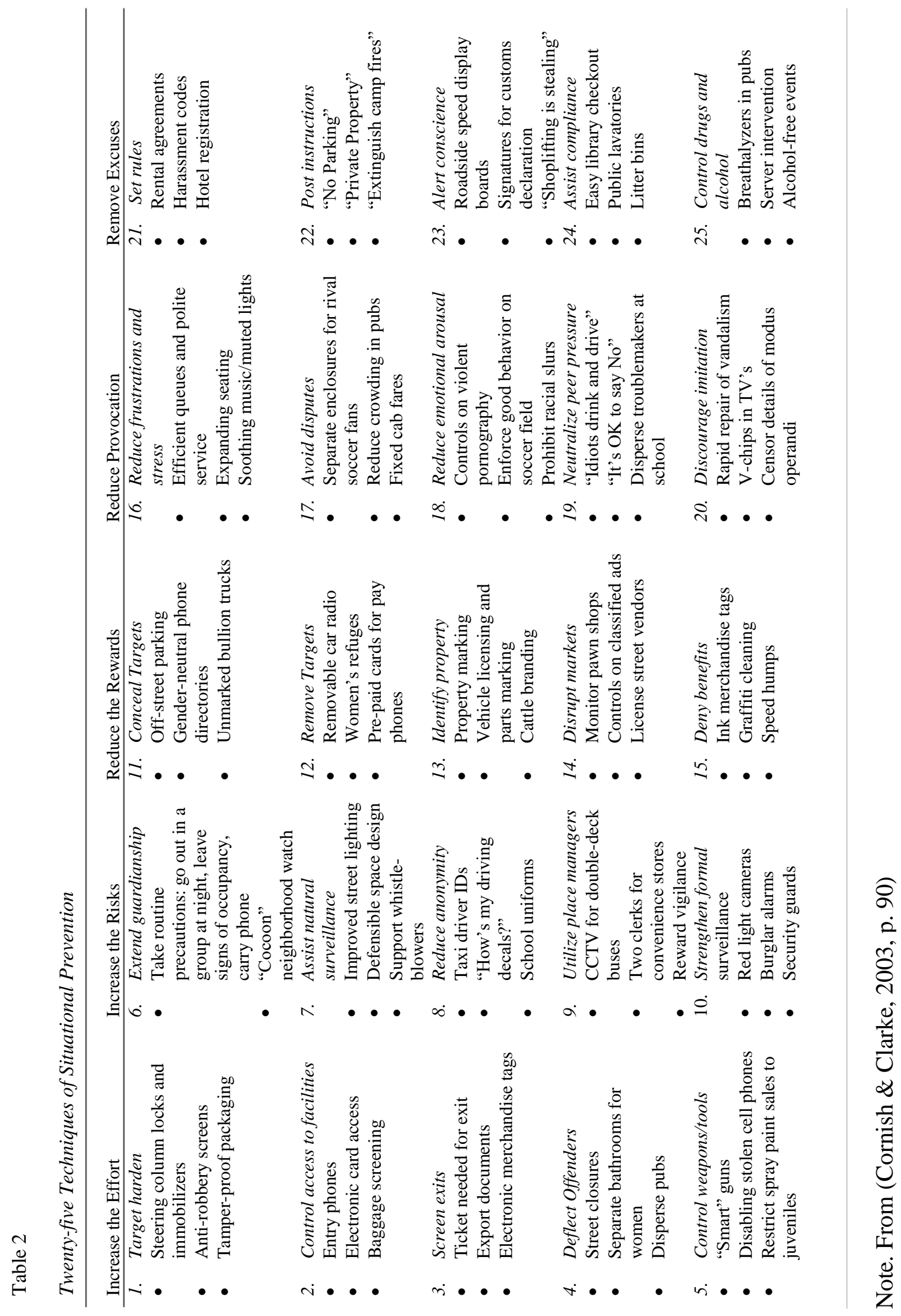




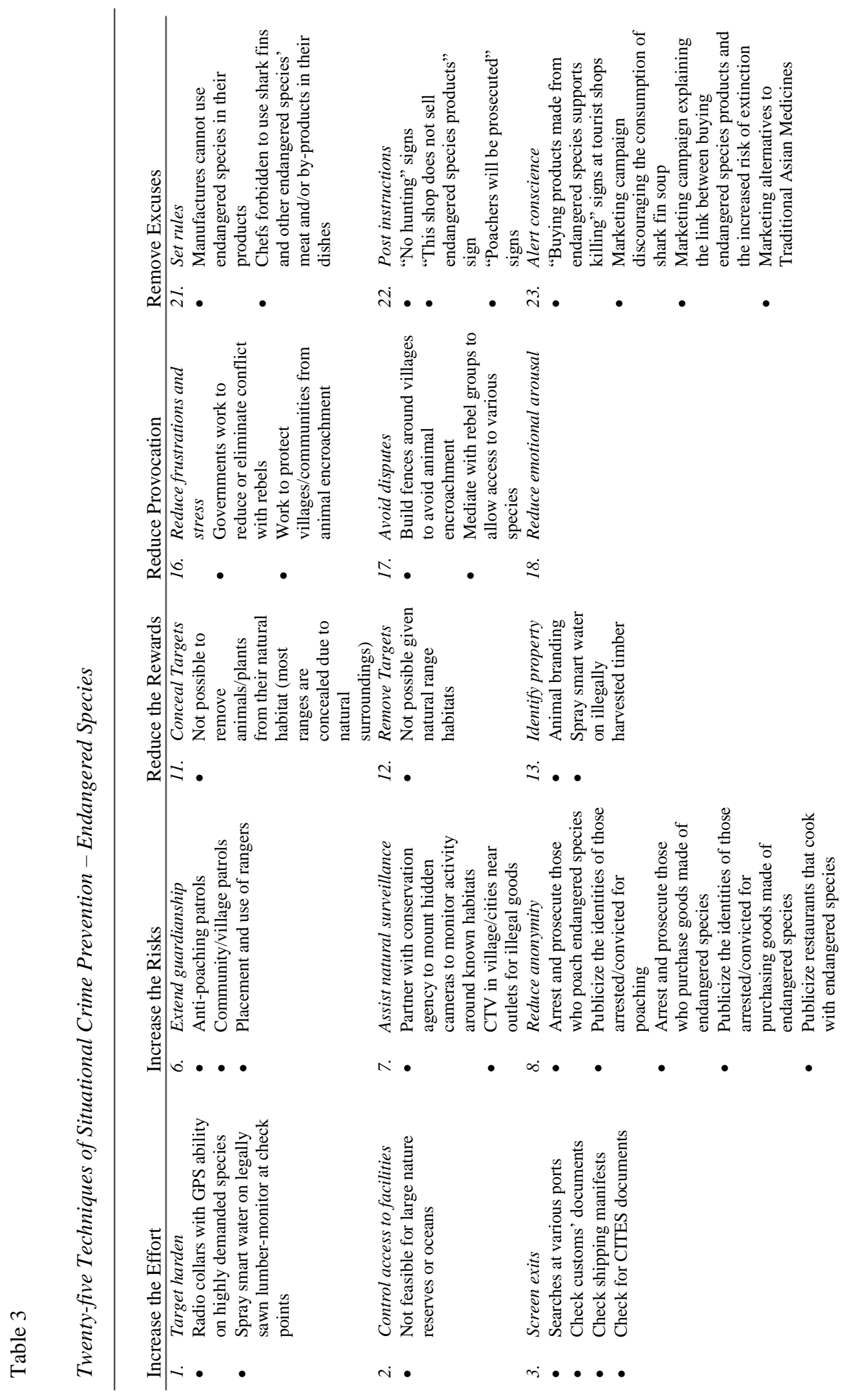

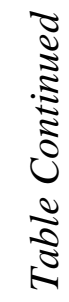




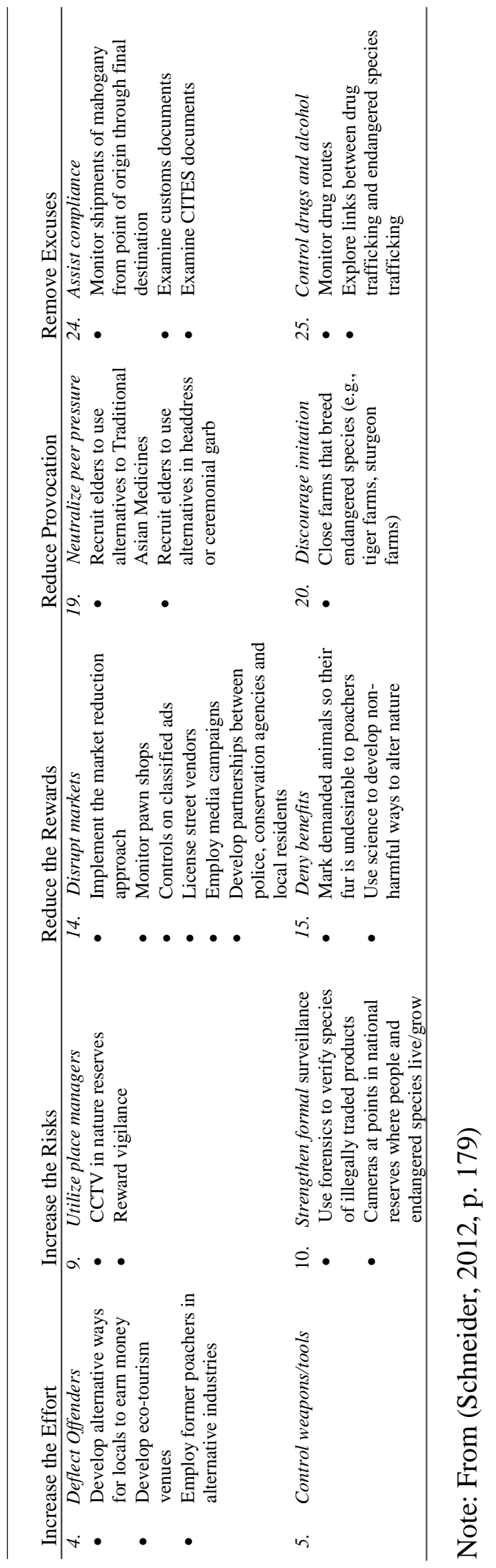




\section{Rational Choice Theory}

Rational choice theory is based on the fundamentals of classical criminology and Cesare Beccaria's theory. Beccaria's theory rests on three main areas which states that all individuals possess freewill, rational manner and manipulability. In other words, Beccaria believed that all individuals make their choices at freewill, by looking out for their own personal satisfaction. The manipulability part of his theory rests on the premise that there is a universal shared human motive of rational self-interest and this makes human actions predictable, generable and controllable (Roshier, 1989, p. 16). The central part to this theory is that crime is committed because human nature is predicated upon the search for pleasure and the avoidance of pain (Hayward, 2007, p. 233).

According to Robbins (2004, p. 157), rationality is the making of choices that are "consistent and value maximizing." Rational choice theory is based on an economic theory called the "expected utility principle," which states "people will make rational decisions based on the extent to which they expect the choice to maximize their profits or benefits and minimize costs or losses (Akers \& Sellers, 2000, p. 26).” In essence, rational choice states that people choose their behavior and are motivated by the pursuit of pleasure and avoidance of pain. Rational choice theory looks at the individual who commits the crime and gives reason as to why the offender chose to engage in a criminal act. These choices can be anything from rewarding, easy, satisfying, and fun. Before an individual commits a crime, s/he evaluates the potential benefits and costs of committing the crime. If the pros outweigh the cons, then the chances of the crime occurring are greater. Thus, one way of ensuring that the costs are greater than the benefits, is by increasing law enforcement or penalties for being caught of committing the crime. 
These are what are known as deterrents. This then means that if an offender perceives the costs of being caught (death, fine, prison sentence) to be too high, the act to risky or payoff to small, then s/he will choose not to engage in the criminal act. Central to this theory is the belief that an offender will decide to commit a crime only after consideration of personal factors and situational factors (McMurtry \& Curling, 2008, p. 42). Personal factors may be a need for money, revenge or entertainment, whereas situational factors the targets vulnerability and the presence of witnesses, guardians or the police (McMurtry \& Curling, 2008, p. 42).

The main concept of the rational choice theory is that every offender's actions are based on rational decision-making. It makes sense that this theory is somewhat related to economics, where one would weigh the costs and benefits to conducting a transaction. This theory provides a framework for understanding why an individual would commit a crime and poach a rhino for its horn. Considering the benefits, one must understand that for a poacher to kill a rhino and obtain its horn, the poachers can often get a large sum of money. The amount of money they receive is often much greater than that of their annual salary and in some instances their lifetime salary. Therefore, the main benefit is the monetary value the poacher will receive. The costs to the poacher can vary and change among each individual. To put it simply, all humans are different and all perceive what a cost is differently. To some, a prison sentence, large fine, or even death is not a cost at all. Many poachers have nothing and come from poor backgrounds. If they are able to kill a rhino, they will receive much more than what they could possibly lose. Rhino poaching is not a crime of opportunity, where one stumbles across a rhino and then decides to kill it. It is not like vehicle theft, where one may stumble across a vehicle that is unlocked or the keys still in the ignition and then the offender makes the rational choice at that instant whether to commit the crime or not. The planning and organization that goes with poaching a rhino, is a long process, 
which enables the offender to evaluate all relative costs and benefits. Even if a poacher does not come from a poor background and is middleclass citizen, the poacher will still make a considerable amount of money for the killing of the rhino and the selling of its horn. Thus, one of the major setbacks in trying to create deterrents with rhino poaching is the amount of money that is involved in poaching. Thus, in order to prevent the crime, through a rational choice approach, one should look at reducing the value of the rhino horn, which will have a domino effect on the amount of currency the poachers receive for the killing of the animal. The next criminological theory that is important to this research and crime reduction is the routine activities theory.

\section{Routine Activities Theory}

Routine activities theory is a theory that attempts to explain the causes of crime. It does not necessarily look at the offender's reasons for committing the crime, but rather it looks at the environment and the routine activities that can cause crime. This theory is one of the main theories of environmental criminology and has what is known as the crime triangle or the problem analysis triangle. This theory relies on the fact that the three different aspects of the triangle must be there in order for crime to occur. Thus, if one is able to remove one of the aspects, then one will be able to reduce the opportunity for crime (Schneider, 2012, p. 8). This theory states that the three aspects for the opportunity to commit a crime are a motivated offender, a suitable target (victim), and the absence of a capable guardian (Braga, 2008, p. 48). Thus when these three entities come together the opportunity for crime increases (see Figure 2.). If one applies these three categories to rhino poaching, one can easily see that the motivated offender is the poacher whose motivation is money, the suitable target is the rhino and the lack of a capable guardian is the lack of field rangers and other law enforcement officials protecting the rhinos. The routine activities theory provides an explanation of the cause of crime. What the 
theory states is without effective controls or guardians, the offender will be able to prey on the targets, when they converge together at the same place and time (Braga, 2008, p. 48; Tewksbury \& Mustaine, 2003, p. 303). The lack of field rangers and law enforcement officers provides an opportunity for the poachers to ease their way into the various game reserves in South Africa and conduct their crimes (poaching) on the rhino population.

Relating this theory to a new concept such as rhino poaching may seem a farfetched to some, thus it is important to understand the theory in its originality. If one evaluates the suitable target section and relates it to everyday crimes, it may become easier to relay back on how it relates to poaching. For property crimes a target could be valuable goods, such as electronics and for personal crimes, the target will be a person. Thus if the target and offender are never in the same place, then the target will never get assaulted or stolen. The capable guardian for these crimes could be law enforcement, thus if the guardians are present they will be able to limit the crime opportunity. It is important to note, that even with a guardian crimes may still occur if the guardian is powerless and is thus an incapable guardian.

Research in this theory has shown that criminal victimization are not randomly distributed in society, but is rather associated with the lifestyles and daily routines of individuals in a society (Tewksbury \& Mustaine, 2003, p. 303). According to Tewksbury and Mustaine (2003, p. 303), the routine activities of individuals often determines the amount of exposure they will have to potential offenders, as well as how vulnerable they or their property is a target and whether they or their property are well guarded. One aspect that is closely related to this theory is the distance traveled to commit crime, where research in this area suggests that criminals often travel very short distances to commit their crime of choice (Schneider, 2012, p. 9). According to Schneider (2012, p.9), criminals often commit crimes near to where they conduct their routine 
activities, such as where they live, work, and play. If one takes this into account, then surely the individuals who are killing the rhinos conduct their routine activities in the area of where rhinos are found. In order to understand this theory, the three main characteristics of this theory ought to be fully explored.

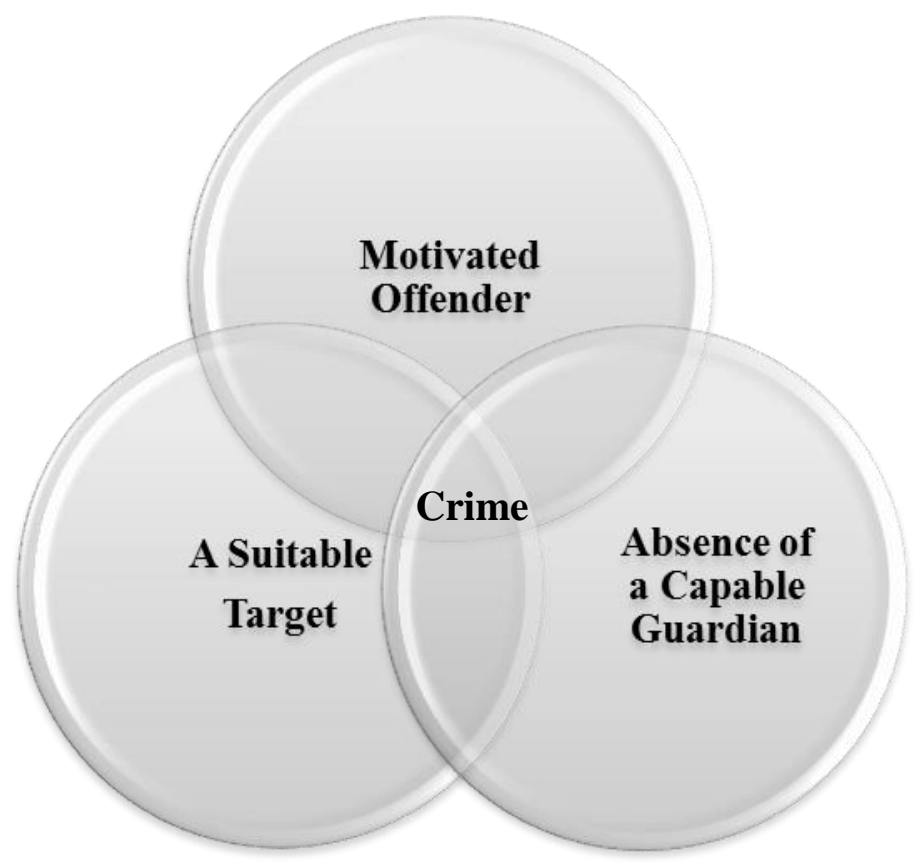

Figure 2. Routine Activities Theory Showing When the Three Parties Come Together, Crime is More Likely to Occur. From (Braga, 2008, p. 48)

\section{Motivated Offender}

When looking at what entails a motivated offender, one needs to evaluate all the possible influences in a potential offender (University of Wisconsin Law School, 2013). The possible influences on offenders can include parents, close relatives, siblings, peers, teachers, intimate partners, and close friends (University of Wisconsin Law School, 2013). These influences are 
what are known as handlers and crimes will often take place when these handlers are absent, weak or corrupt.

A study by Eliason (2012) was designed to look at the trophy-hunting phenomenon in Montana, using a routine activities theoretical perspective. In this study, Eliason found that motivated offenders are driven by ones ego and the need to impress others (Eliason, 2012, p. 75). In American society, "bigger is better," and the fact that an offender can take down such a big and powerful animal, adds to their status as being skillful (Eliason, 2012, p. 76). In Eliason's (2012, p. 76) study, residents of the specific trophy hunting areas were more familiar with the poaching area and often exchanged their knowledge and services to nonresidents for money. The residents usually perform this service as guides or give access to private land that is usually inaccessible to offenders. It is important to note that if the residents are not assisting in the poaching, then they are themselves are conducting the poaching. This is similar in what has been found in the rhino-poaching epidemic in South Africa (Milliken \& Shaw, 2012). It has been found that many of the locals, who know both the area and where the rhinos are, either conduct the poaching or assist in it. In the study by Eliason (2012, p. 76), it was found that residents who engaged in poaching, did so in an opportunistic manner. In the South African context, offenders are motivated by money. The amount that one can receive for killing one rhino and selling its horn is enormous and can be more an individual's entire lifetime salary.

\section{Suitable Targets}

The next important aspect of this theory is the suitable target. One must understand what makes an easy target, where the chances of being caught are slim. In the context of rhino poaching, an easy or suitable target is a rhino that is not guarded correctly. There are over 20,000 rhinos in South Africa and to find an area that has a rhino is not too difficult. In the past, one 
would be able to phone a game reserve and inquire if they had rhinos, if so, the poacher would then know where to go. Rhinos are found in many private and government owned game reserves. Kruger National Park, for example, has the highest concentration of rhinos in South Africa and not all parks are guarded the same. The suitable targets (rhinos) can be found in the poorly run game reserves with less security measures. It is important to note that Kruger National Park has strict security measures and patrols; however, the park is still responsible for the majority of rhinos poached in South Africa. This is important to note because it aims to explain that suitable targets (rhinos) are found in either a tightly secured reserve or a less secure reserve. The poachers will stop at nothing to obtain the horn of a rhino, whether the rhino is in a secure and tightly patrolled area or a less secured area.

\section{Lack of Capable Guardians}

The third and final part of this theory is that of the lack of a capable guardian. Guardians are the ones who try to protect the targets from theft, damage, attack, assault or murder (University of Wisconsin Law School, 2013). According to the theory, guardians can be either informal or formal. Formal guardians include the police, security guards and others whose job it is to protect people and or their property from crime (University of Wisconsin Law School, 2013). Informal guardians include neighbors, friends, and others who are the same place where the target is. This theory states that a target with an effective guardian is less likely to be attacked by an offender than a target without a guardian; in addition, if the guardian is weak, absent or corrupt, then little to no protection can be offered to the target (University of Wisconsin Law School, 2013). For the purpose of this paper, formal guardians will include law enforcement, the military, APU's, security guards, game rangers, and conservationists. Informal guardians will include local residents of the game reserve areas and tourists to these areas. It is important to 
note that, although the formal guardians are the ones who have the weapons to fight the poachers, the informal guardians have just as much power, by calling in anonymous tips to law enforcement and APUs about possible rhino poaching or suspicious activity.

According to Eliason (2012, p. 80), “different actors play a role in the guardianship of wildlife resources." These actors include law enforcement officers and members of public. Cohen and Felson (1979, p. 590) stated that police guardianship is often analyzed widely, however, "guardianship by ordinary citizens of one another and of property as they go about routine activities may be of the most neglected elements in sociological research on crime.” In other words, ordinary citizens can be seen as guardians and if locals or tourists in an area hear or see any signs of poaching, they should act as guardians and report to law enforcement or the APUs. One ought to understand that even if there is a large amount of guardians available, if these guardians are not efficient, they might as well be absent. Game guards, security guards, and even law enforcement officers do not earn high salaries in South Africa. Therefore, the opportunity for corruption is at a higher level. The cost of rhino horn in the illegal market is extremely high and ranges from $\$ 65,000$ to $\$ 85,000$ per Kilogram. The high profit of the horn allows more money to be offered as a bribe to officials and thus decreases the efficiency of the guardians.

\section{Problem Oriented Policing (POP)}

The above theories are the central concepts to SCP. As noted, previously in this chapter, one can conduct SCP techniques in various ways. One such method that can be used with SCP is that of POP. Ultimately, POP is an approach that is used by a policing agency that looks at a problem through microscopic examination and brings together all the resources and stakeholders involved, in order to prevent the problem from occurring. Departments aim to resolve incidents 
instead of solving recurring crime problems (Eck \& Spelman, 1987). POP is a policing concept that looks to improve the way in which the police conduct their business and calls for the police to understand their work in a new way. By understanding, the underlying conditions that give rise to community problems and then to respond to these problems in a wide range of techniques that they may have not used before (Scott, 2000, p. 2).

POP was first introduced in 1979 by Herman Goldstein and was formally tested in Madison, Wisconsin in 1981 (Scott, 2000, p. 36). In 1981, Goldstein and his associates worked with the Madison Police Department in exploring the community's response to intoxicated drivers and repeat sex offenders (Goldstein \& Susmilch, 1982a; Goldstein \& Susmilch, 1982b; Goldstein \& Susmilch, 1982c). According to Scott (2000, p. 36), although the Madison Police Department was the first to formally apply Goldstein's model, it was not the first to systematically study a community problem. The idea of POP originated because researchers, police professionals, and policymakers became interested in improving the effectiveness of policing. It was argued that the police were not being effective in preventing and controlling crime, because they had become too focused on the means of policing and had neglected the goals of preventing and controlling crime and other community problems (Weisburd, Telep, Hinkle, \& Eck, 2010, p. 4).

Weisburd, Telep, Hinkle and Eck (2010) found that POP was associated with a reduction in crime and disorder. It was noted that the effects were modest, but POP was found to be effective across a wide range of crime types (Weisburd, Telep, Hinkle, \& Eck, 2010). This article also found that POP was most effective when the police departments were supportive of the idea and when the interventions were focused on specific crime types or geographic areas. In POP, police identify, analyze, and respond to the problems that create crimes or misconduct. The 
understanding behind this is that underlying conditions create the problems that cause crime (Goldstein, 1979). Therefore, in order to obtain a clearer picture of the problem, officers use the information they gathered in their responses, together with information from other sources (Eck \& Spelman, 1987).

\section{The SARA Model}

In 1987, John Eck and William Spelman utilized Goldstein's idea and created a straightforward model for implementing POP and has become widely accepted (Weisburd, Telep, Hinkle, \& Eck, 2010, p. 7). Goldstein acted as a consultant in the development of this model and is what is now known as the SARA model for problem solving (Weisburd, Telep, Hinkle, \& Eck, 2010, p. 7). SARA is an acronym, which represents the four steps Eck and William suggest police should follow when implementing POP. The "S" represents the first step, the "Scanning" stage; the " $A$ " represents the second step, the "Analysis" stage; the " $R$ " is the third step and is the "Response" stage, and the final step (A) is the "Assessment" part. The SARA model consists of the following stages:

- Scanning - looking for an issue and determining whether it is a problem;

- Analysis - collection of data on the problem to determine how bad it is, the nature of the problem and its causes;

- Response - use of the information gathered from the analysis and designs an appropriate response. This response can involve other agencies outside the normal police arena;

- Assessment - the evaluation of the response and the impact it has had on the problem it was supposed to solve. These results can be used to re- 
examine the problem and appropriate changes can be made if need be (Braga, 2008, p. 15; Eck \& Spelman, 1987).

The idea of the SARA model comes into play by allowing a police department to scan and identify any problems, and then they are able to collect data and thoroughly analyze the problem, such as the cause and nature of the problem. The police department can then bring together a variety of parties and experts, and come up with a realistic and appropriate response. Finally, an assessment needs to be done in order to evaluate if the response has had any effect. If the original response has had no effect, then the police department is able to use the information gathered and develop a new response. If the response shows that it has a positive effect, the police department is able to use this to maintain positive conditions. It is important to note that the response step can go together with SCP and the twenty-five SCP techniques can be used for the response of a problem. Table 4 highlights the elements of the SARA model.

\section{Market Reduction Approach (MRA)}

Another aspect that coincides with SCP is the use of a MRA. According to Schneider (2008, p. 289), the illicit trade in flora and fauna is a complicated trade that involves numerous people from source to destination regions, which cover thousands of miles between. Thus, it is very important to understand how the products are obtained, who obtains them and how and why they get to their final destinations. The MRA is a crime reduction strategy that aims to reduce the flow of stolen goods, as well as to reduce thefts by making it more risky for the thieves (Schneider, 2008, p. 274; Schneider, 2012, p. 8). The MRA has traditionally been used for reducing traditional forms of stolen property, such as electronics and motor vehicles. Schneider (2008) took this traditional crime reduction method and explained how and why it can be used in the endangered wildlife trade. 


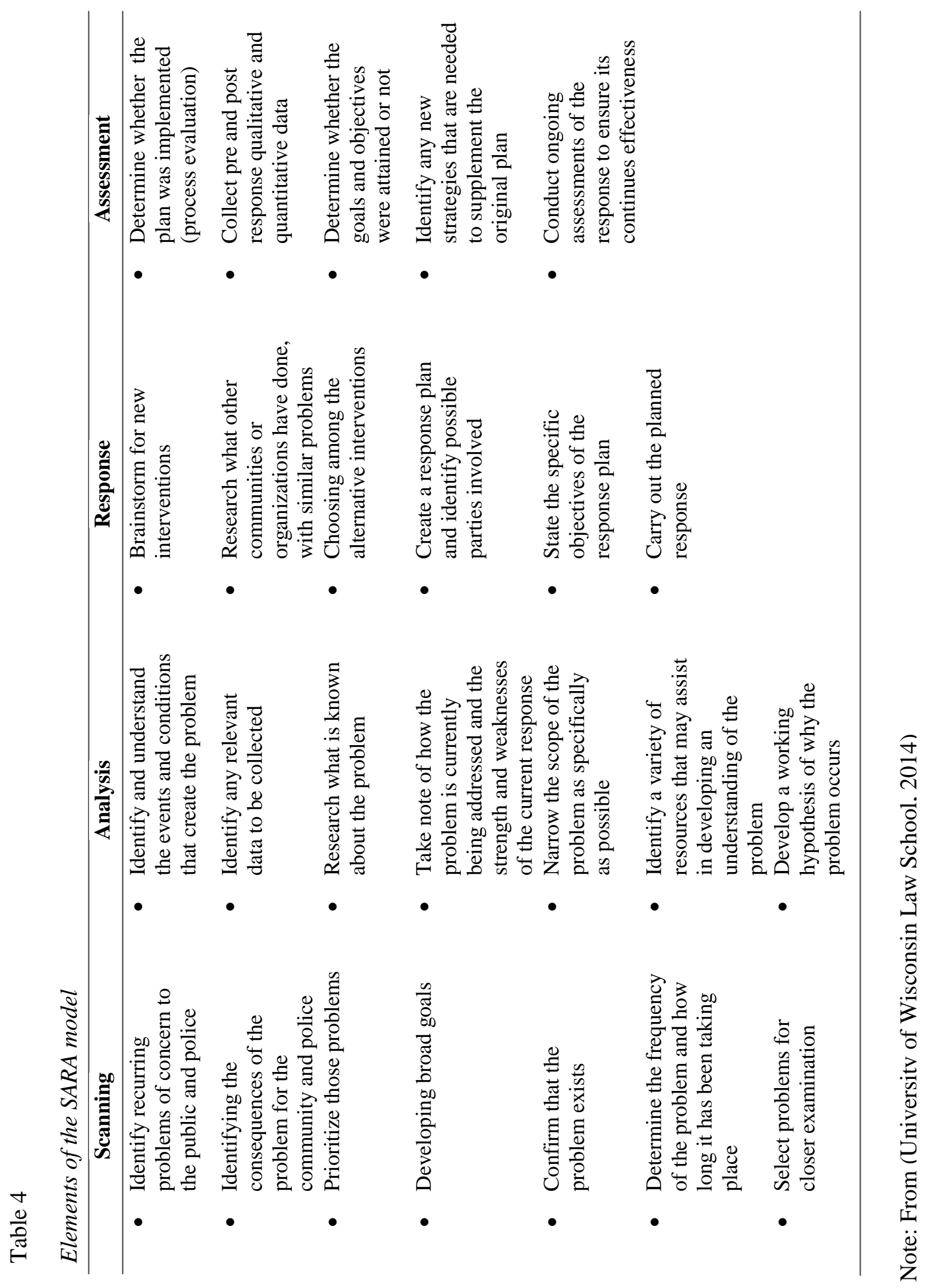


The MRA can be used as a tool for law enforcement and conservation officials to reduce the occurrence of trafficking in endangered flora and fauna, by making it more risky for the trade to continue (Schneider, 2012, p. 8). The MRA is built upon the foundations of SCP and routine activities theory as well as several pro-active policing strategies (Schneider, 2008, p. 275; Schneider, 2012, p. 8). The MRA is situational because it aims to understand how the crime happens and not why it happens. By understand how the crimes happen, authorities are able to develop viable strategies to prevent the crimes from happening again (Schneider, 2012, p. 8). According to Schneider (2008, p. 276), the overall aims of the MRA is to "disrupt and reduce stolen goods markets by discovering what property is stolen, how thieves acquire the property in terms of both location and technique, how goods are recycles back into the community, and who the consumers of these goods are." Only once these patterns are identified can appropriate responses and interventions be implemented. It has been noted by Schneider (2008) that there are two dimensions on which the MRA can be measured. The first revolves around the type of stolen goods market operating and the second is connected to the type of property stolen (Schneider, 2008, p. 276). The first idea is to interrupt the market. MRA is evidence led and this leads to knowledge on the specific type of market and how the products are sold and traded. For example, if rhino horn in South Africa has been found to be traded through the airports, then interventions can be placed at the airports in the country. This creates a disruption in the market and the sellers look for alternative routes. The longer the seller has the horn for, the more likely the police will catch the seller. The second indicator of measurement relates to the type of product and how to alter the product being stolen. A change from the targeted stolen goods market to a different type of market would show disruption. According to Schneider (2008, p. 276), if a successful plan has been implemented it will shift the plans from the demanded item to another item and this would 
be seen as having a successful intervention. When concerning endangered wildlife, can this be seen as a positive or negative thing? If for example, as in South Africa, the rhinos are under constant threat against poachers for their horns, however, elephants are relatively safe for the time being. What if a method is introduced and it disrupts the rhino market and it moves onto the elephant market? This surely is not a positive outcome of the approach. It will be a positive outcome for the rhino, but it does not solve the problem of poaching and now the elephants are now in danger.

The MRA has six main elements in it, which need to be identified in order for a suitable intervention to be placed. The six elements are who, what, where, when, how, and why. Who, being who are the offenders; what, being what is the product; where, being the area where the crimes happen; when, being the times that the crimes happen; how, relates to how the crimes are committed and why is the reason for the crimes being committed (Schneider, 2008, p. 279). By understanding each one of these elements in detail and understanding the actual problem, one will be able to establish a suitable intervention to prevent the stolen goods market. Table 5 explains how these six elements are used in the MRA, the traditional crime approach as well as the MRA for wildlife as developed by Schneider (2008, p. 279). For the purpose of this paper, an additional section will be added on, which will be the MRA for rhino poaching in South Africa. 
Table 5

Focus of Attention for the Market Reduction Approach

\begin{tabular}{|c|c|c|c|c|}
\hline Focus & Traditional & MRA & MRA - Wildlife & MRA - Rhinos \\
\hline Who & $\begin{array}{l}\text { Individual } \\
\text { offender }\end{array}$ & $\begin{array}{l}\text { Thief, handler, } \\
\text { consumer }\end{array}$ & $\begin{array}{l}\text { Hunter, poacher, } \\
\text { handler, } \\
\text { consumer }\end{array}$ & $\begin{array}{l}\text { Poacher, } \\
\text { handler, } \\
\text { consumer }\end{array}$ \\
\hline What & $\begin{array}{l}\text { Individual crime } \\
\text { (burglary, shop } \\
\text { theft, theft from } \\
\text { motor vehicle) }\end{array}$ & $\begin{array}{l}\text { Specific types of } \\
\text { property }\end{array}$ & $\begin{array}{l}\text { Animals, } \\
\text { plants and/or by- } \\
\text { products }\end{array}$ & Rhino horn \\
\hline $\begin{array}{l}\text { Location } \\
\text { (where) }\end{array}$ & Individual address & $\begin{array}{l}\text { Types of } \\
\text { location (house, } \\
\text { shop, shed, } \\
\text { school, business) }\end{array}$ & $\begin{array}{l}\text { Country of origin } \\
\text { (range area), } \\
\text { country of } \\
\text { consumption }\end{array}$ & $\begin{array}{l}\text { South Africa, } \\
\text { all game } \\
\text { reserves in } \\
\text { South Africa, } \\
\text { specifically } \\
\text { Kruger } \\
\text { National Park }\end{array}$ \\
\hline Date (when) & $\begin{array}{l}\text { Date of } \\
\text { victimization }\end{array}$ & Seasonality & $\begin{array}{l}\text { Seasonality, } \\
\text { mating season }\end{array}$ & All year round \\
\hline How & $\begin{array}{l}\text { Modus operandi } \\
\text { of offender }\end{array}$ & $\begin{array}{l}\text { How things are } \\
\text { bought and sold } \\
\text { (type of stolen } \\
\text { goods market) }\end{array}$ & $\begin{array}{l}\text { How things are } \\
\text { harvested, } \\
\text { processed, } \\
\text { shipped }\end{array}$ & $\begin{array}{l}\text { Shot, poisoned } \\
\text { or snared. } \\
\text { Horn chopped, } \\
\text { ground or } \\
\text { whole through } \\
\text { airports and } \\
\text { harbors }\end{array}$ \\
\hline Why & $\begin{array}{l}\text { Drugs, poverty, } \\
\text { greed, abuse }\end{array}$ & Demand & Demand & $\begin{array}{l}\text { Demand in } \\
\text { Asia for TAM }\end{array}$ \\
\hline
\end{tabular}

Note: TAM $=$ Traditional Asian Medicine

Note: From (Schneider, 2008, p. 279)

In order for MRA to be effective, the strategy that is developed needs to be crime or problem specific. One cannot take a MRA, for example, that is being used to stop rhino poaching in Kenya and apply it in South Africa. The crimes are the same, however, the ways in which the offenders operate are different. Thus, each MRA that is developed needs to be problem specific, 
with an understanding of the problem in its entirety. A modified model of the MRA was given by Schneider's (2012) and is made specifically for the illegal trade in endangered species (see Figure 3.). This model of MRA specifically aims to make hunting, harvesting, processing, shipping, trafficking in protected species more risky for those involved in the process. This is done designing specific intervention strategies in conjunction with other relevant agencies (Schneider, 2012, p. 9). This approach, as noted by Schneider (2008, p. 9) should not be the sole responsibility of the police, instead MRA relies on involvement of other agencies who can help provide data and knowledge on the problem in order to develop a viable solution.

\section{Conclusion}

The above section highlighted the use of SCP as a mechanism to reduce crime in general and how it has been used to reduce wildlife crime. The above research shows that that SCP can be utilized in various ways and is not only done in one specific way. Therefore, in order to use SCP as a measure to reduce rhino poaching, one first needs to identify the full extent of the problem and can then create SCP techniques to prevent rhino poaching from happening in South Africa. The research does not suggest that SCP is the only method that can be used to prevent poaching, it does however; suggest that SCP can be one method in combination with a variety of other techniques that can be used to prevent rhino poaching. The twenty-five techniques of SCP is one aspect that will be utilized in the discussion of this paper, where the paper aims to identify ways in which SCP can be used to prevent poaching. 


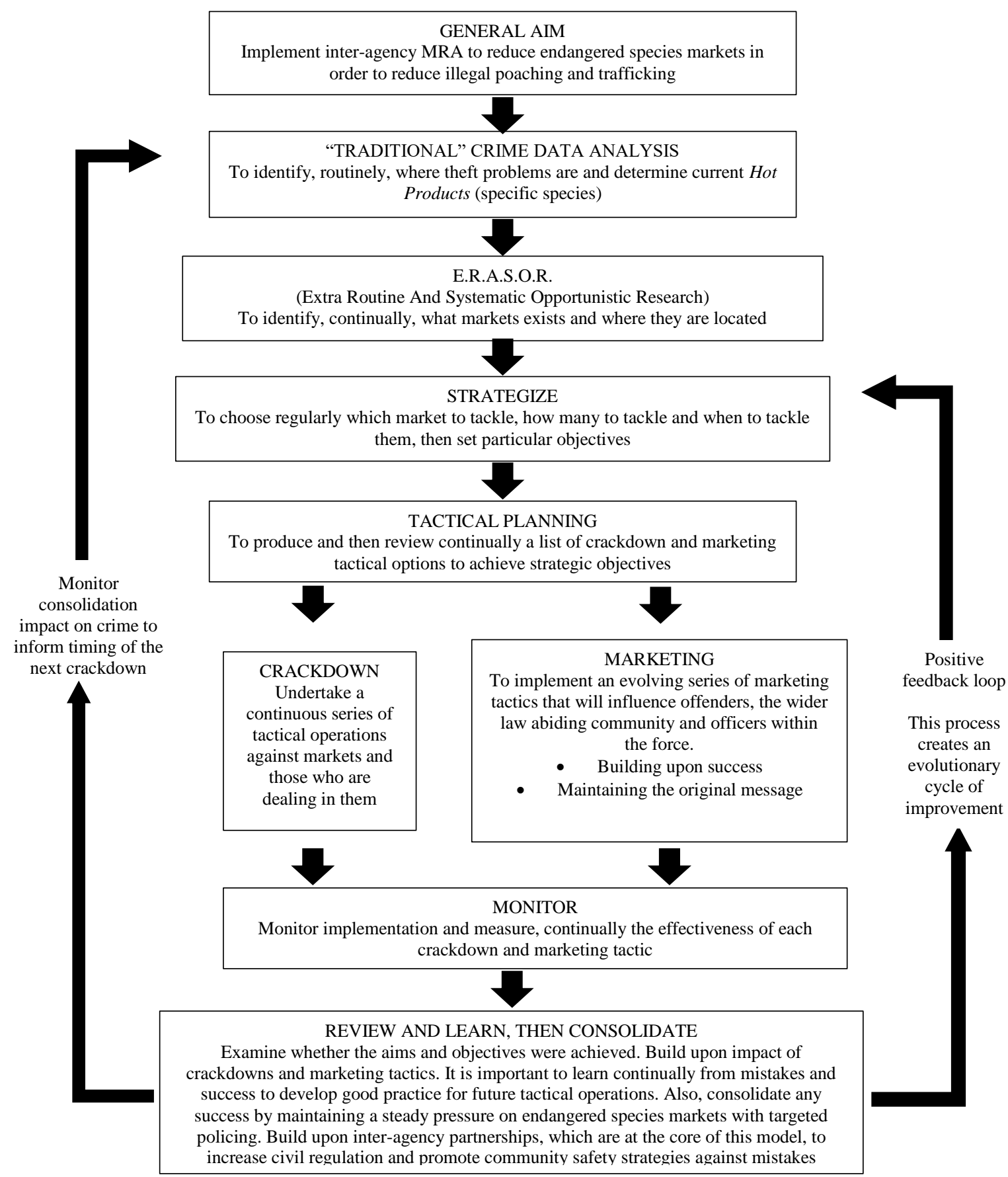

Figure 3. The Market Reduction Approach Interagency Model. From (Schneider, 2012, p. 10) 


\section{CHAPTER IV: METHODOLOGY}

There are multiple ways in which one is able to conduct research and it is therefore important for researchers to supply a methodology of how the research will be conducted so that future researchers can utilize the method that was chosen. This chapter of the paper will discuss the methods that were used to obtain the data for the research study.

The scope of this qualitative study is three-fold: to identify the problem, analyze the problem, and develop possible solutions to the problem. Data for this study was gathered using field research and in-depth interviews with the participants. Qualitative research was the method of choice for this research, as the paper aims to understand the full extent of rhino poaching in South Africa and what is currently being done to prevent it. Thus, instead of generating numerical data and supporting or refuting a hypothesis, the paper aims to produce information based from face-to-face, in-depth interviews from participants in their natural setting. Qualitative research is useful for obtaining information on problems and situations that one may have little knowledge of or where very little is known about the problem (Ebrahim \& Sullivan, 1995, p. 196). Thus, qualitative research is very much exploratory and fits with the scope of this research. Qualitative research is also useful for providing an in-depth understanding of problems that often-quantitative research cannot (Tewksbury, 2009, p. 38). This is mainly due to the way in which the data is collected and analyzed and what the data is able to explain about the area of study (Tewksbury, 2009, p. 38). Information gathered through qualitative research is often more informative, richer and offers enhanced understandings of the problem, when compared to quantitative research (Tewksbury, 2009, p. 38). There is a large amount of research on the rhinopoaching situation in South Africa and Africa (See: Conway \& Goodman, 1989; Dublin \& Wilson, 1998; Ferreira, Botha, \& Emmett, 2012; Ferreira, Greaver, \& Knight, 2011; Lockwood, 
2010; Milliken \& Shaw, 2012; Milner-Gulland \& Leader-Williams, 1992; Montesh, 2012). Prior research has not explored how poaching can be prevented on the ground levels. The majority of the research which is available on rhino poaching mainly focuses on the need of better enforced laws and regulations both nationally (South Africa and Viet Nam) as well as internationally. In addition, much of the research focuses on stopping the demand from Asia, then what can be done to prevent the supply in South Africa. This paper makes a unique contribution to the literature, in that it will provide an exploratory view into what is being done to prevent poaching.

\section{Setting}

Rhino poaching has been found all across Africa over the past decades, however, more recently rhino poaching has reached all-time highs in South Africa. With this in mind, the research was conducted in South Africa and more specifically in the surrounding areas of Kruger National Park (Greater Kruger), the Limpopo Province and Gauteng Province. The surrounding areas of Kruger National Park and Limpopo Province were selected for the research, due to the high prevalence of rhino poaching that is found in these areas, as well as due to the various APUs that are situated in the areas. Gauteng Province was chosen because many of the NGOs and other organizations are situated within the province. The research for this paper was conducted over a three-week period from December 2013 to January 2014, which included the following areas: Bella-Bella (Limpopo), Waterberg area (Limpopo), Hoedspruit (Limpopo/Greater Kruger), Hazyview (Mpumalanga), Pretoria (Gauteng) and Johannesburg (Gauteng). After the research that was conducted in South Africa, the researcher returned to the USA and conducted two more interviews over Skype with the WWF and Rhino Rescue Project. The interviews that were conducted in Gauteng were done so in a private office, where the researcher was able to ask the participant a variety of questions regarding the research (See 
Interview Guide Appendix 1). Once these questions were completed, the researcher allowed for the participant to add any other information that the participant believes is necessary regarding the aims of this research. The understanding for this is because the participant is the expert in the field and the researcher is learning from what the participant can offer. Thus, any information that the participant believes is necessary was given after the questions were completed. The interviews that were conducted in Limpopo and the greater Kruger area were done at various private game reserves. The interviews were conducted either in a private office or out in the bush where the participants were working. Due to the nature of the rhino-poaching problem, not all participants were able to take time from their duties to conduct the interview, thus they allowed the researcher to accompany them into the bush and answer all questions whilst conducting their daily duties as well as add any other relevant information.

\section{Selection of Participants}

For the purpose of the thesis the researcher used two nonprobability sampling technique. The techniques which were used for this research are the purposive and snowball sampling techniques. Purposive sampling was selected for the study, as the researcher has some knowledge on the problem as well as knowledge about where the greatest concern of rhino poaching is and the goals of the paper. Purposive sampling is complementary to this study because one is able to use purposive sampling to select a sample based on one's own knowledge of the problem, its elements and the nature of the research aims (Marshall, 1996, p. 523; Maxfield \& Babbie, 2012, p. 153). Furthermore, purposive sampling was selected for this research, as the researcher wanted the sample to either have knowledge of the research topic (Bryman, 2004, p. 334). 
The main advantage of purposive sampling for this research is that the researcher can select the research participants on a basis of their knowledge on the research topic. Therefore, it was beneficial as the researcher was able to obtain information from a specific group of people who have some knowledge in the research topic (Babbie, 2007, p. 184). By doing this, the researchers sampling selection is quick and easy. Quickness in this sense was of utmost importance as it will enable the researcher to not spend too much time on the selecting of the sample and concentrate on the actual research at hand. The limitation of purposive sampling for this research is that there will be no randomization when selecting the research participants. Therefore, not every person in the population had an equal chance of being selected for the research and thus the results of the research are unable to be generalized back to the population (Castillo, 2009).

The second method that was used in this research is that of the snowball sampling technique. This sampling technique is often used in field observation studies or specialized interviewing (Maxfield \& Babbie, 2012, p. 156). This sampling technique begins by identifying a single participant or small number of participants and then asking the participants to identify others that will be willing to participate in the research (Maxfield \& Babbie, 2012, p. 156). This method was important to use in this research as the APUs and organizations that are involved in rhino protection have better knowledge than the researcher does on who needs to be interviewed on the topic of rhino poaching. Thus, once the researcher had interviewed each member of the APUs and organizations, s/he was able to recommend other potential participants for the project. A second potential advantage of this technique is that snowball sampling is an effective method for participant selection when the research is on a sensitive issue and requires information 
knowledge of insiders in order to locate participants for the study (Biernacki \& Waldorf, 1981, p. 141).

In order to identify the initial purposive sample of participants for this research, the researcher began by conducting a Google search for "Rhino poaching South Africa." The Google search will yield a wide array of resources, including newspaper articles, NGOs, and governmental websites, national and private game reserve websites, as well as anti-poaching task teams or APUs. From the initial search results, the researcher then selected the participants based on their location of their organization in Gauteng, Limpopo, and the greater Kruger, as well as their duties of the organization. In terms of the first criteria of location, the study was limited to only those areas with the highest prevalence of poaching. Regarding criteria two, only participants that are actively involved in the fight against rhino poaching were selected.

Once the researcher had created a master list of potential participants, the researcher contacted each potential participant via e-mail, explaining the purpose of the study, and requesting their assistance in the research (see Letter of Invitation Appendix 2). Given the exploratory nature of the study, the researcher was seeking only ten participants; however, the total amount of possible participants that agreed to participate was six. Through a snowball sampling technique the researcher was able to obtain another six more participant organizations that were willing to give there expertize in this field. The master list consisted of 25 possible participants, and included lawyers, law enforcement officers from the Endangered Species Unit of the South African Police Service (SAPS), members from SANPARKS, APUs, researchers and NGOs that aid in the protection of the rhinos through donations to the APUs in South Africa. The six participant organizations that agreed to assist in the research were two APUs: Quemic South Africa and Protrack APU; one intelligence led organization: Anti-poaching Intelligence Group 
South Africa; an organization for private rhino owners: Private Rhino Owners Association; one NGO: the WWF and one game reserve in Waterberg area. Through these participants, a snowball sampling technique was used and another six organizations agreed to participate in the research. These organizations included: three game reserves, all in the Bela-Bela area; one organization that donates money to an NGO which gives the money to various APUs (Jenna Clifford Jewelry); one NGO that aims to educate and spread the word about the rhino poaching problem and one organization that dyes the rhino horn (the Rhino Rescue Project). The researcher was interested in obtaining a comprehensive range of information, views, and anti-poaching strategies, thus every effort was made to identify potential participants from a wide variety of organizations involved in the fight against poachers. As outlined in the literature review chapter, poaching methods and anti-poaching strategies are likely to vary across different areas, thus only by obtaining knowledge from various parties involved, will one be able understand the full scope of the problem.

The total sample for this report consisted of twelve participant organizations that are involved in preventing poaching and the illegal trade in wildlife. The organizations which have agreed to use their names in the research are Quemic South Africa (Weltrac), Protract APU, Anti-poaching intelligence group South Africa (APIGSA), Private Rhino Owners Association (PROA), Rhino Rescue Project; World Wildlife Fund (WWF) and Jenna Clifford Jewelry. The remaining participant organization requested to remain anonymous due to various reasons. One person who all of the organizations did request the researcher to meet was Jack Greeff. However, due to the short period in South Africa and the long distances traveled for the research, the researcher was not able to interview Jack Greeff. Another important aspect of the research was to not only obtain information on poachers and criminal organizations involved in obtaining rhino 
horn, but also to obtain information on the luxury goods market in Asia. Due to the fact that rhino horn is not only used in Asia for medical remedies, but it is now seen as a luxury good for the middle to upper class society in Viet Nam. It was for this purpose that the researcher aimed to obtain information from an organization that deals with luxury goods from South Africa into Asia and who also donates a considerable amount of money to fight the war against poachers.

\section{Challenges in the Selection of Participants}

There was a range of difficulties when obtaining participants for the research. The reasoning for declining to be part of the research varied from not having time or being on holiday, to not being interested because they have had many people contacting them for information before and all the information that they have either is in the media already or has been published. The period, which the research was conducted, is the summer holidays in South Africa and many people are away on leave. Thus, it was difficult to obtain data from organizations that were closed for the holidays or away on leave. Another aspect that was commonly found was that organizations declined to participate because they did not see how research was going to change the problem. Some of the organization believed that sponsorships and donations are needed to fight the problem, not research. Many of the organizations believed that one cannot solve the problem of rhino poaching behind a desk or computer, but instead needs to be in the bush fighting for the survival of the rhinos. The final reason for declining was due to the fear of revenge attacks, an increase in poaching and not willing to give away any information that could be used by poachers against them. Many of the game reserves and APUs that were approached by the researcher were afraid that information would leak into the wrong hands. The researcher did inform the organizations that they could remain anonymous if they would like. However, the fear of the information being used against them ensured that the 
organizations declined the requests. The researchers found that the organizations who agreed to participate and the ones who did not, both expressed concern about who the researcher was. All the organizations interviewed, mentioned to the researcher that poaching syndicates are becoming smarter and they were wary to disclose some information to the researcher out of fear that the researcher is part of a syndicate.

\section{IRB Approval}

Researchers must receive Institutional Review Board approval for all projects that involve human subjects. For this research, however, the participants were individuals involved in addressing the issue of enforcing wildlife crimes. The participants were asked about their official activities and were not asked about any improper or illegal conduct on their part. In South Africa, there is no known Human Subjects Protection Protocol for social science research. As such, the researcher had approached the Illinois State University's Human Subjects IRB Protocol. The researcher filled in the application for the IRB and went through all the necessary channels in order to get approval for the research. However, the IRB confirmed that the researcher did not require any IRB approval as the questions that were asked did not constitute human subjects as defined by the regulations because the questions are not about the participant or their opinions.

\section{Data Collection Procedures}

South Africa is a large country and the areas where the interviews were conducted were allocated in different regions in the country. In order to conduct the research the researcher had to drive vast distances to obtain the information. Driving times for the research ranged anywhere from 2 hours to 12 hours. Whilst the researcher was in South Africa, the researcher arranged specific days and times to meet with the participant organizations. Once the researcher had 
arrived at the venue, the participant organization allocated one of their members to conduct the interviews with the researcher.

The research was conducted in various phases. Before the research could be conducted, the researcher had to fly to South Africa. Once in South Africa, the researcher got in contact with the participants and finalized any times and day for the interviews. Once the dates and times were set, the researcher planned a route and trip that would enable the researcher to conduct the interviews. During the face-to-face meeting, the researcher would greet the participant and would then discuss the research in detail. Once this was completed, the researcher then requested permission to take notes on any information that the participant may give. The researcher had also handed an informed consent letter (see Informed Consent Letter Appendix 3) to the participant, explaining the requirements of the participant as well as information on the research.

The research that was conducted was done so in seven phases. The first phase of the research consisted of the researcher driving to a private game reserve in the Waterberg area, where the researcher first met with a member from Quemic South Africa, the Weltrac training center. In this interview, the researcher first introduced himself as the researcher and an informal conversation was started about the purpose of the research and the researcher's previous experience. The research interview was conducted in a secluded conference and training room, where the organization conducts their training of their field rangers. The interview first consisted of an informal conversation of the rhino-poaching problem in South Africa. During this stage of the interview, the participant gave details on how the poachers travel, conduct their illegal activity and how the APU conducts their operations to stop and capture the poachers. Once this conversation was concluded, the researcher then used a set of questions that were needed in order 
to obtain the aims and goals of this research. Once the interview was finished, the participant offered to share some other contacts in the field that would be helpful for the research.

The second phase of the research involved the researcher driving to a nearby private game reserve where the researcher met with a member from the Anti-poaching intelligence group South Africa (APIGSA). During this interview, the researcher and participant first had an informal conversation on the rhino-poaching problem in South Africa. Once the conversation was finished, the researcher was able to ask various questions that the participant did not answer in the original conversation. During this interview, the participant gave information on the various means of trafficking and routes that rhino horn is trafficked. Additionally, information was gathered on how the poachers conduct their illegal activities and what other illegal activities are the poachers and syndicates involved in. This interview was conducted in an outdoor conference venue in the African bush.

The third part of the research consisted of the researcher visiting various private game reserves in the Waterberg and Bela-Bela area. During this part of the research, the researcher was able to contact some of the game rangers and managers who work at these private game reserves. The private game reserves names will remain anonymous, due to fear of possible poaching in their game reserves. During this research, the game rangers and managers declined to answer any of the set questions of the research. However, the parties involved were willing to disclose any information they have on rhino poaching as long as they remain anonymous. Information that was gathered during this research includes: how the poachers conduct their activity, what are necessary steps to prevent poaching, what are the private game reserves doing to prevent poaching and information on how poachers have attacked and killed rhinos in the private game reserves in the area. The interviews that were conducted in this stage of the research were 
conducted in a private office, or on a private game. A game drive was offered by a game ranger as a means to get out of the office environment and get into the bush. The belief was that in order to understand the problem of poaching, one needs to be in the bush and not behind a desk in an office. During the game drive, the researcher and participant were able to discuss the problem of rhino poaching and the researcher was able to obtain a wealth of knowledge and information on the methods that the private game reserves use to prevent poaching.

The fourth part of this research consisted of the researcher driving to Hoedspruit. During this phase of the research, the researcher met up with Protrack APU. The researcher was met at the head office of Protrack and was then taken to the training facilities in the bush, where the interview was conducted. During this interview, the participant organization took the researcher on a tour of the anti-poaching training facilities and gave information on not only rhino poaching, but also all poaching of wildlife that is taken place in South Africa. One of the reasons to give information on all types of wildlife poaching is because the organization believes that the international community must not forget other species that are being affected by poaching. Information that was gathered in this interview varied from whom the poachers are to what needs to be done to prevent rhino poaching.

The fifth phase of the research required the researcher to drive to Hazyview. In Hazyview, the researcher met up with the CEO of Jenna Clifford Jewelry who is involved in the luxury goods market in South Africa and Asia. In addition to this Jenna Clifford Designs is a large donator towards the protection of rhinos in South Africa. This research first consisted of an informal conversation on the rhino-poaching problem, where the participant was able to give information on the luxury goods market in Asia and why Asia is the main market for rhino horn. Once the informal conversation was completed, the researcher was able to ask the set of 
questions to the participant. The research for this phase was conducted inside the private home of the participant.

The sixth phase of the research consisted of the researcher returning to Johannesburg where the researcher was able to conduct interviews with a member from the Private Rhino Owners Association (PROA). During this interview, the researcher obtained information on why the organization is pushing for the legalization in the trade of rhino horn and what the organizations members do to prevent poaching. Additionally, whilst in Johannesburg, the researcher was able to interview two other organizations, one in Pretoria and one in Johannesburg regarding what the rhino poaching problem is, what they are doing to combat it and what should be done in the future. The participant organizations requested to remain anonymous in their feedback. These interviews were conducted in a private office.

The seventh phase of the research was completed when the researcher returned to the USA. Once in the USA, the researcher scheduled two Skype interviews, which the participants were unable to conduct whilst the researcher was in South Africa. The two Skype interviews were conducted with a member of the WWF South Africa and the Rhino Rescue Project.

\section{Measurement Instruments}

The instruments that were used for the research paper, was that of the qualitative interview. The interviews were used to obtain information on what the current problem is, what is being done to solve it and what needs to be done to solve the problem. According to Bui (2009, p. 146), interviews are often used in qualitative research, thus this method was best suited for this research. Before any interviews were conducted, an informal conversation was first generated between the researcher and the participant. According to Gall, Gall and Borg (2003, p. 239), an informal conversation relies "entirely on the spontaneous generation of questions in a 
natural interaction, typically one that occurs as part of ongoing participant observation fieldwork". With the informal conversation approach, the researcher does not ask any specific questions, but instead relies on participation interaction to guide the interview process (Turner, III, 2010, p. 755). This type of research is often considered beneficial because it allows for flexibility in the nature of the interview, due to the lack of structure (Turner, III, 2010, p. 755). However, other researchers believe this style of research is often unreliable because of the inconsistency in the interview questions and making it difficult to code the data (Turner, III, 2010, p. 755).

The reason for using the informal conversation method is due to the exploratory nature of this study. The researcher only knows a limited amount of information about the topic and has developed a set of questions to interview the participant in order to obtain the research goals and aims. The participant is the expert in this situation and any information that the participant can offer will be of value to the research. In addition, a general conversation will enable the researcher to obtain information that would not have been given, if the researcher had only used the interview method.

The second method that accompanied the informal conversation was that of the interview method. In this method, the participants were asked questions from a set of questions that the participant had created in order to obtain the goals of this research. These questions were created in order to obtain responses that are open-ended (Gall, Gall, \& Borg, 2003; Turner, III, 2010, p. 756). The open-endedness of the questions allowed for the participants to contribute as much detailed information as possible on the topic as well as it allows the researcher to ask probing questions a means of follow-up (Turner, III, 2010, p. 756). According to Turner III (2010, p. 756), open-ended interviews are often the most popular form of interviewing used in research 
studies due to the nature of the open-ended questions, which allow the participants to fully express their viewpoints and experiences. The downfall of using open-ended interviews is that this method can often be difficult when coding the data (Turner, III, 2010, p. 756). The reason for this is because open-ended interviews allows the participants to fully express their responses in as much detail as possible, thus it can be difficult for researchers to extract similar themes or codes from the interview as one would through closed-ended responses (Turner, III, 2010, p. 756).

The open-ended interview method was used to obtain specific information from the participants. Once the participants had given detailed information in the informal conversation, the interviews allowed the researcher to obtain any other information that was necessary for the research. By combining the two methods for this research, the information that was gained is able to be exploratory and informative to the research.

During the conversations and interviews, the researcher took written notes of the participants' responses. The researcher used a different note pad for each individual participant. The notepad was then divided into two sections, one for the informal conversation and one for the interview. During the conversation, the researcher listened carefully and took note of the information that the participant offered. Any information that the researcher missed, the researcher had asked the participant to repeat the information. This same process was used each time the researcher conducted an interview with a participant. During the data collection, the researcher had put stars next to the information that the participant had mentioned was important and next to information that the researcher believed could help obtain the goals of the research. To ensure that all the important information was gathered, after the interviews the researcher recaped all the important information with the participant to ensure that no important information 
was left out. In note taking it is very easy for one to miss information and not jot it down. Thus, if the researcher heard something and did not jot it down, once the researcher arrived back at the hotel or back home, the researcher typed all the notes and all other relevant information from the interviews that the researcher had heard.

The original time allocation for the interviews and informal conversations was one hour. However, after the first interview took three hours to complete, the researcher opened up the allocated time in order to obtain all the information needed. The information that was needed for the research was very detailed and thus the researcher decided to allow the participants to continue as long as they needed. The length of the interviews ranged anywhere from two to six hours. The reason for the length of the interviews was due to the length of some of the informal conversations and depended on the information that the participant had. The Skype interviews had a two-hour time allocation; however, the interviews only lasted about one hour as the participants had a busy day schedule. The reason for the wide range in time for the interviews depended on how much information the participant had. Although the researcher had a set of questions that were to be asked, the researcher discovered during dialogue with the participants that the participants have a lot more knowledge to offer and thus allowed the participant to open up and share information they have.

\section{Difficulties in Conducting Research}

In all research methods, one is bound to identify some problems or difficulties when obtaining the data. The first difficulty that was identified by the researcher was the time of the

year that the research was to be taken in. The December and January (summer) holidays in South Africa are some of the busiest tourist times in the country. Many people in the country go on holiday and some businesses close down for long periods. The time that the research was done 
was during Christmas and into the New Year where large amounts of people are travelling locally or internationally. This is one of the reasons for the difficulties in obtaining research participants, as at least four of the individuals or organizations that were identified to be part of the research, were either closed or away on holiday.

The second difficulty that was found is that some of the participants were reluctant to talk about the poaching problem in their area. Four large private game reserves declined to be part of this research, due to them not wanting to share any information on their operations or activities in protecting the rhino. One private game reserve said that they were afraid if the information gets into the wrong hands, the poachers could use it against them and attack their animals. Another game reserve declined to be part of this research out of fear that poachers might identify them as having rhinos in their park. Many of the game reserves in South Africa will not disclose if they have or how many rhinos they have in their parks. One will find on their websites that they either have the "Big 5" or do not say anything. It is for this reason that a researcher had to have knowledge of the area and what animals these parks do have, in order to contact the various parks and conduct the research.

The third difficulty that was found is the reluctance of an organization talking to a researcher. Two organizations declined to be part of this research as they do not see how research will stop the rhino-poaching problem or help the rhinos. Both these organizations believe that if South Africa wants to stop the problem, it needs to be done from donations to the APUs and not by research. The two organizations said that any information that one needs is already out on the internet or in print media and mentioned that they have nothing more to offer. In fact, two other organizations that originally declined sharing any information in the initial contact, eventually changed their mind and decided to part of the research. This was because of 
the researcher being able to interview one organization, which then contacted the other two organizations and asked them to help with the research.

The fourth and final difficulty found was due to the researcher's background. When first contact was made, one organization had originally believed the researcher was a foreigner and not a "local" South African. However, once contact was made and the researcher shared his experience and love for South Africa, the organization opened up. The reasoning for this was the organization believed that no foreigner could come into a country and tell that country how to deal with its problems or conduct research on its problems. Other organization agreed to this and said it is difficult for an outsider to come into an area and attempt to fix a problem. For the purpose of this research, it is believed that because the researcher is a South African, the participants were willing to share more information than if the researcher was a foreigner.

\section{Data Analysis}

In order to obtain the goals of this research, the researcher grouped the data that was collected into three different sections. These three sections were organized in the same fashion as the research questions. The first section included all the relevant information that was received in relation to identifying the problem. In order to come up with any possible solutions, one first needs to clearly identify the problem at hand. Thus, this section included information on the poaching of the rhinos. Information here included, how many rhinos have been poached, why they are being poached, where they are being poached, how they are poached and who is committing the poaching. Included in this section was information on the methods of the poachers. The second section of the data was then grouped into a category that analyzed what is currently being done to protect the rhinos and prevent rhino poaching. This included any policing strategies or programs that have been used to combat the problem at hand. The third section of 
the data was grouped into what needs to be done in the future. The information that was received in this section aimed to identify possible programs and techniques that can be used in creating and implementing possible solutions to stop the rhino-poaching problem in South Africa. By evaluating what the problem is and identifying what measures are currently in place, the researcher will be able to combine ideas and techniques from practitioners and research to create a possible working solution for the survival of the rhinos.

\section{Reason for Choosing Methodology}

In order to conduct research there is a wide variety of methods in which to choose from, however, the goals of the research are often what can persuade a researcher to use one type of method over another. Due to the lack of research on the topic of rhino poaching and in particular the methods that are being used to prevent rhino poaching, the researcher decided to use exploratory qualitative research in order to obtain the data. In order to conduct the research, the researcher did not obtain data through e-mail questions, instead opted for face-to-face interviews. The reason for this being that in the nature of the work of an APU, they are unable to sit for a long period of time behind a desk and answer questions. Instead, they would rather meet face-toface and give information about the topic. In addition to this, rhino poaching is a problem in South Africa and the participants would not simply give out information to a researcher if they do not know them. In order to understand why this is true, one needs to understand the South African culture. In South African culture, people are reluctant to express information or ideas over the phone, or even e-mail on a topic such as this. The culture in South Africa is very much on the basis that if you want to know then come to me and let me show you, instead of just telling you. It is for this reason that the researcher believed it was best to go to South Africa, introduce the research and obtain the data on a face-to-face basis. 


\section{CHAPTER V: FINDINGS}

This chapter of the research focuses on the practical elements of the study. This chapter will provide information and analysis on the data that was gathered from the qualitative interviews. The results of the data provide an overview of the data that was collected and is guided by the research questions for this paper. The research questions and aims which were provided in chapter one, are specific to this research paper and therefore this chapter includes a description of the results that were found. Due to the exploratory nature of this research, the results will be discussed in relation to each of the research questions used for the paper.

\section{What is the Extent of the Rhino Poaching Problem in South Africa?}

The research that was conducted for this paper came up with many findings that are important to the research on the rhino-poaching problem in South Africa. To identify the extent of the rhino poaching problem in South Africa, the author used the basis of evaluating the numbers of rhinos being killed, where are the rhino being poached, when are the most prominent times that they are poached, who is committing the poaching, how they are killed, how much is rhino horn worth, how rhino horn is trafficked to other parts of the world, what is the rhino horn being used for? In addition, the research will identify if there are any links between rhino poaching and other forms of crime.

\section{Rhino Poaching Statistics}

The data that was collected for this paper found that rhino poaching is not a new phenomenon, however, a sharp increase of rhino poaching was found in South Africa since 2008. The research found that between 2000 and the end of 2015; approximately 5,168 rhino have been poached in South Africa. The results found that between 2000 and the end of 2007 only 120 rhino were poached in South Africa (See Table 6). The year that had the highest amount of 
poached rhino was 2002, which had 25 rhino poached. The year before the sudden increase in rhino poaching (2007), saw 13 rhino poached in South Africa. In 2008, however, these numbers quickly escalated and 36 were killed in the Kruger National Park alone, which is higher than any total combined amount of rhino poached in the previous years. The total amount of rhino poached in 2008 was 83 and this amount has gradually increased to 122 in 2009, 333 in 2010, 448 in 2011, 668 in 2012, 1004 in 2013, 1215 in 2014, and an approximate 1175 in 2015 rhino poached. According to reports as of September 11, 2016, a further 702 rhino have been poached in 2014 (See Table 7) (Modise, 2016). The research found that the two hardest hit areas of rhino poaching, from 2000 to until 11 September 2016, were the Kruger National Park and the Limpopo Province with the rhino poaching numbers being 3,708 and 448 respectively (See Table 6). It is important to note, that as of 2015 the provincial statistics were incorporated into one category due to safety reasons. Two other areas were found to be of concern were the North West Province and KwaZulu-Natal, with total rhino poaching numbers at 326 and 395 respectively (See Table 6). These four areas collectively account for approximately 90 percent of South Africa's rhino numbers and have been hardest hit, representing approximately 90 percent of all rhino poaching incidents between 2000 and 2015. Figure 4 clearly shows the incidents of rhino poaching per year, from 2010 to 2016, in the various regions in South Africa. South African has been losing rhino on a daily basis, where in 2010 there was about one rhino poached each day. These numbers have gradually increased from 0.91 rhino poached per day in 2010 to 3.22 at the end of 2015 (See Figure 5). Rhino are not free roaming animals; therefore poaching occurs in private game reserves, found in each province, private game farms, or national parks in South Africa. A private game reserve is an area of land that is set aside for conservation purposes 
and is commonly used by tourists for safaris and sightseeing. A game farm is most commonly used for the legal hunting of a species. 


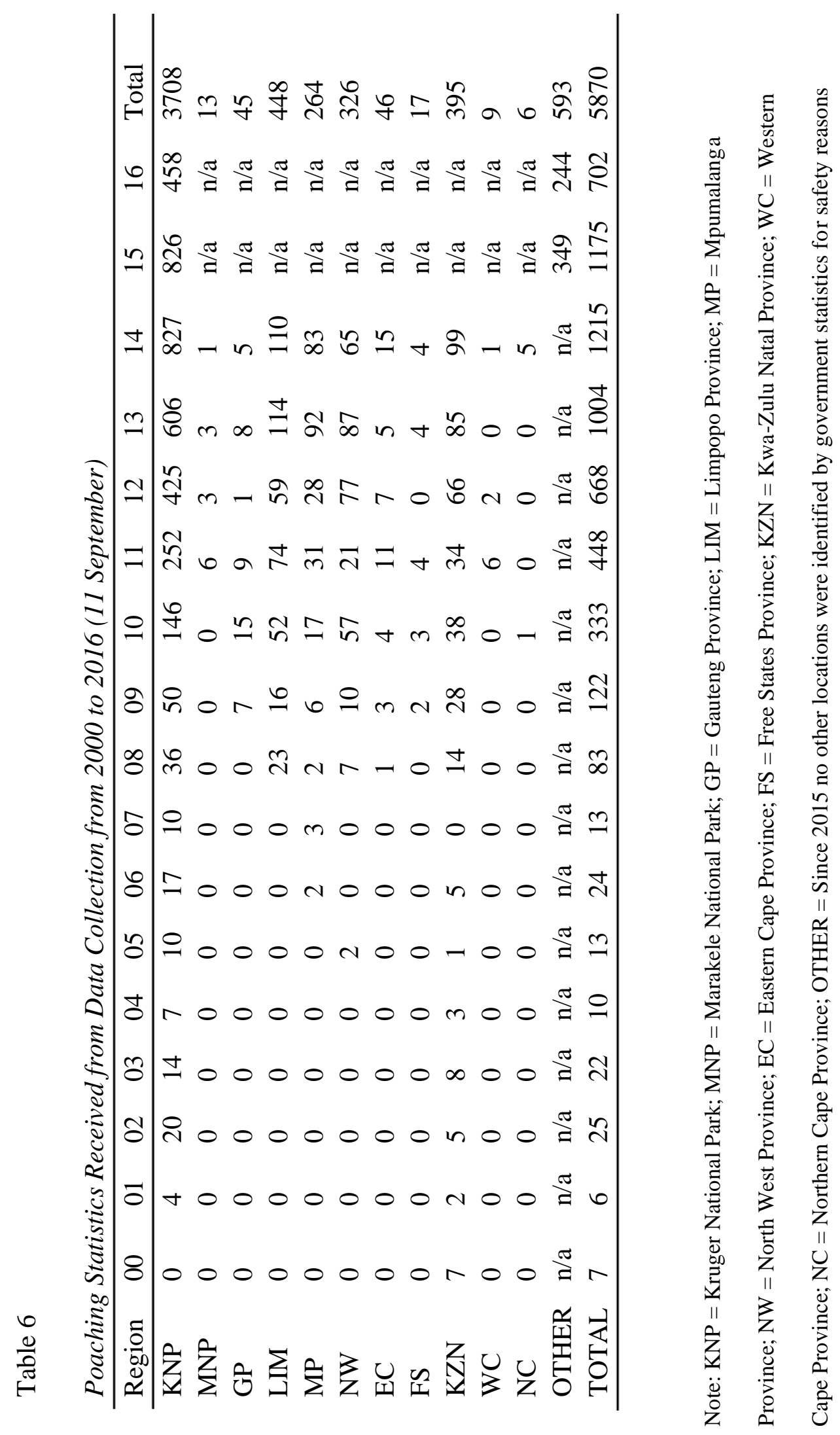




\section{Table 7}

Rhino Poaching Statistics from 2010 to 11 September 2016

\begin{tabular}{lcccccccc}
\hline South African Region & 2010 & 2011 & 2012 & 2013 & 2014 & 2015 & 2016 & Total \\
\hline Kruger National Park & 146 & 252 & 425 & 606 & 827 & 826 & 458 & 3540 \\
Marakele National Park & 0 & 6 & 3 & 3 & 1 & n/a & n/a & 13 \\
Gauteng & 15 & 9 & 1 & 8 & 5 & n/a & n/a & 38 \\
Limpopo & 52 & 74 & 59 & 114 & 110 & n/a & n/a & 409 \\
Mpumalanga & 17 & 31 & 28 & 92 & 83 & n/a & n/a & 251 \\
North West & 57 & 21 & 77 & 87 & 65 & n/a & n/a & 307 \\
Eastern Cape & 4 & 11 & 7 & 5 & 15 & n/a & n/a & 42 \\
Free-State & 3 & 4 & 0 & 4 & 4 & n/a & n/a & 15 \\
KwaZulu-Natal & 38 & 34 & 66 & 85 & 99 & n/a & n/a & 322 \\
Western Cape & 0 & 6 & 2 & 0 & 1 & n/a & n/a & 9 \\
Northern Cape & 1 & 0 & 0 & 0 & 5 & n/a & n/a & 6 \\
Other & $\mathrm{n} / \mathrm{a}$ & $\mathrm{n} / \mathrm{a}$ & $\mathrm{n} / \mathrm{a}$ & $\mathrm{n} / \mathrm{a}$ & $\mathrm{n} / \mathrm{a}$ & 349 & 244 & 593 \\
Total & 333 & 448 & 668 & 1004 & 1215 & 1175 & 702 & 5545 \\
\hline Note & & & & & & & &
\end{tabular}

Note: From (Modise, 2014) 


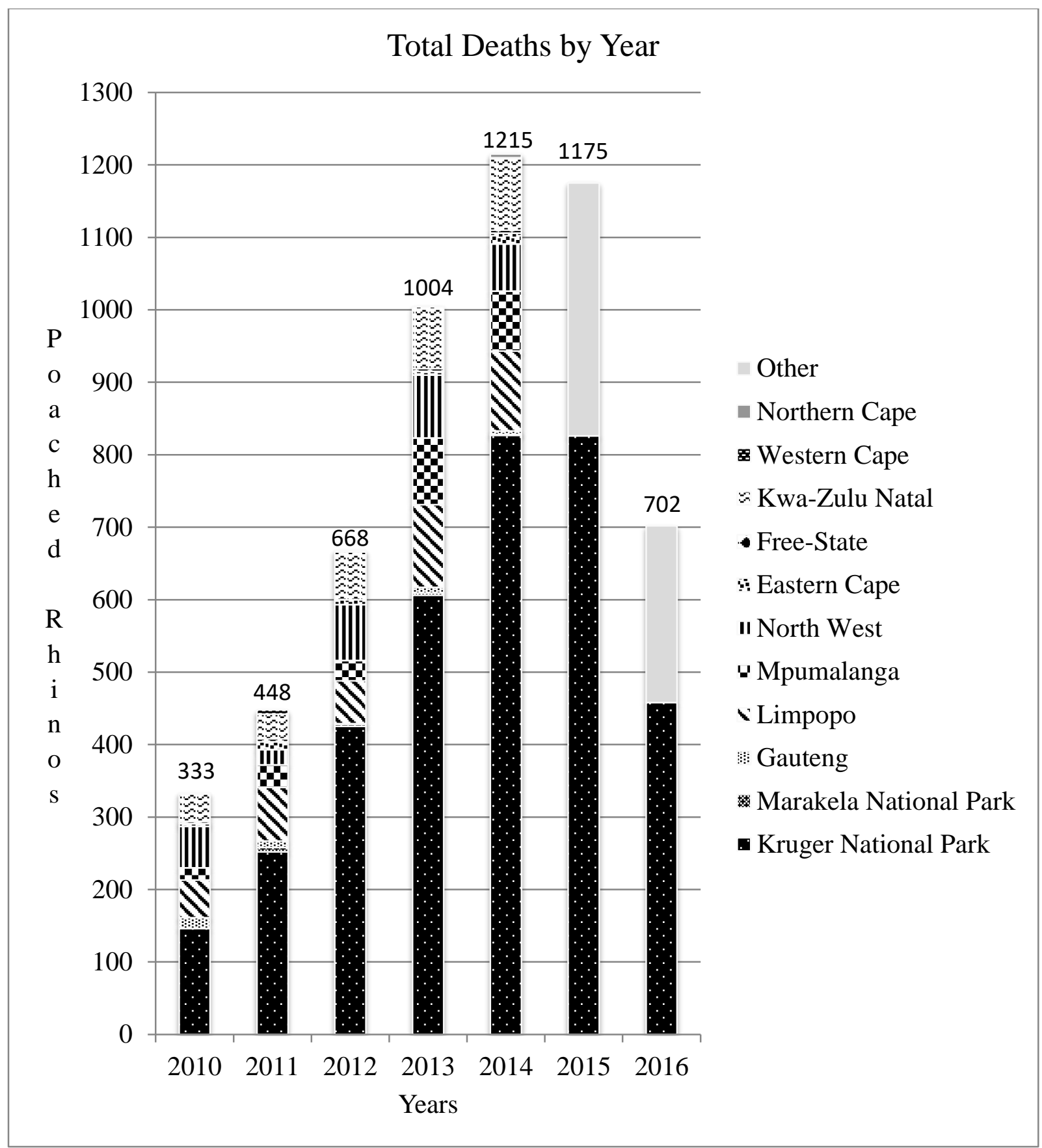

Figure 4. Incidents of Rhino Poaching in South Africa from January 2010 to 11 September 2016. From (Stop Rhino Poaching, 2017) 


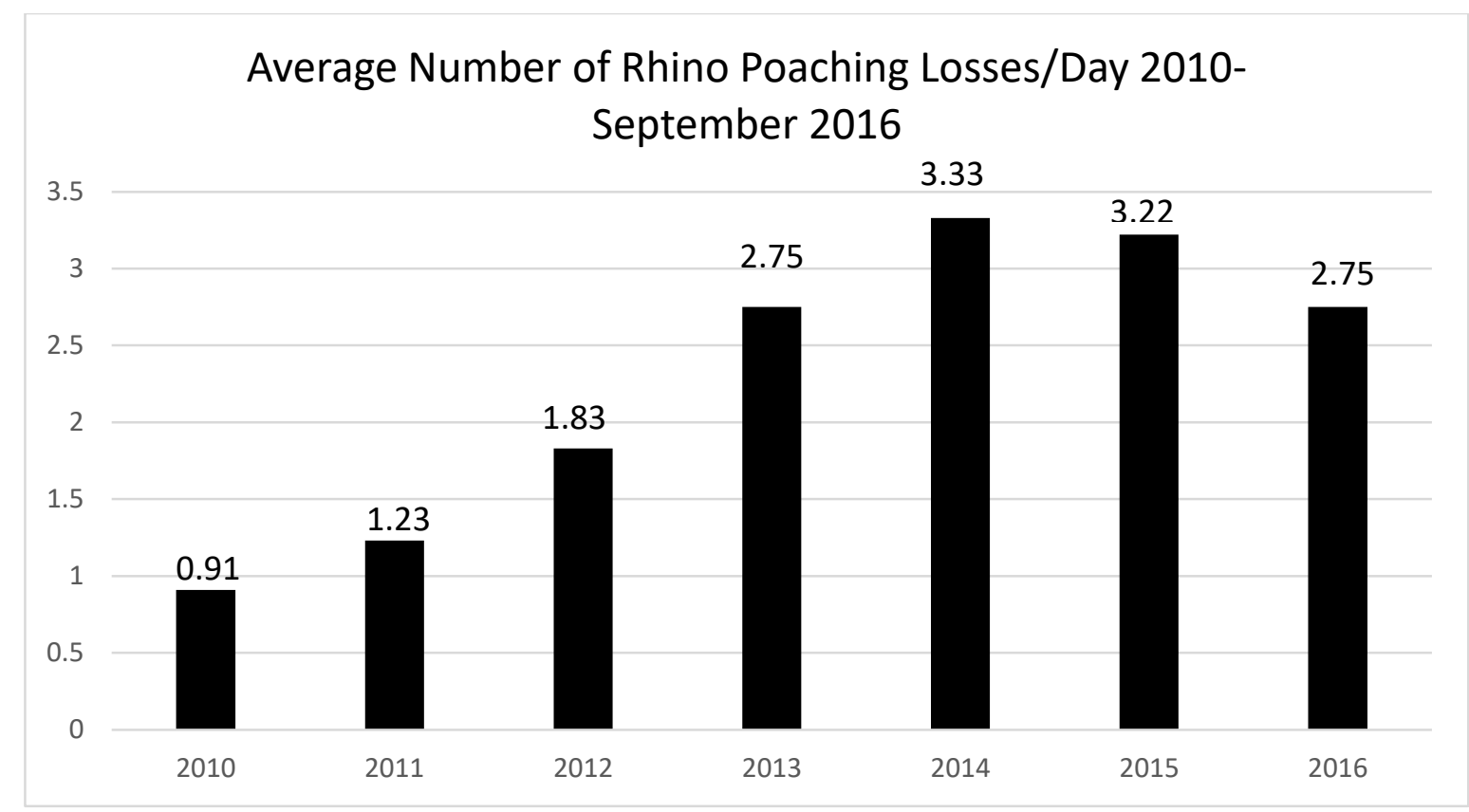

Figure 5. Average Number of Rhino Poaching Losses/Day in South Africa from January 2010 to 11 September 2016. From (Stop Rhino Poaching, 2017)

\section{Cycle of Rhino Poaching}

The research found that rhinos are killed throughout the year in South Africa. One respondent, however, did mention that there was a link between the seasons of the year and poaching. It was suggested that during the rainy season (October - March), rhino poaching increased, whereas, in the dry-season (April - September), rhino poaching seemed to decrease. These results, however, cannot be confirmed as the data for rhinos poached by season or month was not available. Milliken and Shaw (2012, p. 71), however, supplied a graph on rhino poaching by the seasons from 2010 to June 2012, and although it looks as if there is an increase in the rainy season, it is more of a gradual increase of poaching over the months (See Figure 6). 
The participant explained that during the dry-season, water is scarce and the rhino need to obtain water to drink. Therefore, APUs are able to identify the water sources and patrol these areas more heavily. In the rainy season, however, water sources are plentiful and rhino are able to drink from a variety of areas. This then increases the patrol areas for the APUs and the increased patrol area means that it is less likely for the APUs to prevent poaching from happening.

The second time variable, phases of the moon, of rhino poaching was discovered in the research. The research found that poaching incidents seemed to increase during full moon, at night, and is what is now commonly referred to as "Poacher's Moon". It was found that poaching activities seemed to increase at night, when the sky is clear and there is a full moon to brighten up the areas. The full moon makes it easier for the poachers to track, see and poach rhino. In addition, the full moon also enables the poachers to see any APU patrols or predatory animals, and therefore keeps them safe and undetected. The cover of darkness, not only allows the poachers to go undetected by APU patrols, but it allows the poachers to get within close proximity $(+/-5 \mathrm{~m})$ of the rhino because of the rhinos poor eyesight at night. 


\section{Seasonal Patterns of Rhino Poaching 2010-June 2012, Rhino Poached/Day}

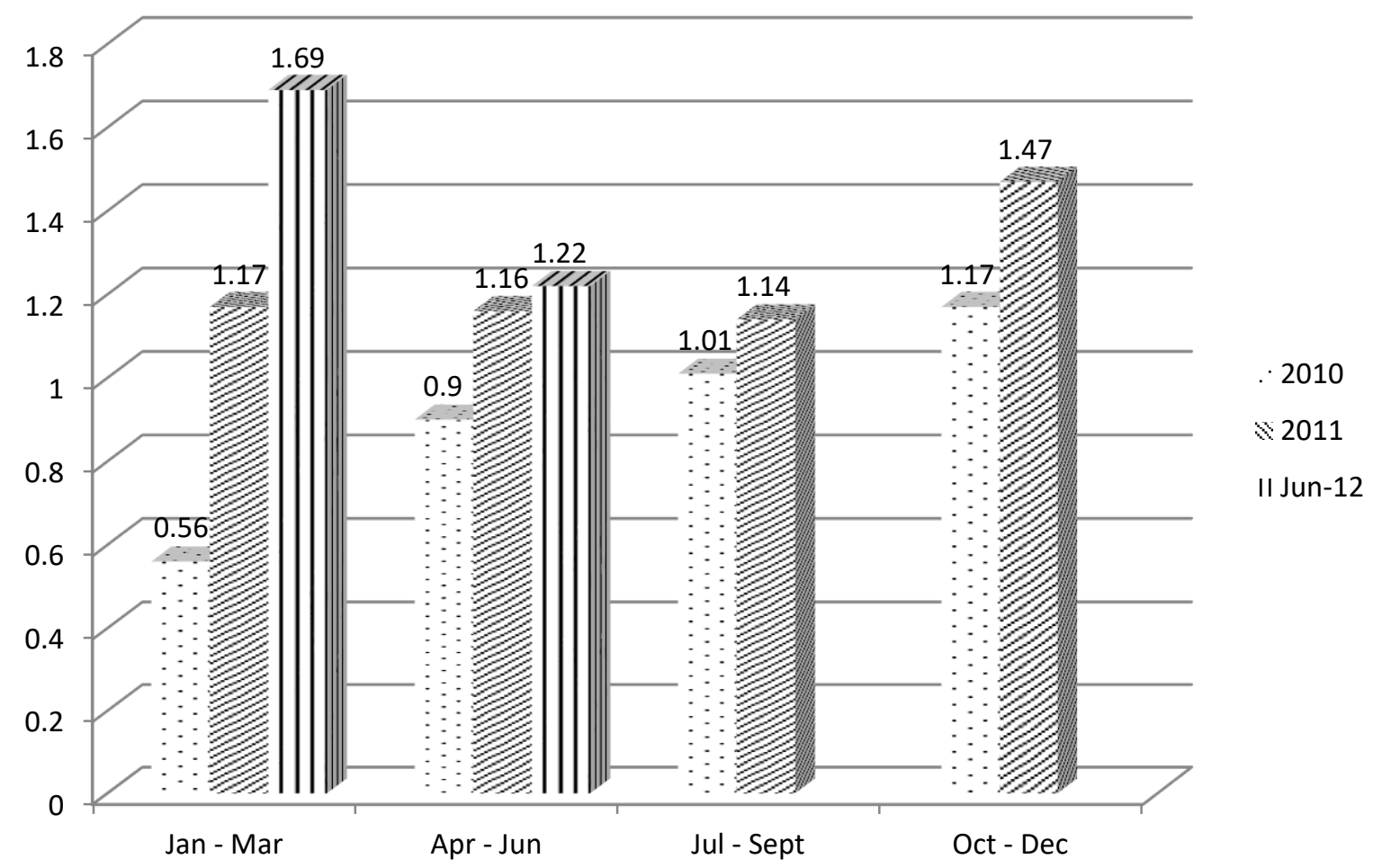

Figure 6. Seasonal Patterns of Rhino Poaching Incidents in South Africa 2010 - June 2012. From (Milliken \& Shaw, 2012, p. 71)

\section{Who Is Committing the Poaching?}

The research found that there are three different types of poachers. The first type of poacher is the subsistence poacher, who poaches animals in order to obtain food for themselves and their family to survive. The second type of poacher is the commercial poacher, who will poach animals to obtain an income, and is often found in the form of bushmeat poaching. The 
last type of poacher and the one that this research is interested in is the syndicate poacher. These types of poachers are the ones who are currently involved in the poaching of rhinos in South Africa.

The research found that there is a variety of different people involved in rhino poaching. The results found that the people involved in rhino poaching include game rangers, law enforcement officers, ex-military personal, private rhino owners, APU field rangers, local community members, and professional hunters. The participants suggested that anyone who is motivated by money, regardless of profession, race or gender could become involved in rhino poaching. In fact, one participant suggested that police lights are often used in vehicles to get away from a crime scene after a rhino-poaching incident. It was also found that transnational criminal networks are currently involved in poaching and trafficking of rhino horn. The research found that there are four main countries involved in the poaching of rhinos and the trafficking of its horn. The four main countries that were identified are South Africa, Mozambique, Viet Nam and China. The results for this study found that more recently the poachers are more commonly of Mozambican heritage, with a few instances of South Africans being involved. The participants suggested that many of the Mozambican poachers have had previous military training and are adapt at tracking and anti-tracking techniques. Mozambique has a long history of conflict and the research suggests that many of the poachers have turned to poaching for a viable income. The techniques of the poachers is so deep that some are able to cover their own tracks and make them look like Zebra spoor. The poachers now have an advantage over the APU as they are trained in both tracking and weapons, and are able to poach the rhinos and shoot back at the APUs with ease and skill. The skill of the poacher is often seen in the precision of the shot and wounds to the rhino. The less experienced poachers will often need more than one shot to kill a rhino, 
where the more experienced poachers only need one shot to kill a rhino. In fact, one APU supplied information about a trainee of theirs, who eventually turned to rhino poaching. The trainee came into their training program and learnt all of the APU strategies and techniques used in anti-poaching. It is believed that the poacher has started his own syndicate and the APU is struggling to catch the poacher. The APU has since had to change their strategies in order to stay ahead of the poaching syndicate. At the time of the research (January 2014), the APU stated that the poacher has yet to be caught.

The research found that a South African is often used by Mozambican poachers as a spotter or someone who does not poach the rhino, but just points out and takes the poachers to where the rhino would be. The poachers often use this tactic of using a local in the community, as a local in the community has grown up in the area, knows where the animals are, how to blend in the community and knows the various entrances and escape routes into and out of the various game parks. These tactics have been found in both the Waterberg area and Hoedspruit area in South Africa. The research also found that poachers in the Kruger National Park will often come from Mozambique and will already have some knowledge of where the animals are and will not always use a South African to find the rhino. To a lesser extent, there has been Zambian, Malawian and Zimbabwean nationals who have been arrested for rhino poaching. In addition, it was discovered during the research the actual shooter of the rhino was usually foreign and was never the syndicate leader. Through this research, it was discovered that around 80 percent of all poachers are of Mozambican nationality, where almost all are males. Some of the reasons given for this was because of extreme poverty conditions in Mozambique and because of the porous borders between Mozambique and South Africa. It was found that Mozambican poachers were able to easily walk into the Kruger National Park, from Mozambique, poach a rhino and then 
walk straight back to Mozambique. Once the poachers are in Mozambique, they are now untouchable and any means to apprehend a poacher across the border may be seen as an act of war. In addition, Mozambicans are used by Asia, because they already have a foot in the country, where China is developing the roads, infrastructure and is involved in logging, therefore it is convenient.

Location played an important part to the size of the group that would enter a game park. Research found that in the Kruger National Park, the size of the group is anywhere from five to thirty members and there is about five or more groups in the Kruger Park at any given time. The smaller areas or areas with private game reserves, such as the Waterberg (Limpopo) area has poaching groups that consist of about three to five foreigners (usually Mozambican) and always at least one local South African as a spotter. The groups that enter the parks are heavily armed and usually carry pistols, high caliber rifles and in some instances assault rifles. In each group, one will find at least one designated shooter of the rhino, one member who acts as the protection for the group and will carry an assault rifle, and one member who will carry an axe or panga (machete) to remove the rhino horn. The research found that the groups that are coming into the areas are becoming more and more sophisticated and have access to equipment, such as night vision, that some of the anti-poaching teams do not have. The "poacher's moon" is when poaching seems to increase, however, the research suggests that as these poaching syndicates become more organized they are able to purchase night vision and other accessories that enable them to poach in the darkness. APUs have found that poachers use sophisticated silencers and other equipment as an attempt to mask any sound as to notify security forces. The fact that poachers are able to purchase better technology to help them poach the rhinos is a worrying fact 
because many of the APUs are often outgunned by the poachers and thus must rely on tactics and intelligence.

The research found that if a game reserve owner treats his employees badly, that reserve would start to lose rhinos. The disgruntled employee can be easily bought by the poachers as a spotter and can often receive anywhere from ZAR15, 000 to ZAR60, $000(\$ 1,130$ - \$4,522, at an exchange rate of 1 USD for 13.27 ZAR in February 2017) to merely point out a rhino. In addition, the research found that the shooter is usually foreign and is hardly ever the syndicate leader. In fact, it was found that the syndicate leader would never carry a weapon. The money that is dealt with in the syndicates is mainly cash and poor areas that border the Kruger National Park, in Mozambique, have seen an increase in luxury vehicles and five or six bedroom houses built among mud huts and shacks. It is suggested that the shooter of the poaching syndicate can earn anywhere between ZAR10, 000 to ZAR30, 000 (\$753 - \$2,261, at an exchange rate of 1 USD for 13.27 ZAR in February 2017) for their involvement of the crime.

The research found that both China and Viet Nam is where the demand is for rhino horn. It was found that Mozambique is most often used by China because they already have an influence in the country. Chinese firms have played a large part in the development of the Mozambican roads in recent years and have been part of the construction of many buildings, including government buildings and stadiums. The research participants that were interviewed believe that this is why there has been an increase in poaching in the recent years. One participant mentioned that because there is so much construction and shipment of goods going to Asia from Mozambique, it is easier to send the rhino horn through legitimate companies. In addition, criminal networks seem to be using Mozambique, as it is a poor country where the 
members of its society are looking for means to make an income. In addition, Mozambique has large-scale corruption that enables these criminal networks to use this to their advantage.

During this research, it became apparent that the treatment of the staff in the game parks, by the game park owners would also have an influence on rhino poaching in the area. The research found that a disgruntled employee has the means to help the poachers as a spotter, because he or she is a local in the area and knows the area very well. In addition, intelligence suggests that the poaching groups often have one to three people already inside the game parks that have been paid for their information. The research found that all participants agreed that in order to help stop the poaching in South Africa, the areas where game parks are situated need to include the local communities as much as possible. If the communities are included and are treated well, they will be able to be the ears and eyes on the ground, which can then give information about possible poaching to the APUs.

The final aspect that was discovered during this research is the "robin hood" effect. The "robin hood" effect is seen in many local communities in and around game parks in South Africa, where many of the poachers are often seen as "heroes" or "robin hood" as they take from the rich and give to the poor. Local communities have often been left out of the riches that come along with the tourism of game parks. Thus, when a poacher goes into a game reserve, poaches an animal, and brings the meat back to the community, the community see the poacher as a hero. This is not only found in the bushmeat trade, but also in rhino poaching. Rhino poachers in local communities earn large sums of money, compared to others in that community, and when they are able to buy new cars, new clothes, and even a new house, many locals admire the poacher. This acts as an incentive for others in the community to engage in poaching activities. The fact that local communities are left out of the possible monetary gains from tourism is worrying fact 
and thus techniques ought to be developed in order to engage the local community in the tourism and conservation of an area.

\section{How are Rhino Poached?}

Rhino poaching takes place in wide variety of ways. In the past, it was found that pseudohunts would take place and Asian syndicates would obtain the horn through these techniques. However, more recently there has been an increase in poaching groups or syndicates coming from Mozambique into South Africa and killing rhino for their horn. Depending on the area where the rhino is located, the poaching groups will travel either by car or on foot to their destination. If the poaching is taken place in the Kruger National Park, the poachers will often only spend a couple of hours to two days in the park and will then obtain the rhino horn and then leave. In areas that are further away and require a vehicle, it was found that the poaching groups could often spend up to a week in the local community of the game parks. The poachers will obtain their spotter, learn the terrain of the area from their spotter, blend in the community, and ultimately kill the rhino and take its horn. To shoot the rhino, the poachers often use a highpowered rifle, however, AK 47s and other assault rifles have been used to both shoot the rhino and defend themselves from the APUs. With the growing organization of the poaching syndicates, APUs are finding that a lot of the poachers now have access to silencers to muzzle the sound of the shot, as to attract less attention. Once the rhino has been shot, one member will use an axe or panga and begin hacking off the horn. Often, the rhino is not dead and the hacking of the horn, often leaves the rhino to bleed to death, as they will hack off half of the rhinos face. Poachers, who are able to kill a rhino with one gunshot, are the poachers who are usually well trained with some military or firearm experience. Another level that shows the professionalism of the poachers is how the horn is removed. The research found that if a horn was removed with 
a clean cut and not hacked off by a panga or axe, then it shows that the poachers had enough time to get the horn cleanly. This means that the poachers had used some type of method to avoid detection, which gave them enough time to take the horn with a clean cut, by using a handsaw. The poachers who are less organized or sophisticated will usually take a horn by chopping or hacking it off with a panga or axe. The reason for removing a horn in the different ways, can either be as a result of not having enough time, or it could simply be because of the expertize of the poachers.

Another less common method for the poachers is the use of M99 or Etorphine. This is usually used in a dart gun, which is used to dart the rhino, which enables the poachers to get within close proximity of the rhino, and then shoot it and remove the horn. The use of M99 usually means that the poachers have some experience or training in veterinarian work or that a veterinarian was involved in the poaching. Another interesting method that is used by the poachers is the use of fires. Poachers have been found to start fires as a means to cover or destroy evidence, as diversion tactic and even as a funneling method. It has been found that after poachers have shot, killed and removed the horn of a rhino, they will sometimes start a fire as a means to destroy any evidence that they may have left behind at the scene. Additionally, poachers have also started fires in different areas of a game park; this is done so that all personal are deployed to that area to try to combat the fire, while the poachers are in a different area poaching a rhino. Another tactic the poachers have found to use is the use of a fire to funnel animals into a certain kill zone. This is used to get the animals to run in a certain direction where the poachers are usually waiting in an ambush. Finally, the poachers have also used fires as a means to block off the APU's, so that the poachers are able to get away. 
One of the organizations that were interviewed for this research took the researcher on a tour of the training facilities, where they were able to show the various snares that are used in poaching all animals in South Africa. One of the ways in which the less organized poachers kill rhinos is through snares. Snaring is a major problem in South Africa and Africa and is found in almost every private, provincial or national game reserve. Snaring of rhinos is done in such a manner that when the animal walks through the wire snare, it will be caught around the animal's neck and will eventually kill the animal. The poachers who use this tactic, though somewhat less sophisticated than the poachers who use technology to kill the rhino, have great knowledge of the bush in South Africa and use this to their advantage. They do not have the money to obtain weapons or expensive equipment and hence resolve to using snares.

\section{How much is Rhino Horn Worth?}

It has already been shown that the rhino poachers obtain a relatively large sum of money for their involvement in the crimes. This amount, although small to some, is considered a lot to poachers who come from poor impoverished areas. Therefore, in order to understand how these poachers obtain these sums of money, it is important to understand the actual value of the horn in the illegal markets and the volume of horn that is being trafficked.

The first error that one encounters in this is by only looking at the total number of ceased rhino horn by law enforcement agencies around the world. It is very difficult to estimate the total value or the volume of rhino horn that is being trafficked around the world, let alone the value or volume through individual cities or countries. One way that this can be done is to take the total amount of rhinos poached per year, take an average weight of the horn and multiply this number to get an estimate of volume. However, one needs to take into account that the white rhino horns are larger and weigh more than the black rhino horns. Although this may be true, white rhinos 
count for approximately 90 percent of all rhinos poached in South Africa. Taking this into account the average weight of a pair of black rhino horns is approximately $2.5 \mathrm{KG}$ and the average weight of a pair of white rhino horn is approximately 6-8KG. The 2011 statistics noted that out of 448 rhinos poached in that year, 429 were white rhinos and 19 were black rhinos. These statistics gives that 95.8 percent of the time a white rhino is killed. If one takes into account that 95.8 percent of rhinos poached are white rhinos, then out of the total rhinos poached from 2010 until January 1, 2014 (2,350), the total number of black rhinos lost due to poaching is approximately 103 and the total number of white rhinos lost to poaching is 2,453 . If one takes an average of 7KG for a pair of white rhino horns and multiplies this by the total number of rhinos lost $(2,350)$ due to poaching, then since 2010 until January, 1, 2014, one can estimate that the total volume of white rhino horn that is likely to be trafficked during this time period is approximately $16,450 \mathrm{KG}$. Additionally, if one takes the total number of black rhinos lost to poaching (103) during the same period and multiplies it by the average horn weight of $2.5 \mathrm{KG}$, then the average volume of black rhino horn to be trafficked during this time period is approximately $258 \mathrm{KG}$. By adding the totals up, it gives an approximate volume amount of possible trafficked rhino horn of $16,708 \mathrm{KG}$ during the period of January 2010 to January 1, 2014. This estimate is closely related to the estimate of the rhino horn stockpile in South Africa as of July 2013, which was $18,438 \mathrm{KG}$. However, it is important to note that not all rhino horn that is poached makes it over to its final destination. Many rhino poachers are caught and horns are confiscated at ports of entry and thus the volume for trafficking could be considerably lower. The volume of $16,708 \mathrm{KG}$ is an indication of how much rhino horn could be trafficked to the Asian market. 
Research has suggested that the price of rhino horn in the black market has increased at a rapid rate. The research for this paper gave an indication that rhino horn in the black market can be sold for anywhere between $\$ 65,000$ to $\$ 85,000 / \mathrm{KG}$. If one takes the possible volume of trafficked rhino horn and multiplies it by the total price per KG of rhino horn one is able to get that the total value of possible trafficked rhino horn between January 2010 and January, 1, 2014. The total value of trafficked horn is anywhere from $\$ 1,086,020,000$ to $\$ 1,420,180,000$. South Africa was hardest hit in 2014 by poachers and lost 1215 rhinos, this equates into approximately 1164 white rhinos $(95.8 \%)$ and 51 black rhinos. By taking these populations one can work out that the total possible volume and value of trafficked rhino horn in 2014 alone, could be $8,276 \mathrm{KG}$ and this equates to anywhere between $\$ 537,940,000$ and $\$ 703,460,000$. As stated above these numbers are estimates of total possible trafficked rhino horn. However, like all illicit good markets, it is difficult to determine the full value or volume of rhino horn trafficked.

\section{Trafficking of Rhino Horn}

The research for this paper came across various means of trafficking and the different routes that are used by the traffickers to obtain their product. The main countries from which the rhino horn is sent, is usually the country of source, thus being either South Africa or Mozambique. The main area where the horn is smuggled from is through wet and dry ports. The most common of these is the O.R. Tambo International Airport in Johannesburg, South Africa, Durban Harbor in KwaZulu-Natal, South Africa and Cape Town International Airport in the Western Cape, South Africa. The research also found that rhino horn that has made its way into Mozambique would often leave from the harbors and airports in Mozambique. However, the rhino horn does not simply go directly to Viet Nam or China, there is often a few countries that the horn will go through before it has landed in Viet Nam or China. One method that is used in 
air transport is to fly from South Africa or Mozambique, through Ethiopia and then onto Viet Nam. The following countries have also been listed by intelligence as countries that are of concern that the horn is trafficked through: Thailand, Laos, Cambodia, Viet Nam, Hong Kong, Philippines, China and Ethiopia, where the host countries such as South Africa and Mozambique are usually the starting points of the horn. According to an intelligence source, there are two main syndicates currently in operation. These first is a Peoples Republic of China syndicate and the second is Taiwanese based syndicate.

In the wet ports or harbors, the rhino horn is usually trafficked in containers where the traffickers have various means of trying to hide the rhino horn. Some of the ways that were identified in the research was by doing a rip off. This entails a member or transporter of the rhino horn adding the horn to a legal consignment in a container. The syndicates will have a member at the harbor where they will open the container and hide the horn among the legal goods. The syndicate will then have another person at the port of entry in the destination country, where the syndicate will have a member that opens the container and retrieves the rhino horn before any law enforcement can find it and before the legal consignment is delivered. Another tactic that is used by the syndicates is to set up fictitious company that is able to send the rhino horn with little to no inspection. The third way of transit is very similar to the above-mentioned fictitious company; however, this time the syndicate will utilize a legal already established company and pay them for their services for the transit of the rhino horn. Often the legal company may not know that the rhino horn is in the consignment and is an innocent bystander. However, there are times when the company does know what the goods contain and are then paid off by the syndicates. Another method that is used by the syndicates is an attempt to mask to the smell of the rhino horn, so the sniffer dogs are unable to identify the smell. Some of these methods 
include the same methods that traffickers have used on ivory masking. These methods include covering the horns with Cayman pepper, garlic, dipping it in chocolate, covering the horn in green beans and even hiding the horns among very strong smelling chemicals. The next method that was identified during the research was by creating false compartments within the container, or within the "legal" goods of the container.

In the dry ports or airports rhino horn is trafficked various ways. Research has found that rhino horn is hidden in suitcases of passengers and consignments headed for Asia. The horns have also been found to be covered in similar masking techniques used in containers. In fact, some seizure cases of rhino horn have found that the rhino horn is covered with blood and in some instances the blood is fresh, which illustrates that the time taken from poaching to trafficking can be hours. Another common method, which has been found, is the same trafficking methods that have been seen in ivory trafficking. The transporters of rhino horn have been found to make jewelry or ornaments out of rhino horn as technique to try to avoid detection.

\section{Use of Rhino Horn}

The research found that there is a wide variety of uses of rhino horn in Asia. Like the literature review, this research found that rhino horn is used in Traditional Asian Medicine. Rhino horn, in Asia, is believed to reduce body temperature, and eradicate the body and blood of toxins. The research also suggests that rhino horn can treat high fevers, headaches, measles, convulsions, epilepsy and strokes. More recently, rhino horn is now being promoted as a treatment to cancer, where a government official claimed that rhino horn helped cure his cancer. This story, however, could not be confirmed by the research and the government official has never been located or the story verified. 
The results from this research also suggest that a new use of rhino horn includes the consumption of the horn (usually in ground form) after excessive alcohol intake and rich food. The research also found that rhino horn is now seen as a luxury goods item, and can be placed in the same category as a luxury vehicle. According to one research participant, rhino horn is often shared among upper class members of society in Asia. If one takes out all their friends for dinner and drinks and they all consume too much alcohol, one member will offer rhino horn as a remedy for a hangover. This gesture is then repeated when the group goes out again and another member strives to keep up this elite status. The rhino horn, which has no effect, is now seen as a status symbol, hence any member of the group will try to obtain rhino horn in order to keep up their status among the group. This has a ripple effect onto the other member of the group and the demand for rhino horn keeps increasing.

The research found that the common idea that the uneducated members of society in Asia use rhino horn is somewhat false. The value of rhino horn is too great to be used by the uneducated and poor. Due to the large amount of fake rhino horn, however, the demand for it in the poorer and uneducated communities is still prevalent. Research suggests that rhino horn has no nutritional value; therefore, the educated members of society and the upper class members of society will know that there is no nutritional value to it. For this reason, one participant suggests, that the main consumers of rhino horn in Asia are the upper class and social elites of society. These members use rhino horn as an acceptable form of currency, and like diamonds and jewelry is seen as a luxury goods item.

\section{Link between Rhino Poaching and Other Forms of Crime}

The final section of the findings of this research question will explore if there are any linkages between rhino poaching and other criminal activities. From the participants interviewed 
it became evident that there was no linkage between poaching of abalone and rhino poaching. One source mentioned that there is a link between the illegal ivory trade and the illegal rhino horn trade. Additionally, this source stated that there is a link between the illegal ivory trade and illegal logging, where ivory is often hidden inside the logs and sent to China. The source then speculated that if illegal ivory and illegal logging had a link, then what stops there from being a link between the illegal rhino horn trade and illegal logging. The same source mentioned that there are currently approximately 1,500 criminal syndicates in South Africa in 2014. These syndicates are not all rhino poaching syndicates, but include human trafficking, counterfeit goods, counterfeit currency, counterfeit sporting goods, counterfeit pharmaceuticals, ivory, drugs, pangolin and abalone. In addition, one source who has had close contact with the poaching syndicates states that the syndicates that are running the rhino poaching are the same syndicates that are running the diamonds and weapons trafficking. Finally, the same source stated that the rhino horn poachers and buyers often barter rhino horn for more powerful and better quality weapons and tactical equipment. By doing this, the poachers can become more organized and sophisticated in their methods used to poach rhinos.

\section{What is Being Done to Prevent Rhino Poaching in South Africa?}

The research for this paper found varies techniques and measures that are currently in place to prevent rhino poaching in South Africa. It must be noted that the APU techniques used are found in some of the private game reserves around South Africa. Techniques used in Kruger National Park were unattainable for this research. It must also be noted that the areas where the techniques are used will not be listed in this paper, due to the request of the various parties involved in the research. 


\section{Awareness}

The first method that was identified in the research was that of awareness campaigns by various NGOs involved in the fight against rhino poaching. Many of these NGOs are actively involved in spreading the word about the effects of rhino poaching. These awareness campaigns vary from international events, where members of the event offer to raise awareness for the rhinos, to more local awareness, such as advertisements and education of local people in and around game parks in South Africa. Some organizations take celebrities from Asia and other parts of the world, and show them videos of dying rhinos and show what disastrous effects poaching has on the animal. The organization will then take the celebrity on a safari and tour of game parks, and the celebrity will return to their home country, and raise awareness about rhino poaching problem. These awareness campaigns can also be found on the internet, print media, and other forms of electronic media. The NGO campaigns do not simply raise awareness, because of the high cost of equipment for APUs, these NGOs are able to obtain donations from people and companies from all over the world to give to the various APUs involved. These donations are then used by the APUs to fund their operations, equipment and daily duties. One participant mentioned that a NGOs role is vitally important in the fight against poaching, as without the awareness and donations, many APUs would not exist and more rhinos would be lost.

\section{APU Activities}

The measures that the APUs used were very similar in all regions of the research. In general it was found that APUs use an informer network as a means to prevent poaching from occurring. This informer network often consists of members from the local community, who will hear or see signs of poaching activity or threats. The research found that the APUs are 
intelligence driven units, which analyze the data obtained from their informers and then act to prevent poaching from occurring. The research also found that APUs do rely upon public knowledge and visual intelligence, and have set up tip-off hotlines in the areas of the game parks.

It must be noted that there is a difference between what is commonly known as a game ranger (field guide) and a field ranger (field guard). A game ranger is a person who takes people on guided tours of the game reserves, whereas a field ranger is an actual armed guard with tactical, weapon training, and act as law enforcement in the game reserves. The APUs have a very strict selection process, where one APU firstly requires a physical and psychometric testing. This is done to ensure that a field ranger will be physically capable to spend up to three weeks in the bush and chase or fight poachers, if need be. The psychometric evaluation is to identify if the candidate is psychologically fit to see the results of poaching, and to ensure that the field ranger will not turn on the APU, and use the training obtained to poach rhinos. The next phase of the selection process is the use of fingerprint checks to ensure that the field ranger does not have a criminal background or any outstanding warrants. The final phase of the selection process, includes a credit check to ensure that the candidate is not in debt, and does not need the skills taught during training to become a poacher. Once the candidate has passed all the prior checks and tests, they can begin their training. The APUs have their own style of training, and training lasts anywhere from five weeks to three months. Overall, it was found that the APUs strive to improve the candidates fitness and train the candidates in laws and legislation in South Africa; tracking of humans and animals; poaching methods; ambushing; sweeping formations; dangerous game; vehicle extraction drills; road blocks; rhino crime scene management; advanced weapon drills, and fire and movement; basic survival methods; patrol formations; extended clandestine patrols; camouflage and concealment; map reading; and night operations. It was 
suggested that the field rangers are trained to deal with any situation, and are trained by exspecial forces members of the South Africa Police or South African Military. The reasoning for this is because the APUs believe that what they have right now is war, and in order to fight the war, one has to train as a soldier. Another method that was found was to make one black male and one white male partners, when out on patrol. The idea behind this was to break away from the general stereotype of racism in the country, and bring about some unity in the units.

The research found that field rangers are on duty 24 hours a day, seven days a week for 21 days. During this time, the field ranger spends his/her time in the bush, in the game parks, and is required to conduct daily patrols of the area. These patrols can last from hours to days, however, the field rangers will live in a picket when not on patrol. The pickets often contain a bed and fridge. The field rangers are required to conduct two types of patrols, which are known as reconnaissance patrols and attack patrols. When the APU obtains information about a possible syndicate entering the game park, the APU will instruct their informer (the spotter for the poachers) to enter the park in a certain area. The APU will then use a V-shaped ambush, military tactic, in order to catch their offenders. The APU can lie in wait at the ambush site for hours or days, depending on how long it takes their informant to bring in the poachers. The idea of the ambush is not to kill the poachers, but rather to catch the poachers and question them to obtain more information about the rhino poaching syndicates. Therefore, correct intelligence is needed in order for the operations to be conducted smoothly, without any shots fired. One participant mentioned that a dead poacher is of no use. It was also mentioned that in order to obtain any information from the poachers, the field rangers and APU members should treat the poachers with respect and dignity, and the poachers should not be beaten or tortured. The research also found that many of the APU work on operational security, where information is on a need to 
know basis. It was suggested that if too many people know about operations, then it increases the chances for the poaching syndicates to get away.

Other methods that were identified during the research was the use of preventive methods such as roadblocks, and fence or perimeter patrols. Roadblocks have been used on national roads that go through the game parks. The idea here is to stop the poachers before they have the chance to enter the game reserve. The problem with this is that there are many side roads that lead to the game reserves and the APUs sometimes miss the poachers. The perimeter patrols require the field rangers to patrol the fences in a game reserve and ensure that the fences are not broken or tampered with in anyway. One result of doing perimeter patrols is that if the field ranger notices any signs of human interaction with the environment, they will be able to notify the head office of the APU because there should be no human interaction in the areas. Human interaction in a natural environment, generally means poaching, therefore if the field ranger pick up the signs, they can begin to track the poachers and prevent them from poaching animals. The next method that was found, is the use of signboards in a community and when entering the game reserve areas. Signboards are erected as a precautionary measure to poachers that there are APU activities in the area. The signs are meant to act as a deterrent and are just one of the situational prevention techniques that have been found. The final method that was used by the APU is community engagement aspect. The APUs were found to be actively involved in development and assistance in the local communities around the game reserves. The APUs are aware that the locals of the community are the ones who know the area best, and are easily persuaded into assisting in poaching activities. For this reason, the APUs strives to maintain a working and good relationship with the community elders and leaders. The APUs have been found to offer assistance wherever necessary and in return obtain valuable information from the community. 
Community members have also been employed by the APUs, which in turn strengthens the ties between the APU and the community and can help lead to information on poaching activities.

\section{What Needs to Be Done to Prevent Rhino Poaching in South Africa}

The third research question, which will be evaluated, is identifying methods that the participants suggested need to be implemented in order to prevent rhino poaching from occurring. The results for this section varied from participant to participant; however, some key methods were identified among the participants. The first method that was a commonality among the research participants was that of academic research. Although some participants were hesitant at first with this method, after a discussion of the importance of academic research and the success it has had in the past for other endangered species the research participants believed that further academic research is of great importance. The understanding here is that if research is completed, the data and findings can be shared with the members who are dealing with the problem at the root levels. Academic research will not only help identify the issues at hand, but academic research will in fact assist in finding possible solutions to curb the rhino-poaching problem. It was found that the research participants agreed that academic research will be useful to reduce the need of rhino horn at user-end markets and will assist in reducing rhino poaching at the root levels.

The second method that was identified by the research participants was solving the need or want of rhino horn at the user-end market. The idea of this stemmed from if there is a want for a product and the price is high enough, there will be members of society who are willing to obtain the product at all costs. The research participants stated that even if South Africa was able to reduce rhino poaching, the need for the product will always be there and eventually rhino poaching incidents will rise again. Therefore, in order to reduce the levels of rhino poaching one 
needs to attend to the problem at both the user-end market and the root levels. Some methods of solving the problem at user-end markets included that of educating the users that rhino horn had no nutritional value. Another method was that of implementing stricter punishment, laws and regulations for the users of rhino horn in the countries that are identified as user-end markets. The final method that was identified was to implement awareness programs in the end-user market countries. This would consist of various methods including advertising in the media of the negative affects the poaching has on both the country and the animal populations. It would also include educating the youth in schools and youth programs of the inhumane methods used to kill the rhinos and that rhino horn has no known nutritional value.

The final method identified was to implement various strategies in certain areas in the country and communities where the rhino poaching is taking place. Firstly, the research participants were concerned that even if they are able to implement strategies in various areas to curb rhino poaching, they were worried that the high level of corruption in the country, including the SAPS would not yield any results. Hence, the participants suggested that before any methods can be implemented at the root levels, one would first need to reduce the levels of corruption that enable the poachers, as well as the sellers and buyers of the horn to actually get the product out of the country. Not all participants had a strategy to prevent corruption, however, two APU's suggested using policing methods and "sting" type operations. In addition to this, they suggested that the "name and shame" method is used against the government officials and other members of society that are found guilty of corruption.

One identified method that was not agreed upon by all participants, was the legalization of the trade of rhino horn. One research participant had suggested that if the trade in rhino horn was legalized it would dramatically reduce the number of rhino poached. It was mentioned that 
many private rhino owners have thousands of kilograms of rhino horn stockpiles. Many private rhino owners are in fact keeping onto these stockpiles waiting for the legalization of rhino horn trade. It was mentioned that if the ban were lifted one would be able to flood the market with rhino horn, reducing the cost of horn and ultimately reduce poaching for a long period. During this break in poaching, the rhinos would have time to increase their numbers. In addition to this, the participants mentioned the use of rhino farming as a mean to obtain rhino horn in a legal and humane method for the end-user market. It was suggested that a subsistence or commercial farming technique could be used to increase the rhino numbers and use these rhino simply for the production of their horn. Once the horns are long enough, they will be cut off and traded to the user-end markets. By managing ones "livestock", one will be able to give the rhino enough time for their horns to grow back for the next "harvesting" season. The reasoning given behind this method is that the rhino would not need their horns for defense purposes as in the wild and would be able to survive in a farming environment without them. This method would not only give a constant supply of rhino horn to the end-user market, it would reduce the poaching numbers, increase the population of rhinos and stabilize the cost of rhino horn preventing future rhino poaching.

The next solution at root levels was the criminal justice system in the form of punishment. This solution was somewhat split between the participants involved in the research, in that some believed harsher laws and more severe punishment should be dealt to those involved in rhino poaching. The punishment methods included longer prison sentences to all involved in rhino poaching. It was mentioned that regardless of ones involvement in the poaching, the punishment should remain the same. In other words, the driver of the getaway vehicle, the shooter and the spotter should all get the same long sentence. In fact, it was mentioned that due 
to the rhino being an endangered species the prison sentence for the act of rhino poaching should be similar to that of murder.

The other participants believed that alternative punishment methods must be used against the perpetrators. Here it is believed that simply putting poachers in prison would not curb the incidents of rhino poaching. One APU mentioned that for every poacher caught there is another one waiting to take his/her place. The participants who mentioned alternative punishment should be used stated that one could learn a lot about prevention from the perpetrators and the methods they use to poach the rhinos. They believed that gaining information from the poachers and using them as a means of educating the communities they are from, are more useful than sending them to prison. This concept of using alternative methods of punishment is closely linked to the theory of restorative justice that was not the main concept in this paper, but will be discussed in the next chapter of this paper. 


\section{CHAPTER VI: RECOMMENDATIONS AND CONCLUSION}

The research conducted for this thesis was exploratory in nature and aimed to identify the various aspects of rhino poaching, including the extent of rhino poaching, what is currently being done to prevent rhino poaching and to identify possible solutions to reduce the rhino poaching epidemic in South Africa. The final chapter of this paper explores the findings of the research and relates it with that of the theoretical aspects identified in Chapter Three. Finally, this chapter will discuss possible recommendations and solutions to assist in reducing the numbers of rhino poached.

One aspect that became apparent throughout the research was the use of SCP techniques by the APU's in the various regions in South Africa. It was found that various SCP techniques were being used without the knowledge of the APUs involved, or that these techniques have actually been researched and implemented before. Two other schools of thought that the APUs did not know they were implementing was the use of community oriented policing and POP. The APU's had stated that in order to prevent poaching in their areas they often relied on the community's involvement to inform them of possible poaching incidents. It was mentioned the APU's would create relationships with the community and would assist in various aspects of their daily lives in order to reduce poaching. The APU's meet with the community leaders, and assist in solving problems in the community, such as crime prevention, assisting with medical treatments, education, offer jobs to the community members and sanitation issues. Partnerships have been created with community elders and in return, for the APU's assistance, the communities assist with knowledge of possible poaching. Two APU's that have implemented the community approach have stated that they have since had a decrease in poaching in their areas that they patrol. 
The other criminological school of thought that has been used unbeknown to the APU's is POP. The APU's are aware that the local communities around the areas which they patrol know the areas the best and have a hand in the poaching which is found in the area. The APU's utilize all stakeholders that are involved in rhino poaching in order to develop the various strategies they use to combat the problem. Another example of POP is the different techniques that are used by the APU's to prevent rhino poaching. The techniques often differ from region to region as it was found that it is different individuals who commit the poaching and different methods are used to conduct their poaching activities. An example of this is how the game parks and reserves found in central South Africa often have a member from a local community who is involved in the poaching, whereas in the larger areas, such as the Kruger National Park, closer to the Mozambican border often have outsiders coming into the park to poach the rhino. In addition to the above, the APU's have stated that their techniques used to prevent poaching differ in the dry and wet season as well as the time of the month (full/poachers moon).

The next aspect that goes hand in hand with POP is the use of the SARA model. Again, the APU's were unaware that they were using a technique that is linked to a criminological framework. Firstly, poaching and in particular rhino poaching is problem in South Africa hence the APU's need to develop specific strategies to prevent rhino poaching. The scan section of the SARA model would be identified as the rhino-poaching problem in South Africa. The APU's stated that before they implement a strategy they first conduct their own research on the problem at hand and attempt to identify where the problem areas lie. This is known as the Analysis part of the SARA model. The APU's then implement their strategy to prevent rhino poaching through the knowledge gained from the analysis part of the SARA model. The APU's often include NGO's, the police, other private security companies, the game rangers and the local community 
in their response to the problem. Finally, under the assess section of the SARA model, the APUs assess the strategy they implemented by counting the number of rhinos poached in the area they patrol. If it is found that their strategy has not worked they then amend their strategy until there is a reduction in poaching. It was found that due to the changing of the poacher's methods and the use of newer technology by the poachers the APUs are having to change their approach to prevent the poaching from occurring. It was stated by the APU's that they could amend their strategy monthly depending what new information is received.

\section{Recommendations}

The third research question of this thesis aimed to identify any possible techniques that could be used in the future to reduce the amount of rhino poaching. Taking the various criminological theories that were discussed in Chapter Three of this thesis and the findings of the research, the following techniques are suggested ways in which one can reduce the amount of rhino poaching.

\section{Community Oriented Policing}

The first suggestion is the use of community oriented policing in the areas in and around the game reserves and game parks in South Africa. The APU's who had used this method had found to have a reduction in rhino poaching in their various areas. The idea here is to work together with the community to assist them with their daily needs and in return obtain vital information on possible poaching in the area. In conjunction with this method the various organizations involved in anti-poaching, like the SAPS, the South African Military, APU's and game rangers need to work together as a unified unit with the community in order to prevent poaching. If one of the parties involved in anti-poaching does not have the community on their side, the poaching incidents in the area will not subside. It was found in this research that there is 
at least one local resident of the community who is involved in the poaching, usually a spotter, hence if the APU's are able to work together and work with the community they will be able to reduce the incidents of rhino poaching. Another important aspect of being involved in the community is the possibility of job opportunities for the local residents in the community. The possibility of employment aids as an alternative method for income for the local community and as the research has shown, alternative methods of income is one aspect that could be used to prevent poaching. Finally, if one involves the community in the fight against poaching, the community will not see the problem as an "us against them" situation, but through educating and marketing the community will see how poaching actually affects their own community and possible avenues of income.

\section{Situational Crime Prevention}

As discussed in Chapter Three, SCP is often cited and used as a possible method to prevent or reduce poaching. It is important to note, however, that in order to utilize SCP to prevent rhino poaching one needs to amend the twenty-five techniques of SCP to that of locally targeted strategies in South Africa. Additionally, in order to reduce rhino poaching, one would need to look at it from the community upwards. My second recommendation for the reduction of rhino poaching in South Africa is the use of the twenty-five techniques of SCP. Table 8 is an amended table of the twenty-five techniques of SCP and how these techniques should be used to reduce rhino poaching in South Africa. As discussed in Chapter Three the five main mechanisms and sub categories for SCP do not change, as these are the foundations for SCP. The only aspects that change are the techniques that are used for prevention in each sub-category (see Table 8). In order to utilize the twenty-five techniques of SCP, one first needs to understand the environment in which the poaching is taking place and adapt the techniques accordingly. 


\section{Routine Activities Theory}

The next technique that is recommended to reduce rhino poaching stems from the routine activities theory. The routine activities theory states that there are three aspects for the opportunity to commit a crime and if one of these aspects is removed then a crime is less likely to occur. The first aspect being a motivated offender, the second a suitable target (victim) and the final being the absence of a capable guardian. In order to reduce rhino poaching in South Africa the agencies involved in the fight against rhino poaching need to remove one of these aspects.

In order to remove a motivated offender one needs to understand the reason for the motivation. A poacher is motivated by monetary gain and therefore if one were to remove a motivated offender from the scenario, one would need to identify an alternative income for these poachers. In both the community oriented policing and SCP sections above, it was stated that alternative income methods are desired in order to reduce poaching. Alternative income methods can come from the various agencies that work in the fight against poaching and may involve employing members of the local communities in the game reserves and in the APU's.

A rhino with a horn is a suitable target in this scenario. Firstly, by removing a rhinos horn in order to make it less desirable will not reduce the chances of the rhino from being poached. In order to make a target less desirable one needs to reduce the want or need of the product. Therefore, for this section two possible techniques can be used to reduce rhino poaching. Firstly, in order to remove a suitable target, one needs to reduce the need of rhino horn. This can be done by educating the users of rhino horn of the non-nutritional values of the horn, as well as reducing the value of rhino horn in the black market. The second method removing a suitable target is that of increasing the security in a game reserve and introducing the one field ranger per herd of rhino approach. This approach not only removes a suitable target from the scenario, but it also 
introduces a capable guardian and therefore removes the absence of a capable guardian.

Therefore, if one is able to remove one of the aspects one will reduce the chances of rhino poaching from occurring. 


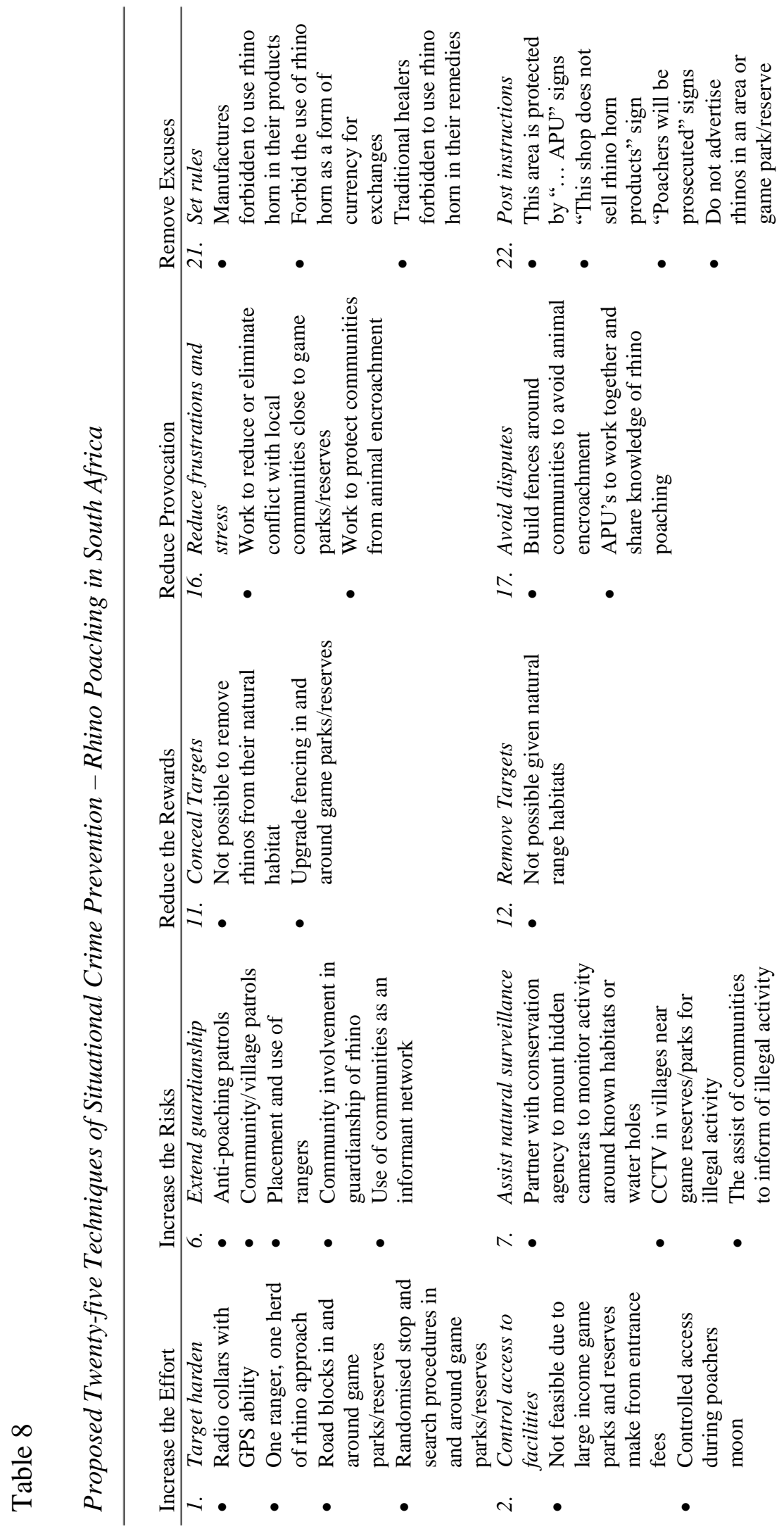

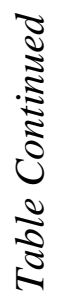




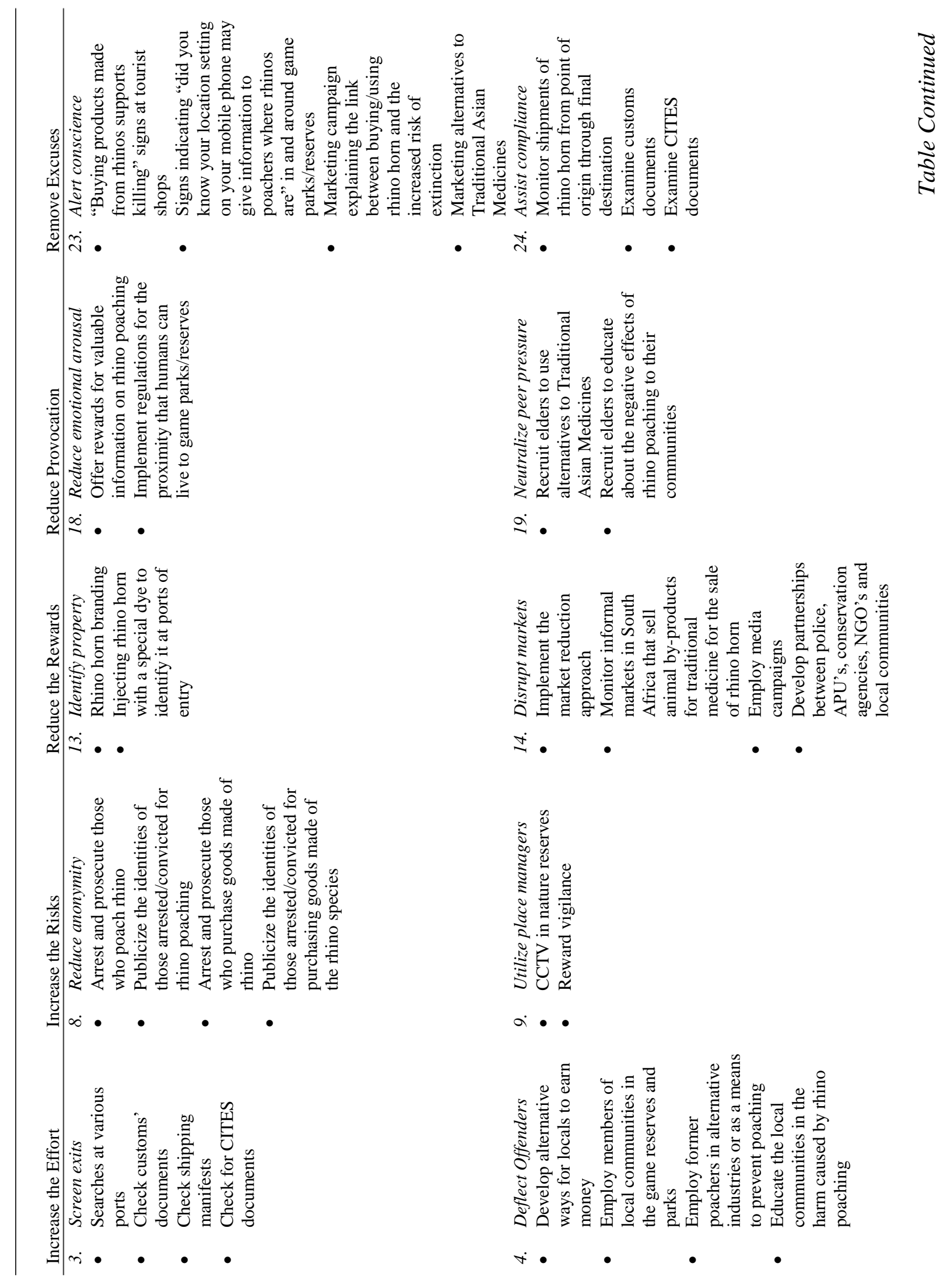




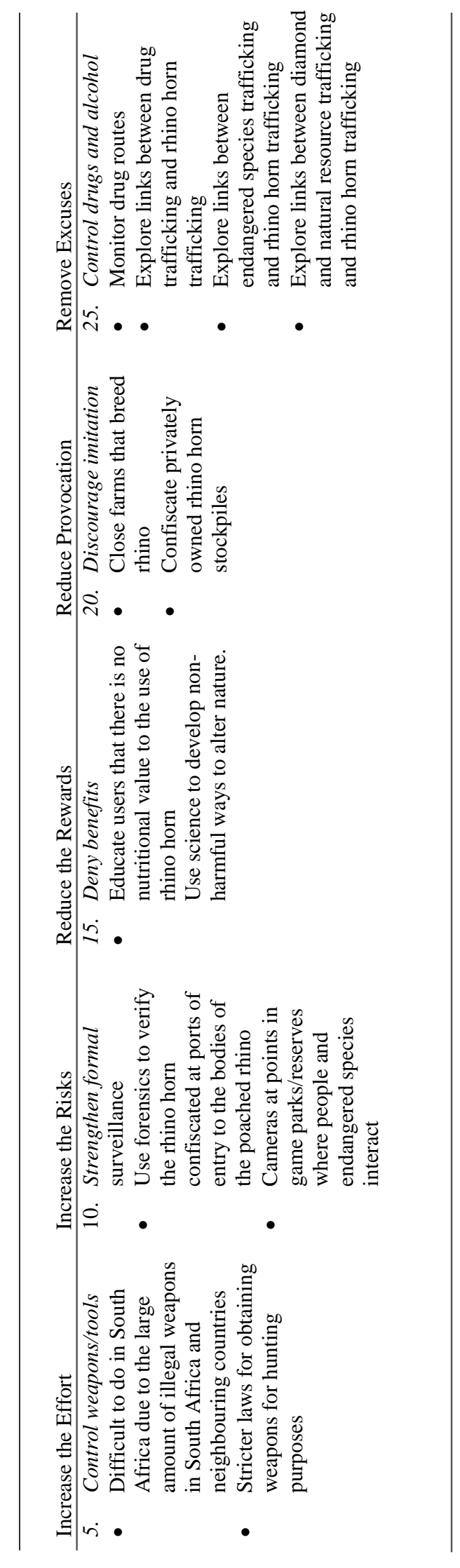




\section{Conclusion}

The research conducted for this thesis is not a bible for the reduction in rhino poaching; it does, however, give insight into the rhino-poaching epidemic in South Africa and offers possible techniques that can be used to prevent rhino poaching in the future. The research in this thesis displays that criminology is a viable subject that can be used in conjunction with conservation in order to prevent poaching all around the world. By using the techniques identified from SCP as well as community oriented policing and the routine activities theory one can identify possible ways to reduce rhino poaching in their community. It is important to note that in order to measure the techniques used to prevent poaching one needs to establish correct measuring techniques of the methods one has implemented. The suggestion of the SARA model, found in policing, is a recommendation for APU's and other agencies dealing with anti-poaching all around the world to implement strategies to fight poaching.

Animals around the world are innocent victims of poaching and especially rhinos in South Africa. If the academic world does not come together in the form of interdisciplinary research, academics will not be able to assist with the protection of rhinos and other wildlife. It is for this reason that I finally recommend further research in the form of implementing criminological strategies in the fight against rhino poaching that needs to implemented and measured correctly. This research will useful for both criminologists and biologists who, if work together, can create specific strategies to prevent rhino poaching in the future. 


\section{REFERENCES}

Akella, A. S., \& Cannon, J. B. (2004). Strengthening the weakest links: Strategies for improving the enforcement of environmental laws globally. Washington, DC: Center for Conservation and Government.

Akers, R. L., \& Sellers, C. S. (2000). Criminological theories: Introduction, evaluation, and application. Los Angeles, CA: Roxbury Publishing Company.

Armitage, R. (2011). Introduction: A new look at environmental crime. European Journal on Criminal Policy and Research, 17, 83-85.

Ayling, J. (2012). What sustains wildlife crime? Rhino horn trading and the resilience of criminal networks. Canberra: Transnational Environmental Crime Project.

Babbie, E. (2007). The practice of social research. Belmont, CA: Wadsworth.

Baird, R. J. (2006). Aspects of illegal, unreported and unregulated fishing in the southern ocean. Netherlands: Springer.

Beattie, K. H. (1976). Evaluative criteria used in anti-poaching campaigns. Wildlife Society Bulletin, 29-39.

Biernacki, P., \& Waldorf, D. (1981). Snowball sampling: Problems and techniques of chain referall sampling. Sociological Methods and Research, 10(2), 141-163.

Biggs, D., Courchamp, F., Martin, R., \& Possingham, H. P. (2013). Legal trade of Africa’s rhino horns. Science, 339, 1038-1039. 
Braga, A. A. (2008). Problem-oriented policing and crime prevention. Monsey, NY: Criminal Justice Press.

Bryman, A. (2004). Social research methods. New York, NY: Oxford University Press.

Bui, Y. N. (2009). How to write a master thesis. Thousand Oaks, CA: Sage Publications.

Bulte, E., \& Rondeau, D. (2007). Compensation for wildlife damages: Habitat conversion, species preservation and local welfare. Journal of Environmental Economics and Management, 54, $311-322$.

Burton, M. (1999). An assessment of alternative methods of estimating the effect of the ivory trade ban on poaching effort. Ecological Economics, 93-106.

Cantu, J. C., Saldana, M. E., Grosselet, M., \& Gamez, J. S. (2007). The illegal parrot trade in Mexico: A comprehensive assessment. Washington, DC: Defenders of Wildlife.

Castillo, J. J. (2009). Judgemental sampling. Retrieved June 20, 2011, from Experiment resource: http://www.experiment-resources.com/judgmental-sampling.html\#ixzz1PvAKrnkS

Chan, J., \& Oxley, D. (2004). The deterrent effect of capital punishment: A review of the research evidence. Sydney: New South Wales Bureau of Crime Statistics and Research: Crime and Justice Bulletin.

Chundawat, R. S., Habib, B., Karanth, U., Kawanishi, K., Ahmad Khan, J., Miquelle, L. T., . . . Wang, S. (2011). Panthera tigris. Retrieved April 16, 2014, from IUCN Red List of Threatened Species: http://www.iucnredlist.org/details/15955/0

CITES. (2013). Appendices I, II and III. Geneva, Switzerland: CITES. 
CITES. (2016). Convention on International Trade in Endangered Species of wild fauna and flora. Geneva: International Environment House.

Clarke, R. V. (1983). Situational crime prevention. In M. Tonry, \& N. Morris, Crime and justice: An annual review of research (pp. 225-256). Chicago, IL: University of Chicago Press.

Clarke, R. V. (1997). Situational crime prevention: Successful case studies. Guilderland: Harrow and Heston.

Clarke, R. V. (1999). Hot products: Understanding, anticipating and reducing demand for stolen goods. London: Policing and Reducing Crime Unit.

Clarke, R. V. (2008). Situational prevention. In R. Wortley, \& L. Mazerolle, Environmental criminology and crime analysis (pp. 178-194). Cullompton: Willan Publishing.

Clarke, R. V. (2009). Situational crime prevention: Theoretical background and current practice. In M. D. Krohn, A. J. Lizotte, \& G. Penly, Handbook on crime and deviance (pp. 259276). Ney York: Springer.

Clifford, M. (1998). Environmental crime: Enforcement, policy, and social responsibility. Gaithersburg, MD: Aspen.

Cohen, L. E., \& Felson, M. (1979). Social change and crime rate trends: A routine activity approach. American Sociological Review, 44, 588-608.

Collar, N. J., \& Juniper, A. T. (1992). Dimensions and causes of the parrot conservation crisis: Solutions from conservation biology. In S. R. Beissinger, \& N. F. Snyder, New world parrots in crisis (pp. 1-24). Washington D.C.: Smithsonian Institution Press. 
Conway, A. J., \& Goodman, P. S. (1989). Population characteristics and management of black rhinoceros diceros bicornis minor and white rhinoceros ceratotherium simum simum in Ndumu game reserve, South Africa. Biological Conservation, 109-122.

Cornish, D., \& Clarke, R. V. (2003). Opportunities, precipitators and criminal decisions: A reply to Wortley's critique of situational crime prevention. In M. J. Smith, \& D. B. Cornish, Theory for practice in situational crime prevention (pp. 41-96). Monsey, NY: Criminal Justice Press.

Cousins, J. A., Sadler, J. P., \& Evans, J. (2008). Exploring the role of private wildlife ranching as a conservation tool in South Africa: Stakeholder perspectives. Ecology and Society, 13(2).

Crawford, C. (1995). Conflicts between the Convention on International Trade in Endangered Species and the GATT in light of actions to halt the rhinoceros and tiger trade. The Georgetown International Environmental Law Review, 555-585.

Daily Mail. (2014). South Africa's rhino population close to 'tipping point' after poachers kill a record 1,000 in a year - up 50\% on 2012. Retrieved March 12, 2014, from Daily Mail Online: $\quad$ http://www.dailymail.co.uk/news/article-2541495/South-Africas-rhinopopulation-close-tipping-point-poachers-kill-record-1-000-year-50-2012.html

Davis, B. (2005). Black Market: Inside the endangered species trade in Asia. San Rafael, CA: Earth Aware Editions.

Decker, D. J., Brown, T. L., \& Siemer, W. F. (2001). Human dimensions of wildlife management in North America. Bethesda, MD: The Wildlife Society. 
Department of Environmental Affairs. (2014). Update on rhino poaching statistics. Retrieved March 12, 2014, from Department of Environmental Affairs: Republic of South Africa: https://www.environment.gov.za/mediarelease/rhinopoachingupdate_26february2014

Department of Environmental Affairs. (2015). Rhino poaching statistics update. Retrieved from Department of Environmental Affairs: Republic of South Africa: https://www.environment.gov.za/projectsprogrammes/rhinodialogues/poaching_statistics \#2015

Department of Environmental Affairs and Tourism. (1997, July 28). White paper on the conservation and sustainable use of South Africa's biological diversity. Pretoria: Department of Environmental Affairs and Tourism.

Deppe, B. (2013). Western black rhino declared extinct. Retrieved March 25, 2014, from Peoples World: http://peoplesworld.org/western-black-rhino-declared-extinct/

DiLonardo, R. B. (1997). The economic benefit of electronic article survailance. In R. V. Clarke, Situational crime prevention: Successful case studies (pp. 122-131). Guilderland, NY: Harrow and Heston Publishers.

Douglas-Hamilton, I. (1987). African elephant population study. Pachyderm, 1-10.

Doulman, D. J. (2000). A general overview of some aspects of illegal, unreported and unregulated fishing. Rome: FAO Fisheries.

Dublin, H., \& Wilson, A. (1998). The fight for survival: Four decades of conserving Africa's rhinos. Switzerland: WWF. 
Ebrahim, G. J., \& Sullivan, K. R. (1995). Mother and child health: Research methods. London: Book Aid.

Eck, J. E., \& Spelman, W. (1987). Problem-solving: Problem-oriented policing in Newport news. Washington DC: National Institute of Justice.

Eliason, S. L. (2012). Trophy poaching: A routine activities approach. Deviant Behavior, 33, 7287.

Ellis, S. (1994). Of elephants and men: Politics and nature conservation in South Africa. Journal of Southern African Studies, 9(1), 53-69.

Emslie, R. H. (2012a). Ceratotherium simum. Retrieved February 25, 2014, from IUCN Red List of Threatened Species: http://www.iucnredlist.org/details/4185/0

Emslie, R. H. (2012b). Diceros bicornis. Retrieved March 12, 2014, from IUCN Red List of Threatened Species: http://www.iucnredlist.org/details/6557/0

Emslie, R. H. (2013). Diceros bicornis ssp. longipes. Retrieved Febuary 25, 2014, from The IUCN Red List of Threatened Species: http://www.iucnredlist.org/details/39319/0

Emslie, R. H., Milledge, S., Brooks, M., van Strien, N. J., \& Dublin, H. T. (2007). African and Asian rhinoceroses - Status, conservation and trade. Gland, Switzerland: International Union for Conservation of Nature.

Emslie, R. H., Milliken, T., Talukdar, B., Ellis, S., Adcock, K., \& Knight, M. H. (2016). African and Asian rhinoceroses - Status, conservation and trade. Johannesburg: TRAFFIC. 
Engler, M., \& Parry-Jones, R. (2007). Opportunity or threat: The role of the European Union in global wildlife trade. Brussels: TRAFFIC.

FAO. (2003). Grassroots potential unleashed: Good news from west African fishing communities. Rome: FAO.

Felbab-Brown, V. (2011). The disappearing act: The illicit trade in wildlife in Asia. Washington, DC: Brookings Institution.

Felson, M. (1995). Those who discourage crime. In J. Eck, \& D. Weisburd, Crime and place: Crime prevention studies (pp. 53-66). Monsey, NY: Criminal Justice Press.

Ferreira, S. M., Botha, J. M., \& Emmett, M. C. (2012). Anthropogenic influences on conservation values of white rhinoceros. Plos One, 7(9), 1-14.

Ferreira, S. M., Greaver, C. C., \& Knight, M. H. (2011). Assessing the population performance of the biacic rhinoceros in Kruger National Park. South African Journal of Wildlife Research, 41(2), 192-204.

Gall, M. D., Gall, J. P., \& Borg, W. R. (2003). Educational research: An introduction. London: Allyn \& Bacon.

Gibbs, C., Gore, M. L., McGarrell, E. F., \& Rivers III, L. (2010). Introducing conservation criminology: Towards interdisciplinary scholarship on environmental crimes and risks. British Journal of Criminology, 124-144.

Gladstone, F. J. (1980). Co-ordinating crime prevention efforts. London: Home Office. 
Goitom, H. (2013). Wildlife trafficking and poaching: South Africa. Retrieved April 16, 2014, from The Law Library of Congress: http://www.loc.gov/law/help/wildlifepoaching/southafrica.php

Goldstein, H. (1979). Improving policing: A problem-oriented approach. Crime and Delinquency, 236-259.

Goldstein, H., \& Susmilch, C. E. (1982a). Drinking-driver in Madison - A study of the problem and the community's response. Madison, WI: University of Wisconsin.

Goldstein, H., \& Susmilch, C. E. (1982b). Repeat sexual offender in Madison - A memorandum on the problem and the community's response. Madison, WI: University of Wisconsin.

Goldstein, H., \& Susmilch, C. E. (1982c). Experimenting with the problem-oriented approach to improving police service - A report and some reflections on two case studies. Madison, WI: University of Wisconsin.

Graycar, A., \& Felson, M. (2010). Situational prevention of organised timber theft and related corruption. In K. Bullock, R. V. Clarke, \& N. Tilley, Situational prevention of organised crimes (pp. 81-92). Cullompton: Willan Publishing.

Guerette, R. T., \& Bowers, K. J. (2009). Assessing the extent of crime displacement and diffusion of benefits: A review of situational crime prevention evaluations. Criminology, 47(4), 1331-1368.

Hauck, M., \& Sweijd, N. A. (1999). A case study of abalone poaching in South Africa and its impact on fisheries management. ICES Journal of Marine Science, 56, 1024-1032. 
Hayward, K. (2007). Situational crime prevention and its discontents: Rational choice theory versus the culture of now. Social Policy and Administration, 232-250.

Herbig, F. J. (2011). South African conservation crime and routine activities theory: A causal nexus? Pretoria: University of South Africa.

Herrera, M., \& Hennessey, B. (2007). Quantifying the illegal parrot trade in Santa Cruz de la Sierra, Bolivia, with emphasis on threatened species. Bird Conservation International, 295-300.

Hübschle, A. (2010). Organised crime in Southern Africa: First annual review. Pretoria: Institute for Security Studies.

Interpol. (2014). Environmental crime. Retrieved April 14, 2014, from Interpol: http://www.interpol.int/en\%20\%20\%20\%20\%20\%20\%20\%20\%20\%20\%20\%20\%20\%2 0\%20\%20\%C5\%B8\%20\%20\%20\%20\%20\%20\%20\%20/Crime-areas/Environmentalcrime/Environmental-crime

Jackson, T. (2008). Coming of age. Africa Geographic, 16(4), 29-33.

Juniper, T., \& Parr, M. (1998). Parrots: A guide to parrots of the world. New Haven: Yale University Press.

Kennedy, D. M. (2009). Deterrence and crime prevention: Reconsidering the prospect of sanction. New York: Routledge.

Knecht, G. B. (2006). Hooked: Pirates, poaching and the perfect fish. Emmaus, PA: Rodale. 
Knight, M. (2013, November 6). Western black rhino declared extinct. Retrieved Febuary 25, 2014, from Cable News Network: http://www.cnn.com/2011/11/10/world/africa/rhinoextinct-species-report/

Koshy, E., Koshy, V., \& Waterman, H. (2011). Action research in healthcare. London: SAGE Publications.

Krantz, L. (2001). The sustainable livelihood approach to poverty reduction: An introduction. Sweden: Sida: Division for Policy and Socio-Economic Analysis.

Lee, J. (1996). Poachers, tigers, and bears...Oh my--Asia's illegal wildlife trade. Northwestern Journal of International Law and Business, 497-515.

Lee, R., Gorog, A., Dwiyahreni, A., Siwu, S., Riley, J., Alexander, H., . . Ramono, W. (2005). Wildlife trade and implications for law enforcement in Indonesia: A case study from north Sulawesi. Biological Conservation, 123(4), 477-488.

Lemieux, A. M., \& Clarke, R. V. (2009). The international ban on ivory sales and its effects on elephant poaching in Africa. British Journal of Criminology, 49, 451-471.

Lewin, K. (1947). Group decisions and social change. In T. M. Newcomb, \& E. L. Hartley, Readings in social psychology (pp. 340-344). New York: Atherton Press.

Lin, D. (2011). What is poaching? Retrieved April 15, 2014, from About Animal Rights: http://animalrights.about.com/od/wildlife/g/What-Is-Poaching.htm

Linkie, M., Wibisono, H. T., Martyr, D. J., \& Sunarto, S. (2008). Panthera tigris ssp. sumatrae. Retrieved April 16, 2014, from IUCN Red List of Threatened Species: http://www.iucnredlist.org/details/15966/0 
Lockwood, C. (2010). Analysis of rhino poaching in KwaZuluNatal, South Africa. (Unpublished masters thesis). London: Imperial College London.

Mail and Guardian. (1995). SADF Used ivory to fund war in Angola. Retrieved from Mail and Guardian: http://mg.co.za/article/1995-09-01-sadf-used-ivory-to-fund-war-in-angola

Maingi, J. K., Mukeka, J. M., Kyale, D. M., \& Muasya, R. M. (2012). Spatiotemporal patterns of elephant poaching in south-eastern Kenya. Wildlife research, 234-249.

Marshall, M. N. (1996). Sampling for qualitative research. Family Practice, 522-525.

Matthews, R. (1997). Developing more effective strategies for curbing prostitution. In R. V. Clarke, Situational crime prevention: Successful case studies (pp. 74-82). Guilderland, NY: Harrow and Heston.

Maxfield, M. G., \& Babbie, E. R. (2012). Basics of research methods. Belmont, CA: Wadsworth.

McMullan, J. L., \& Perrier, D. C. (2002). Lobster poaching and the ironies of law enforcement. Law \& Society Review, 36(4), 679-720.

McMurtry, R., \& Curling, A. (2008). The review of the roots of youth violence. Ontario: Service Ontario Publications.

Milliken, T., \& Shaw, J. (2012). The South Africa - Viet Nam rhino horn trade nexus: A deadly combination of institutional lapses, corrupt wildlife industry professionals and Asian crime syndicates. Johannesburg, South Africa: TRAFFIC. 
Milner-Gulland, E. J., \& Leader-Williams, N. (1992). A model of incentives for the illegal exploitation of black rhinos and elephants: Poaching pays in Luangwa Valley, Zambia. Journal of Applied Ecology, 29(2), 388-440.

Modise, A. (2013). The president of South Africa assents the National Environmental Management Laws Amendment Act, 2013. Retrieved March 30, 2014, from Department of Environmental Affairs: https://www.environment.gov.za/president_sign_nemlaa

Modise, A. (2014, April 17). South Africa and Mozambique sign Memorandum of Understanding in the field of Biodiversity, Conservation and Management. Retrieved April 25, 2014, from $\begin{array}{llll}\text { Department } & \text { of } & \text { Environmental }\end{array}$ https://www.environment.gov.za/mediarelease/sa_mozambique_signmou

Modise, A. (2016, September 11). Minister Edna Molewa highlights progress in the fight against rhino poaching. Retrieved from Department of Environmental Affairs: https://www.environment.gov.za/mediarelease/molewa_highlightsprogress_onrhinopoach ing2016

Montesh, M. (2012). Rhino poaching: A new form of organised crime. Pretoria: College of Law Research and Innovation Committee of the University of South Africa.

Moyle, B. (2009). The black market in China for tiger products. Global Crime, 10, 124-143.

Nellemann, C. I., \& Refisch, R. J. (2010). The last stand of the gorilla - Environmental crime and conflict in the Congo basin. United Nations Environment Programme. 
Newman, G. (1997). Introduction: Towards a theory of situational crime prevention. In G. Newman, R. V. Clarke, \& S. Giora Shoham, Rational choice and situational crime prevention (pp. 1-23). Dartmouth, NH: Ashgate.

Nijman, V. (2009). An overview of international wildlife trade from Southeast Asia. Biodiversity Conservation, 19, 1011-1114.

O'Neill, L., \& McGloin, J. M. (2007). Considering the efficacy of situational crime prevention in schools. Journal of Criminal Justice, 511-523.

Pires, S. F., \& Clarke, R. V. (2011). Sequential foraging, itinerant fences and parrot poaching in Bolivia. Bitish Journal of Criminology, 314-335.

Pires, S. F., \& Clarke, R. V. (2012). Are parrots CRAVED? An analysis of parrot poaching in Mexico. Journal of Research in Crime and Delinquency, 122-146.

Pires, S. F., \& Moreto, W. D. (2011). Preventing wildlife crime: Solutions that can overcome the tragedy of the commons. European Journal on Criminal Policy and Research, 101-123.

Plowden, C., \& Bowles, D. (1997). The illegal market in tiger parts in northern Sumatra, Indonesia. Oryx, 59-66.

Poyner, B. (1997a). An evaluation of walkway demolition on a britsh housing estate. In R. V. Clarke, Situational crime prevention: Successful case studies (pp. 59-73). Guilderland, NY: Harrow and Heston Publishers.

Poyner, B. (1997b). Situational crime prevention in two parking facilities. In R. V. Clarke, Situational crime prevention: Successful case studies (pp. 157-166). Guilderland, NY: Harrow and Heston Publishers. 
Poyner, B., \& Webb, B. (1991). Crime free housing. Oxford: Butterworth Architect.

Pratt, T. C., \& Cullen, F. T. (2005). Assessing macro-level predictors and theories of crime: A meta-analysis. In M. Tonry, Crime and justice: A review of research (pp. 373-450). Chicago: University of Chicago Press.

Project Tiger. (2005). The report of the tiger task force: Joining the dots. New Delhi: Union Ministry of Environment and Forests.

Rademeyer, J. (2012). Killing for profit. Cape Town: Zebra Press.

Rao, K. S., Maikhuri, R. K., \& Saxena, K. G. (2002). Crop damage and livestock depredation by wildlife: A case study from Nanda Devi Biosphere Reserve, India. Journal of Environmental Management, 66, 317-327.

Reeve, R., \& Ellis, S. (1995). An insider's account of the South African security forces' role in the ivory trade. Journal of Contemporary African Studies, 13(2), 227-243.

Robbins, S. P. (2004). Organizational behavior. UpperSaddle River, NJ: Prentice-Hall.

Rodrigues, A., Pilgram, J. D., Lamoreux, J. F., Hoffmann, M., \& Brooks, T. M. (2006). The value of the IUCN Red List for conservation. Trends in Ecology and Evolution, 71-76.

Roshier, B. (1989). Controlling crime: The classical perspective in criminology. Chicago, IL: Lyceum Books.

Scherdin, M. J. (1986). The halo effect: Psychological deterrence of electronic security systems. Information Technology and Libraries, 232-235 . 
Schneider, J. L. (2008). Reducing the illicit trade in endangered wildlife: The market reduction approach. Journal of Contemporary Criminal Justice, 274-295.

Schneider, J. L. (2012). Sold Into Extinction. Santa Barbara, CA: Praeger.

Schneider, J. L., \& Charlton, R. W. (2014). The endangered species trade: Characteristics, commonalities, and criminality. Unpublished Report.

Scott, M. S. (2000). Problem-oriented policing: Reflections on the first 20 years. Washington D.C.: U.S. Department of Justice, Office of Community.

Shepherd, C. R., \& Magnus, N. (2004). Nowhere to hide: The trade in Sumatran Tiger. Southeast Asia: TRAFFIC.

Siegel, L. J. (2007). Criminology: Theories, patterns, and typologies. Belmont, CA: Thomson.

Smith, R. J., Muir, R. J., Walpole, M. J., Balmford, A., \& Leader-Williams, N. (2003). Governance and the loss of biodiversity. Nature, 426, 67-70.

Smith, R., \& Anderson, K. (2004). Understanding non-compliance in the marine environment. Trends \& Issues in Crime and Criminal Justice, 275, 1-6.

Stop Rhino Poaching. (2017, February 4). Rhino Poaching Statistics. Retrieved from Stop Rhino Poaching: http://www.stoprhinopoaching.com/pages.aspx?pagename=stats

Taylor, A., Brebner, K., Coetzee, R., Davies-Mostert, H., Lindsey, P., Shaw, J., \& 't Sas-Rolfes, M. (2014). The viability of legalising trade in rhino horn in South Africa. Pretoria, South Africa: Department of Environmental Affairs. 
Tewksbury, R. (2009). Qualitative versus quantitative methods: Understanding why qualitative methods are superior for criminology and criminal justice. Journal of Theoretical and Philosophical Criminology, 1(1), 38-58.

Tewksbury, R., \& Mustaine, E. E. (2003). College students' lifestyles and self-protective behaviors. Criminal Justice Behavior, 30(3), 302-327.

TRAFFIC. (2002). Food for thought: The utilization of wild meat in eastern and southern Africa. Nairobi, Kenya: World Wildlife Fund, TRAFFIC East/Southern Africa.

TRAFFIC. (2008). What's driving the wildlife trade? A review of expert opinion on economic and social drivers of the wildlife trade and trade control efforts in Cambodia, Indonesia, Lao PDR and Vietnam. Washington DC: World Bank.

Turner, III, D. W. (2010). Qualitative interview design: A practical guide for novice investigators. The Qualitative Report, 15(3), 754-760.

University of Wisconsin Law School. (2013). A theory of crime problems. Retrieved March 3, 2014, from problem-oriented center: http://www.popcenter.org/learning/pam/help/theory.cfm

University of Wisconsin Law School. (2014). The SARA model. Retrieved March 22, 2014, from Center for problem-oriented policing: Source: http://www.popcenter.org/about/?p=sara

van Strien, N. J., Manullang, B., Sectionov, W. I., Khan, M. K., Sumardja, E., Ellis, S., ... Bradley, M. E. (2008a). Dicerorhinus sumatrensis. Retrieved March 12, 2014, from The IUCN Red List of Threatened Species 2008: http://www.iucnredlist.org/details/6553/0 
van Strien, N. J., Steinmetz, R., Manullang, B., Sectionov, H. K., Isnan, W., Rookmaaker, K., .. . Ellis, S. (2008b). Rhinoceros sondaicus. Retrieved March 12, 2014, from The IUCN Red List of Threatened Species 2008: http://www.iucnredlist.org/details/19495/0

Van Vuuren, H. (2006). Apartheid grand corruption: Assessing the scale of crimes of profit from 1976 to 1994. Pretoria: Institute for Security Studies.

Warchol, G., Zupan, L., \& Clack, W. (2003). Transnational criminality: The illegal wildlife trade in southern Africa. International Criminal Justice Review, 1-27.

Webb, B. (1997). Steering column locks and motor vehicle theft: An evaluation from three countries. In R. V. Ckarke, Situational crime prevention: Successful case studies (pp. 4658). Guilderland, NY: Harrow and Heston Publishers.

Webb, J. T. (2000). Prosecuting wildlife traffickers: Important cases, many tools, good results. Vermont Journal of Environmental Law, 2(1), 1-12.

Weber, E. P. (2016). Endangered species: A documentary and reference guide. Santa Barbara: Greenwood.

Weisburd, D., Telep, C. W., Hinkle, J. C., \& Eck, J. E. (2010). Is problem-oriented policing effective in reducing crime and disorder? Criminology \& Public Policy, 9(1), 139-172.

Wellsmith, M. (2010). The applicability of crime prevention to problems of environmental harm: A consideration of illicit trade in endangered species. In R. D. White, Global environmental harm: Criminological perspectives (pp. 132-149). Cullompton: Willan Publishing.

Wellsmith, M. (2011). Wildlife crime: The problems of enforcement. European Journal on Criminal Policy and Research, 17(2), 125-148. 
World Wildlife Fund. (2014). Rhino overview. Retrieved March 12, 2014, from World Wildlife Fund: https://worldwildlife.org/species/rhino

Wright, T. F., Toft, C. A., Enkerlin-Hoeflich, E., Gonzalez-Elizondo, J., Albornoz, M., RodríguezFerraro, A., .. . Wiley, J. W. (2001). Nest poaching in neotropical parrots. Conservation Biology, 710-720.

Zimmerman, M. E. (2003). The black market for wildlife: Combating transnational organized crime in the illegal wildlife trade. Vanderbilt Journal of Transnational Law, 1657-1690. 


\section{APPENDIX A: INTERVIEW GUIDE}

\section{General Questions:}

1. What is the name of your organization?

2. What is the goal of your organization? (For example prevention, awareness etc...)

3. What challenges has your organization identified in obtaining its goals?

\section{Research Question 1: What is the extent of the problem?}

4. How many rhinos have been poached?

5. What are the main areas that are being poached in South Africa?

6. How are the rhinos poached?

7. How are the horns removed?

8. Who are the main people involved in the trade and poaching of rhinos? (E.g.: South African, Asian, other Africans, European, Middle East, North American or South American)

9. How much does one earn for killing a rhino

10. How much does one earn for sending the horn?

11. How much is a horn worth?

12. What are the common reasons given, that people commit poaching?

13. Where are the horns going?

14. How do the horns get there?

15. What areas are the horns being transported from?

16. How many people are involved in rhino poaching syndicates?

17. Which criminal networks are engaged in poaching, trafficking and trade of which species?

18. What are the transnational and transcontinental trade routes used by these networks from South Africa to end-use market, such as East Asia and the Middle East? 
19. What is the volume and value of rhino horn being trafficked along these routes?

20. Are there any known transnational criminal networks that are part of trafficking, poaching and trade, if so who and where?

21. How are criminal networks currently exploiting countries (whether as source, transit, or enduse destinations) with weak governance and enforcement capacity, high corruption and porous borders?

22. How are profits from illegal wildlife trade fuelling other transnational criminal activities, including terrorism and trafficking in weapons, drugs and humans?

23. How does the money flow between hands for these products?

24. Is there any money laundering or offshore accounts?

\section{Research Question 2: What is currently being done to prevent rhino poaching?}

25. What does your organization do?

26. What is your organization currently doing to help combat the rhino-poaching problem?

27. Are you affiliated with other organizations, if so, what are those organizations?

28. What are those organizations doing to combat the rhino-poaching problem?

\section{Research Question 3: What needs to be in the future to combat the rhino poaching problem?}

29. What is your organizational priority, in assessing a need for an effective, efficient and strategic response to evolving threats at the international and national levels?

30. From the organizational perspective who needs to be in charge of implementing and maintain these strategic interventions 


\section{APPENDIX B: LETTER OF INVITATION}

To whom it may concern,

My name is Richard Wayne Charlton and I am currently a graduate (masters) student at Illinois State University in the USA. I am currently working on my master's thesis in Criminal Justice. I am a South African who, like yourself, has an extreme interest in protecting our country and its natural environments. The recent spike in rhino poaching over the past few years is something that worries me and I feel that more needs to be done about it. I have decided to conduct research on the problem of rhino poaching in South Africa and turn this research into my master's thesis.

The purpose of this research will be:

1. To identify the full extent of the rhino poaching problem

2. To identify what steps are currently being taken to prevent poaching of rhinos in South Africa

3. Identify possible future techniques and methods that can be implemented to help stop the poaching of these gracious animals.

I am e-mailing you to find out if you would be interested in being part of this research that I am conducting. You are by no means required to partake in this research and it is a voluntary process. I was wondering if you would be available for a few questions regarding your organization and the current rhino poaching and trade problem.

If you would like to partake in this research, we could set up a time and place where it would be convenient for yourself to meet and conduct the interview. The interview will be compromise of about 40 questions which should take approximately two hours to complete.

I look forward to your response. 
Thanks and regards

Richard Charlton

Graduate Assistant - Illinois State University 


\section{APPENDIX C: INFORMED CONSENT LETTER}

\section{Dear Participant,}

I am a graduate student at Illinois State University and am conducting research on the rhinopoaching epidemic in South Africa. You have been invited to take part in a research study because you or your organization have identified yourself as a role-player in trying to bring about awareness and the prevention of rhino poaching and trade. Before you decide to participate in this study, it is important that you understand why the research needs to take place and what it will involve. Please take some time to read the following information carefully and if you have any questions, please ask the researcher for more information.

The purpose of this study is to identify the full extent of the rhino-poaching problem in South Africa, while evaluating what steps are currently being taken to prevent poaching of rhinos in South Africa. In addition to this, the research will aim to identify possible future policies or techniques that can be implemented to help stop the poaching of these gracious animals.

The expected time commitment for this study will be approximately two hours. The procedure of this research will consist of the research participant having to answer questions regarding rhino poaching in South Africa.

Please note that this research is completely confidential and all research participants' personal information is kept confidential. The only information that will be used in this research will be that of your organizations name, and if you agree for us to use it, please sign the consent form. The signature form will be removed from the main consent form, so that your name will not be linked to you or to any of your responses.

Your participation is voluntary and if you do decide to take part in the research, you may withdraw from the research at any time, without any consequences and without giving a reason. If you do decide to take part in the study, you will be asked to sign a consent form. You are free to not answer any question or questions if you choose and this will not affect your position in any negative way.

In this study, there are minimal risks to the research participants. The topics of the questionnaire may upset some of the research participants and you have the choice to answer them or not. Unforeseeable risks can occur; however, if you encounter any of these during the research please contact Family Life Center (Johannesburg) for counseling at 011788 4785. To avoid possible identification of the participants, the signed copy of the informed consent will be removed from the interview responses.

There will be no direct benefits, including monetary compensation, for the research participants in this study. However, we hope that this research provides valuable information to the policy makers and others interested in prevention of rhino poaching.

If you have any further questions regarding your rights as a research participant, or if any problems arise that you wish not to discuss with the researcher, please contact the Institutional Review Board Office at (Illinois, USA) (309) 438-2529 or Dr. Dawn Beichner (Faculty Member and principle investigator in the Department of Criminal Justice Sciences) at (309) 438-8278. For specific 
questions regarding the interview, please contact Richard Charlton (Co-Investigator, Graduate Student in the Department of Criminal Justice Science, Illinois State University) at (South Africa) 0824644712 or (USA) 309-660-7073.

\section{Consent:}

By signing this consent form, I confirm that I have read, understood the information, and agreed to voluntarily participate in the research. I do understand that my participation is voluntary and that I am free to withdraw at any time, without giving reason and without cost to me. I understand that I will be given a copy of this consent form to be signed. I understand all personal identification in this study is confidential and anonymous.

\section{Sign:}

If you agree to use your organizations or companies name in this research, please sign, date and write your companies details below.

Sign:

Date:

\section{Date:}

\section{Companies Details}

